
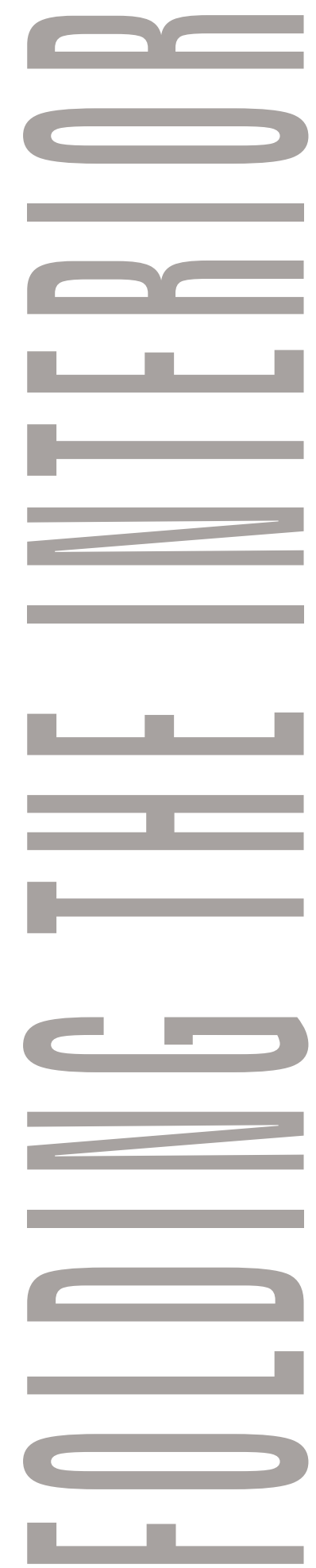



\title{
Elevation: Folding the Interior
}

\author{
By
}

Kristin Grace Kilgour

A 120-point thesis

submitted to the Victoria University of Wellington

in partial fulfilment of the requirements for the degree of Master of Interior Architecture

Victoria University of Wellington

School of Architecture

2016 


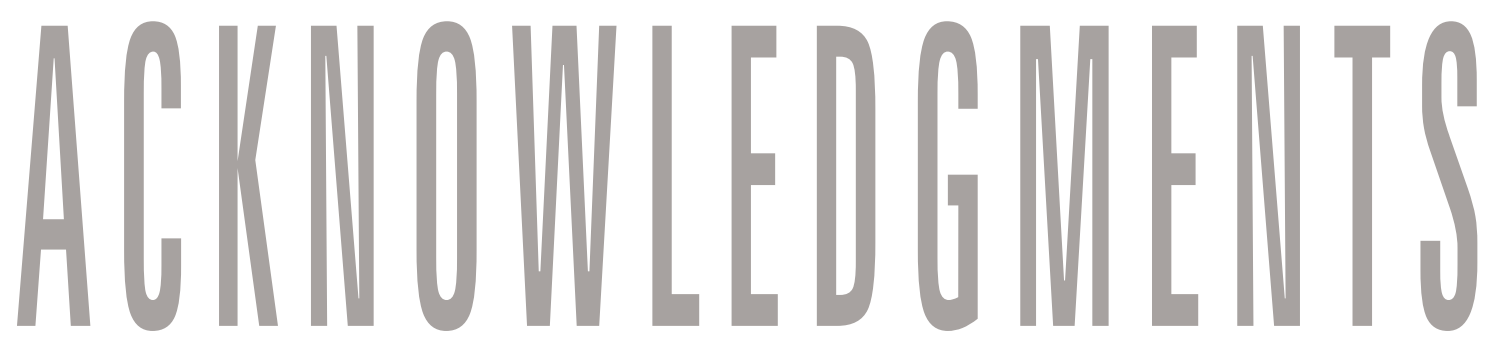

I would like to say a big thank you to all those who have helped and encouraged me during the course of my studies. I have been fortunate in receiving a vast range of support and valued input during this time and I would like to acknowledge those people who made this happen.

A special thank you to my supervisor Natasha Perkins for her valued input and support throughout my years of university study and this research.

I would also like to say thank you to my family, friends and fellow classmates for their interest and words of encouragement this past year: I am so privileged to have you all, thank you. 


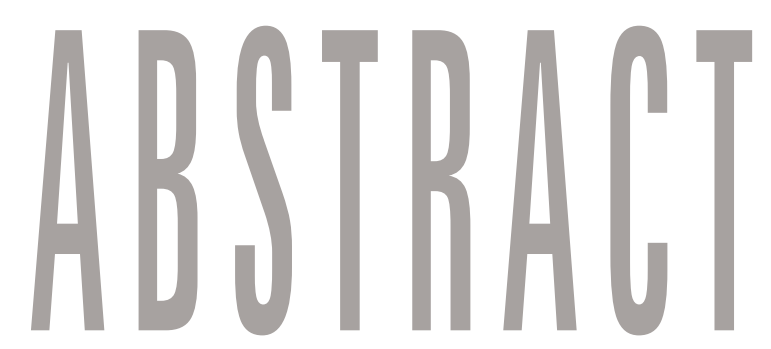

7 his research anticipates that by repurposing the interior 1 of existing and vacant historic architecture, significant to the community it serves, the life span of buildings can be prolonged. This in turn will lead to the progress of New Zealand's history in architecture.

This research proposes to introduce a transient intervention, in which design disregards the site context and is influenced by the historic materials. The design offers new and relative functions for buildings, thereby offering a stay of demolition, for a period of time. It reasons that the process of repurposing can be done exclusively through interior development, using installation methods that will not compromise the integrity of the historic materials. This will enable the design to be removed and the architecture to be returned to the condition it was in prior to the engagement of this research design. It is assumed by research that at this time the building's historic value will outweigh the perceived financial gains of redevelopment.

Change is inevitable in society. However, architecture is not so malleable and tends to resist change. It needs help adjusting with time. When communities develop, buildings do not always meet their increasing demands. They can become too small or the programme loses relevance. According to Johannes Cramer and Stefan Breitling "architecture should outlive humans" (Cramer), however, Heritage New Zealand notes that in the last fourteen years 26 historically listed buildings have been demolished to accommodate redevelopment, in New Zealand.

This research takes three sites from Lower Hutt to represent this architecture in need. Each will give new insight for physical material and intangible features which are important to retain when working to preserve historic architecture. 


\section{CUITEET}

Acknowledgments

Abstract

Introduction

Research Problem

Site Significance

Background to the Research 3

Process Diagram 5

Research Question $\quad 7$

Site Analysis - A part of New Zealand's Historic Architecture 8 Central Lower Hutt

Lower Hutt Methodist Church

Lower Hutt Automatic Telegraph Exchange 21

Lower Hutt Central Fire Station 29

Literature Review + Case Studies - Introducing the concept of 38 intervention that provides support for historic architecture until its heritage and significance to society can support itself.

Restored Expired Architecture $\quad 40$

In Support of the Architecture $\quad 44$

Kintsugi 48

Hybrid Reassemblage $\quad 49$

Methods of Alteration $\quad 50$

Site Specific Renovation $\quad 54$ 
Siteless Interior

Discussion

Economics and Programme

Folding the Interior

Structures from Triangles

Preliminary Design 71

Series One - A-POC

Series Two - Folding Around a Point

Series Tree - Origami - Folded Plate Structures

Lower Hutt Methodist Church

Design Development - The implications of introducing form to a space. $\quad 98$

Development Process Diagram 101

Ergonomics 103

Materials 104

Connection Details 110

Structure 120

Technology 122

Lower Hutt Automatic Telegraph Exchange 124

1:1 Component Prototype 128

Lower Hutt Central Fire Station 155

Programme: Florist 164

Bakery 166

Gallery 168

Conclusion + Critical Reflection $\quad 170$

References + Sources of Figures + Appendices 172 


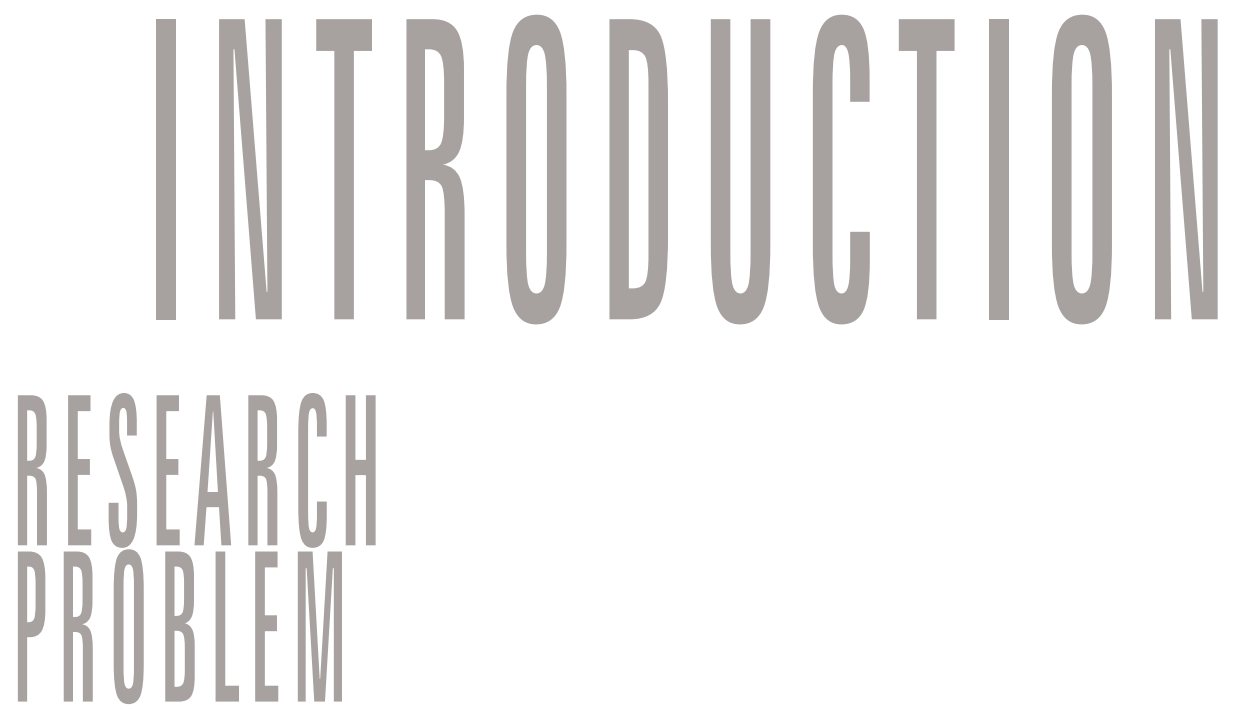

In the view of the author society should not outlive the architecture surrounding it currently. This research proposes an alternative solution to demolition for vacant, existing architecture, significant to the community it serves, that could prolong the life span of buildings. For the objective to achieve this, the design will need to offer the existing architecture support for what it is lacking. It is identified that an empty building shell lacks a use for the space. The aim is to provide a method for repurposing these historic buildings by adopting the architecture theory that designing out of context can generate new ideas. The intent is to design a scheme to be applied to the interior of a series of buildings significant to society. The original use for these buildings has lost relevance: these buildings were originally configured explicitly for a single use. The simplest solution is to remove the interior to enable more spatial options for use. However this typically destroys important interior qualities of the building. This research will seek ways to protect the heritage interiors, rather than simply the heritage exteriors. 


\section{Site Significance}

This research develops in stages, at specific locations in Lower Hutt. The intervention is implemented in three buildings. The first to be considered is the former Laings Rd Methodist Church. The church was first opened in 1927. However, despite having a Category 2 listing from the Historic Places Trust, the church was demolished in 2003 for the redevelopment of a concrete block building. This site is proposed as a location for 'what might have been' had the congregation not sold the church for the immediate financial benefits. The second piece of architecture is the former Automatic Phone Exchange, built in 1932. While the exterior façade still stands, the interior has undergone a series of alterations which have impacted negatively on the historic material and the buildings structure. The third building is the former Lower Hutt Central Fire Station. Built in 1955 and having served the community for over 50 years, the Fire Station is now uninhabited after the restructuring of the local fire service.

The research recognises the heritage of the architecture through the façades and acknowledges that certain features warrant saving for their heritage value. It also discloses that certain elements of the three heritage buildings are simply functional, for example the walls, floors and ceilings are what is expected of any architecture. Their removal will not jeopardise theintegrity of the architectures history. When achieving a refurbishment that encapsulates the atmosphere and character of the buildings heritage. This proposal for site-less interior architecture recommends the removal of non-heritage features. The question asked is: could this still maintain the heritage value of the building? The reason for the removal of some interior walls is that most historic buildings are composed of a warren of many little rooms and hallways, whereas most businesses, such as retail or small offices, no longer function that way. The removal of these walls would allow for greater experiential movement and would appeal to how most contemporary businesses work these days.

The research has different programme typologies for each site. It explores how the final design could reactivate the three different buildings, with varying heritage that represent three different users, without being programme and building driven. That is not to say that the final

\section{Introduction}


design will not propose a potential solution for a new programme.

\section{Background to \\ the research}

The approach of the research combines the writing of international theories and designs realised by architects within historic architecture, the concurrent process is best documented in Figure.1. page 5.

The case studies in this research have main focuses; some reflect on what has been written by theorists, others are used to identify completed projects that respond to the methodology discussed by the theorists. The research looks internationally for the learnt wisdom of older countries, such as those in Europe. Literature by theorists Johannes Cramer and Stefan Breitling discusses the challenges when faced with architecture that no longer serves a purpose. They acknowledge that for many architects the task of creating an intervention for an existing building is daunting. This is linked to the belief that the parameters and constraints set by a historic building are too difficult to work with and they compromise the final design. Fred Scott is an advocate for sympathetic alteration to architecture and suggests what he believes to be reasonable solutions.

While all the theorists present thought-provoking strategies, all the design methodologies rely on site context to inform the aesthetic of the restoration. Although Jennifer Hill presents six approaches for alternation using site context, she discloses that some approaches are better than others. Hill also advises that a new intervention can be interpreted as an important next chapter in the ongoing history of a building. When applied in a considerate way it can allow previous chapters of a building to still be told and also create a new chapter. The intervention for this research is a viable way to maintain the heritage of the buildings without necessitating that all the little rooms and programmes are maintained.

\section{Introduction}


François Blanciak is a strong believer that architects should disregard site context and design using experimentation with forms; reviews of his book suggest that this is considered a new way to think about architecture. The 1001 building forms explored in his book cover a diverse range of design stimulants that do not include considering the context of a site. Disregarding the site context of the historic buildings will allow for an installation that can serve a wider range of architecture. Other texts echo these thoughts.

The research notes that current successful interior interventions are most interesting when decay preservation occurs and it is something the research will aim to achieve with its own design. Two case studies used to present this are the Neues Museum in Berlin, designed by David Chipperfield Architects, and Warehouse 17c in Madrid Spain, designed by Arturo Franco office.
Taking direction from Hill, this research will look at interior architecture renovation as a series of layers, the proposed installation is an additional layer for each of the three Lower Hutt buildings. It is like adding another layer to the interior surfaces, such as a layer of paint, wallpaper, carpets or fabric. Often, a heritage building builds up these layers over time, then with age they peel back and become exposed. The design will present the new layer as a contemporary chapter sitting adjacent to the historic layers. This enables the intervention to be viewed as part of the ongoing history. The actualisation of the design will create a working dialogue between the historic buildings and the new design, relieve the buildings of impairments, and will provide a barrier between decaying materials and occupants of the interior.

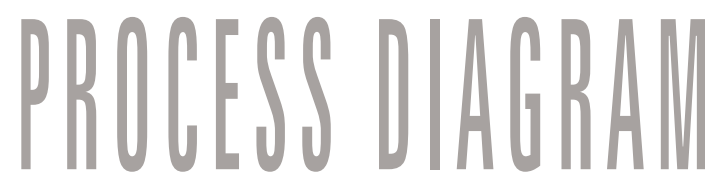

Figure.1. Diagram of the research

process, reads from top to bottom. 


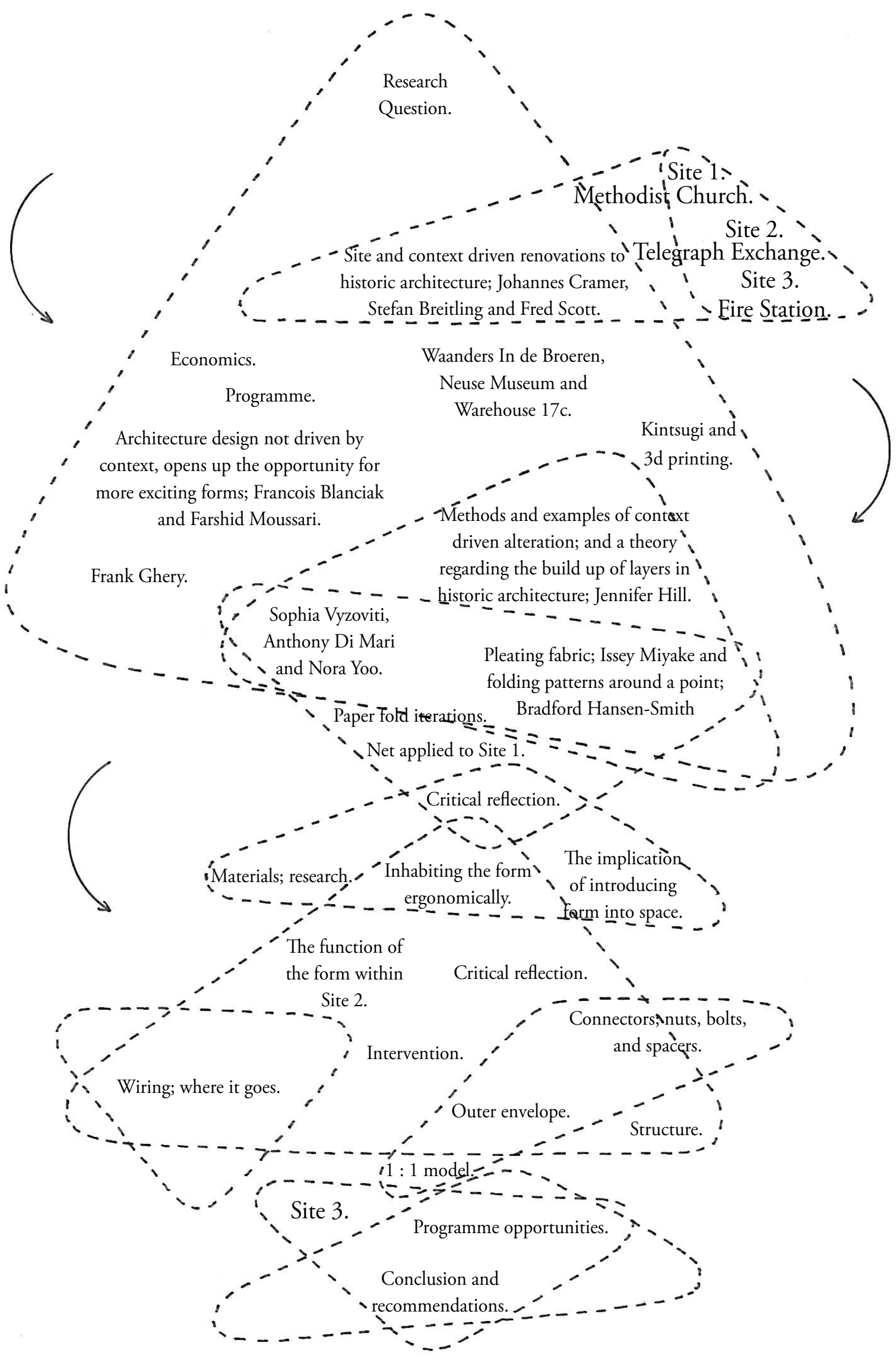




\section{RESEARCH QUESTION}

As architecture achieves innovative responses by eliminating context as a design driver, could the same be done with the interiors of historic architecture to offer an alternative to demolition? Secondly, when site context is eliminated as the design driver what will influence the new design? 


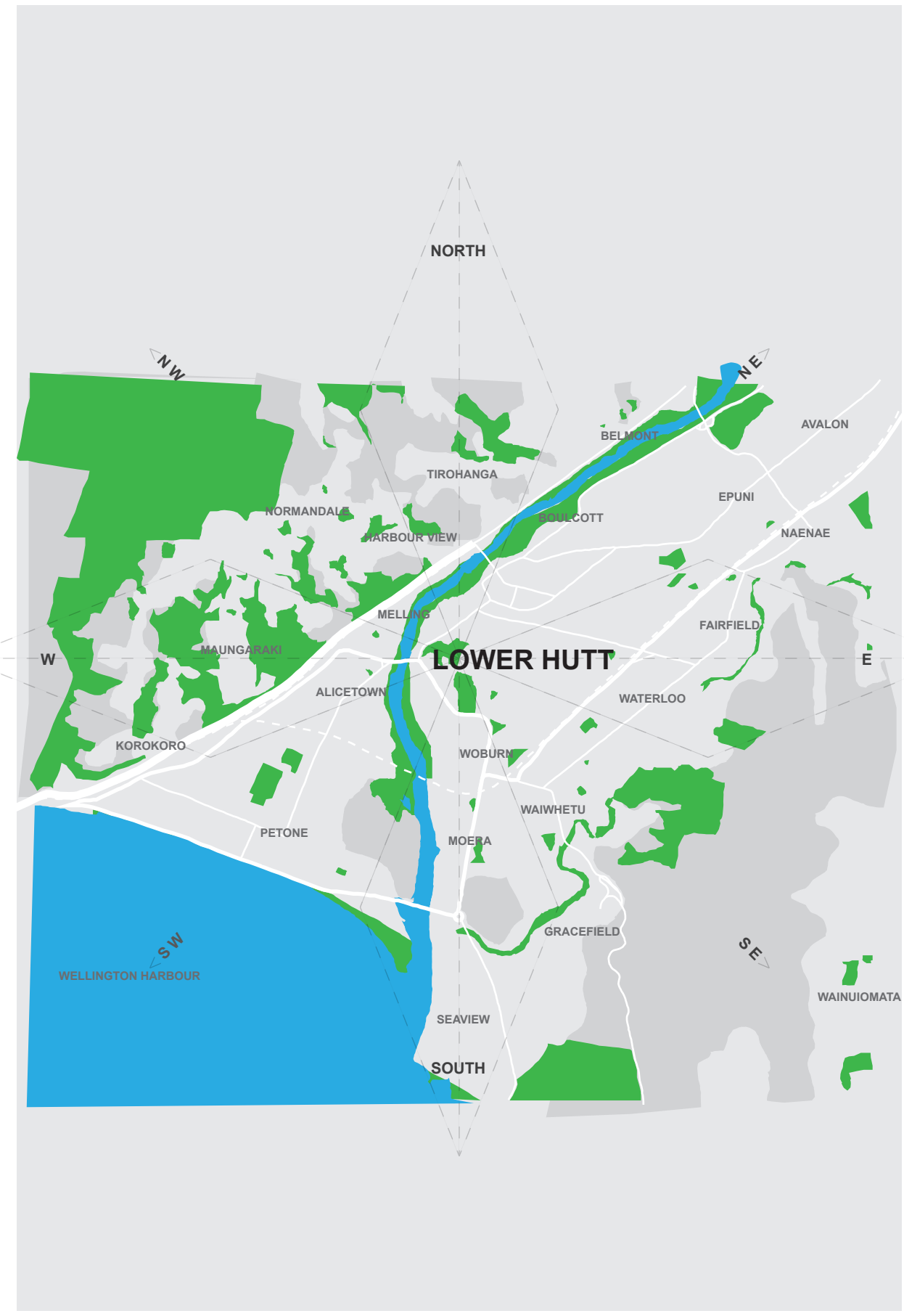

Figure.2. Map of the Lower Hutt Region. 


\section{SIIE ANALISISS}

\section{A PART OF NEW ZEALAND'S HISTORIC ARCHITECTURE - CENTRAL LOWER HUTT}

The research critiques the design within three buildings in the Central Lower Hutt area. The sites have been selected for their diverse range of qualities; the dissimilar aesthetic styles, varying degree of alteration and different programme typologies. The site analysis explores how the final design could reactivate the three buildings. Built 30 years apart, the buildings are considered as representing different architecture styles; the historic value attributed to elements of the architecture will inform the interior restorations; what historic elements that should be retained, what can be removed and which elements suffering from decay that should be preserved? 
Site Analysis 


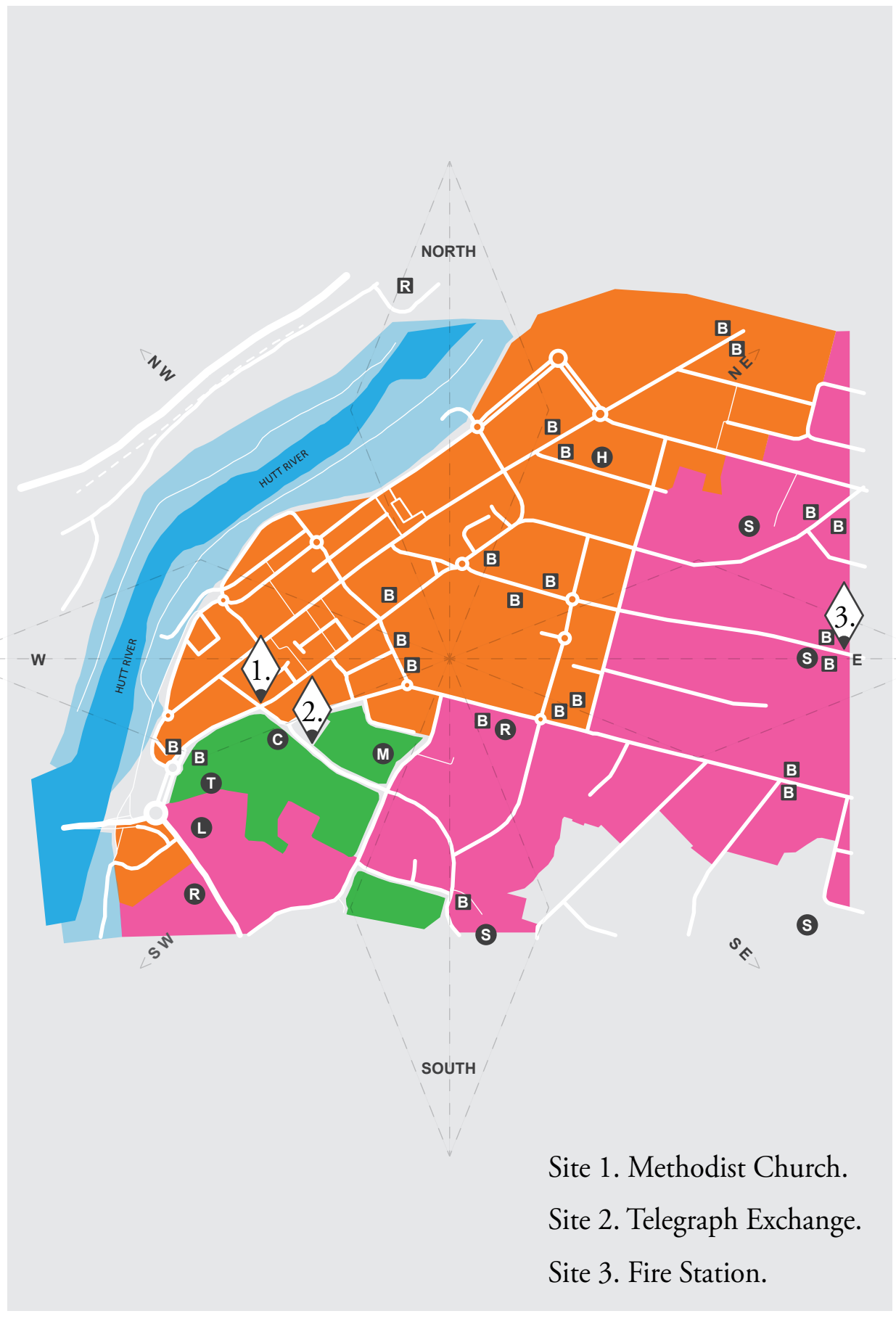

Figure.3. Central Lower Hutt District Plan. 


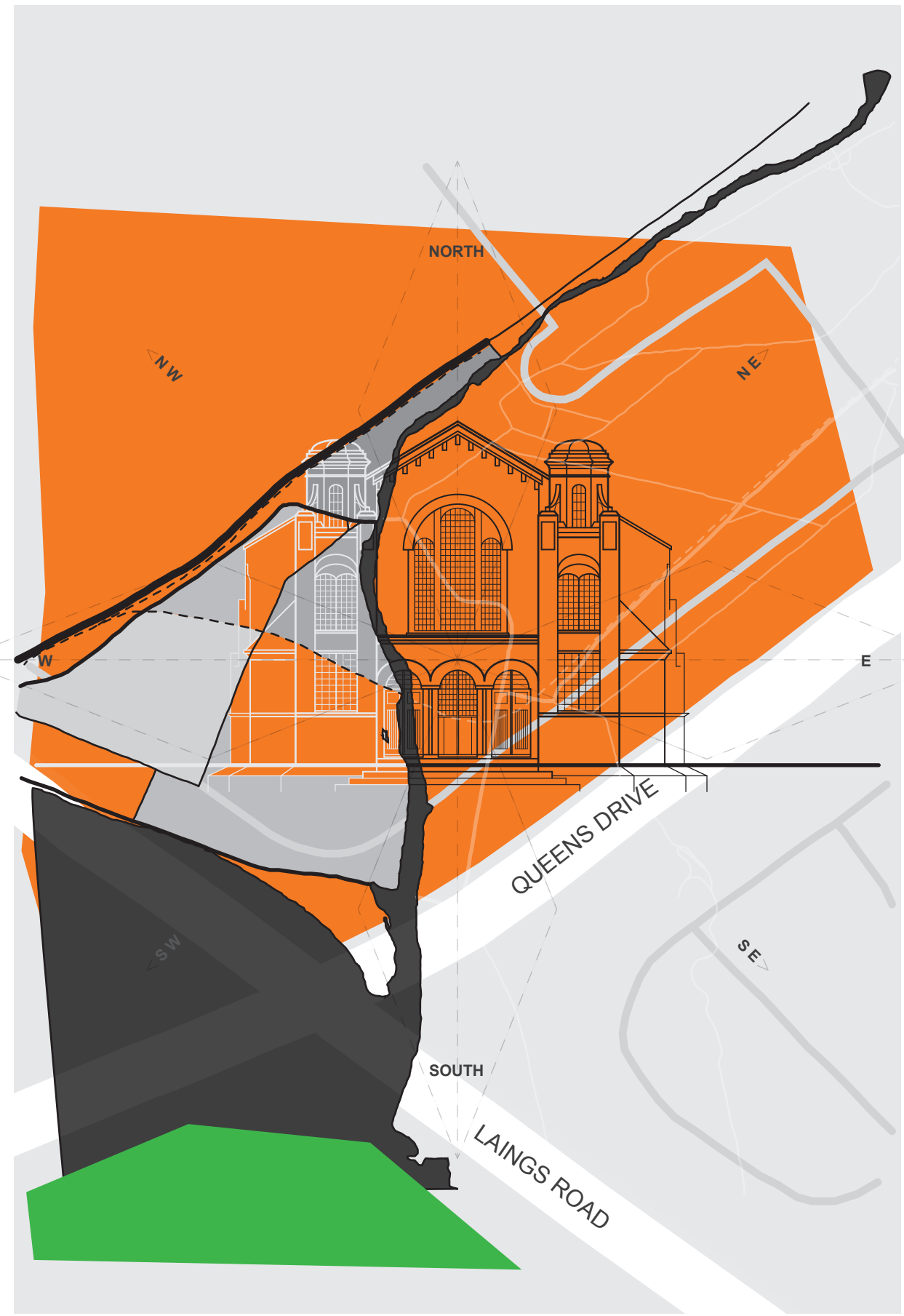

Figure.4. Location of the Methodist Church, also shown in Figure.3. Central Lower Hutt District Plan. 


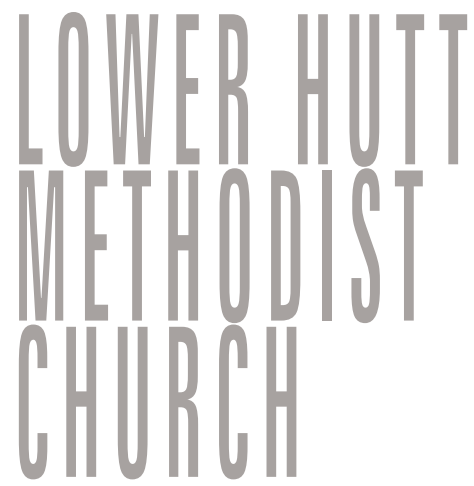

The Lower Hutt Methodist Church, Laings Rd, was built in 1927 (Heritage New Zealand). It received a Category Two listing on the Heritage List (Heritage New Zealand) due to its noteworthy social significance to the community and aesthetic appeal. However, in 2003 it was demolished (Heritage New Zealand) for the redevelopment of a retail store, which stayed at the site until the end of 2015 (The Dominion Post). The research is arguing that had renovation occurred, sensitive to the buildings historic listing, architecture history need not have been lost. Key features to retain during such a renovation would have been the ceiling height and sight lines between the vestibule, the gallery above, the nave and the organ. The ceiling heights are considered significant as they influence the atmosphere of the Church, preserving them would aid in retaining the grandeur of the church. Less significant areas such as the vestries, either side of the choir stage, could be opened up with the removal of walls. The features to preserve would have been the stained glass windows and the old organ, influential entities from the previous programme in the building. 


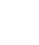




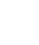




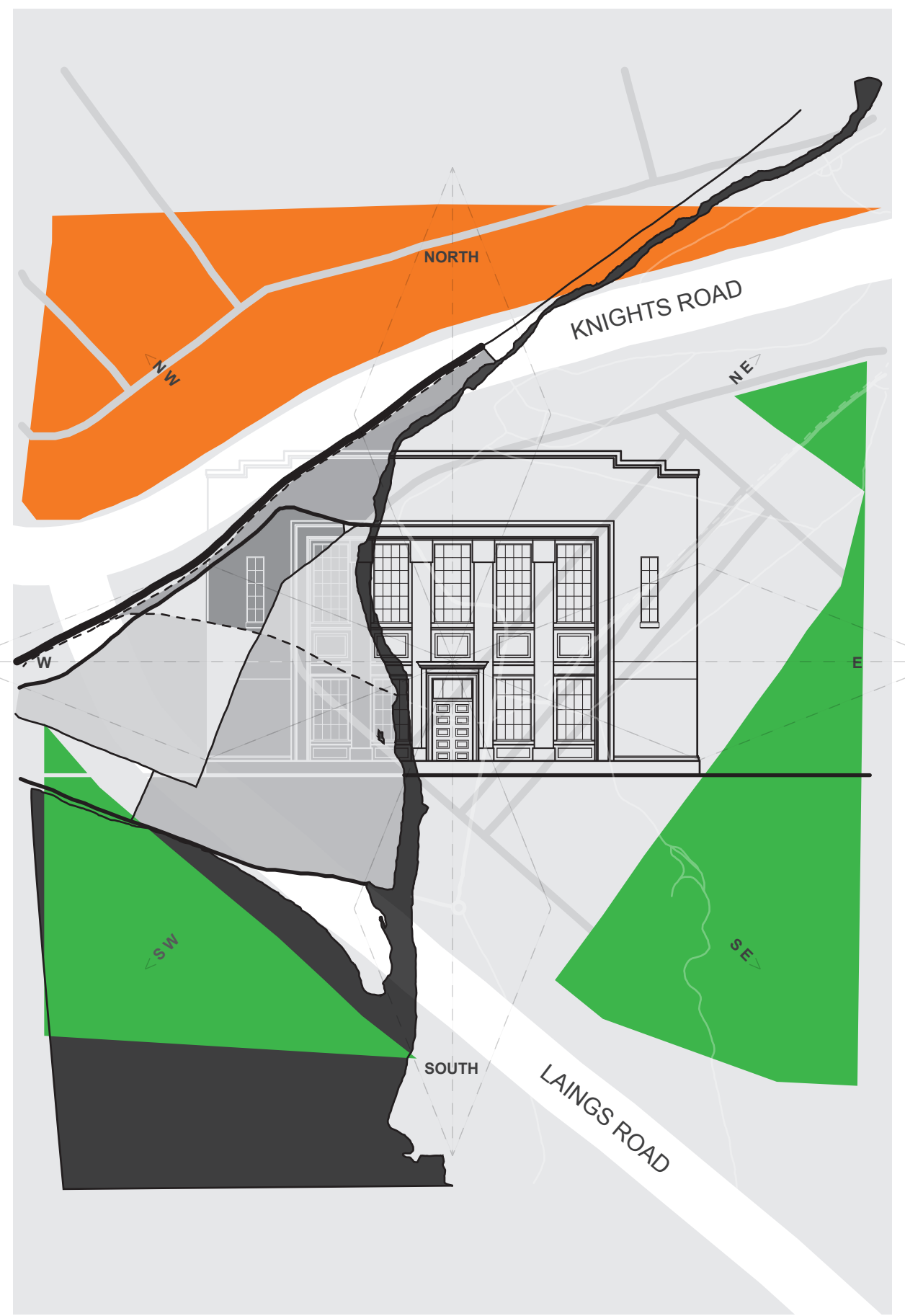

Figure.8. Location of the Automatic Telegraph Exchange, also shown in Figure.3. Central Lower Hutt District Plan. 


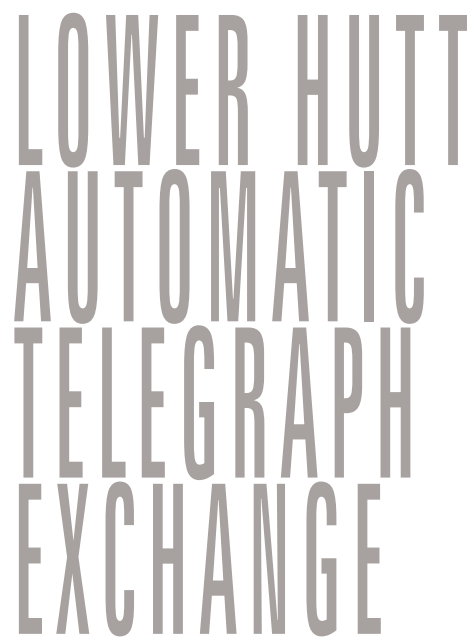

The Former Lower Hutt Automatic Telegraph Centre, Laings Rd, was built in 1932 (Lower Hutt Borough Council). It does not have a historic listing, however, the research argues that had the building been altered with attention to the historic detail, it would be considered as having significant importance to the community as the former Post and Telegraph office. The spiral stairwell is one of the few internal features that remains of the Georgian revival building, it is a feature that the research proposes to retain with its renovation, and it would also be desirable to retain the remaining Georgian revival mouldings. Less significant internal features that would be removed are the walls that divide the building into smaller rooms. However, the research would preserve elements which have been installed in the building for its various programmes, and this could include wall layers and various surface treatments. 


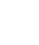




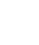




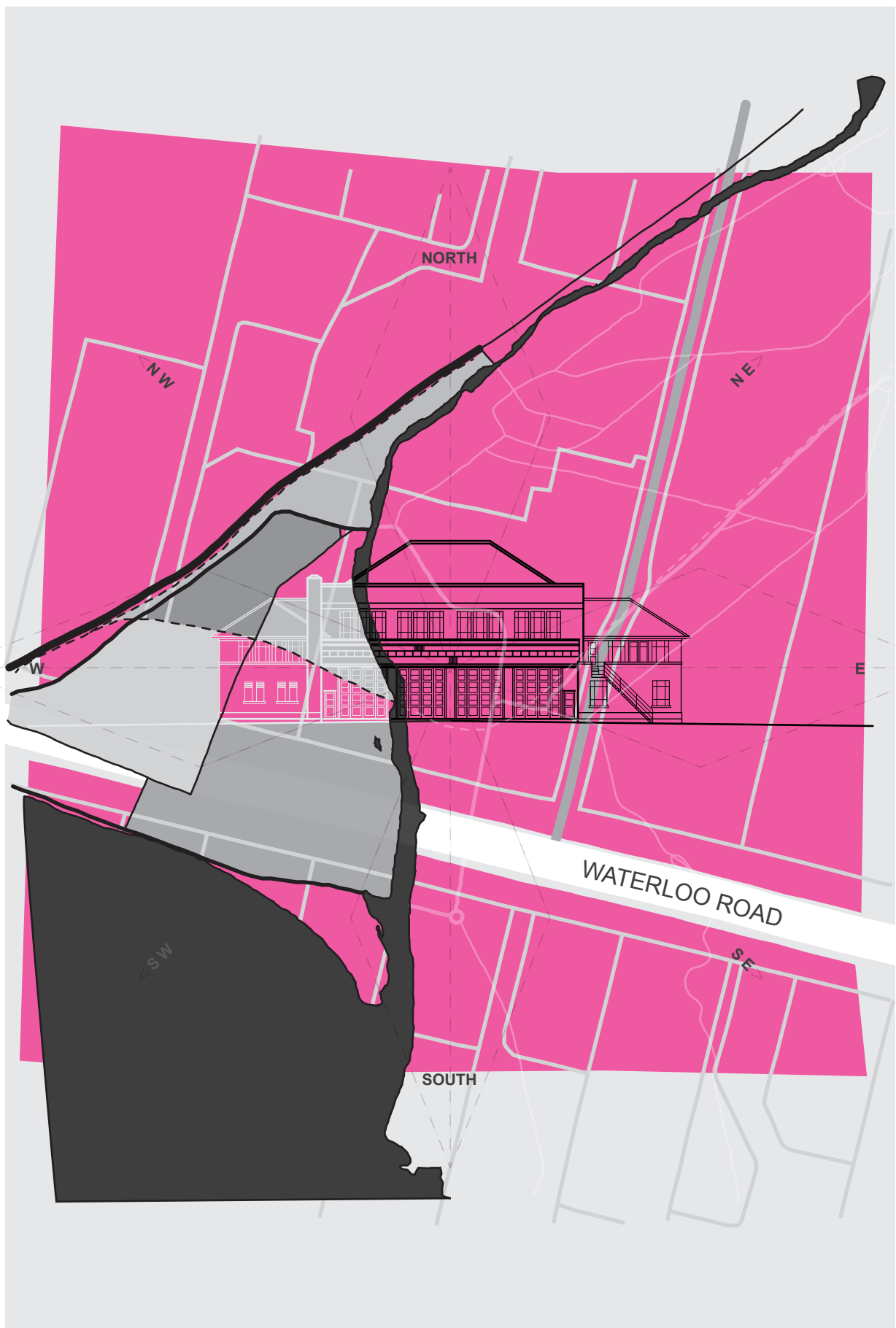

Figure.11. Location of the Fire Station, also shown in Figure.3. Central Lower Hutt District Plan. 


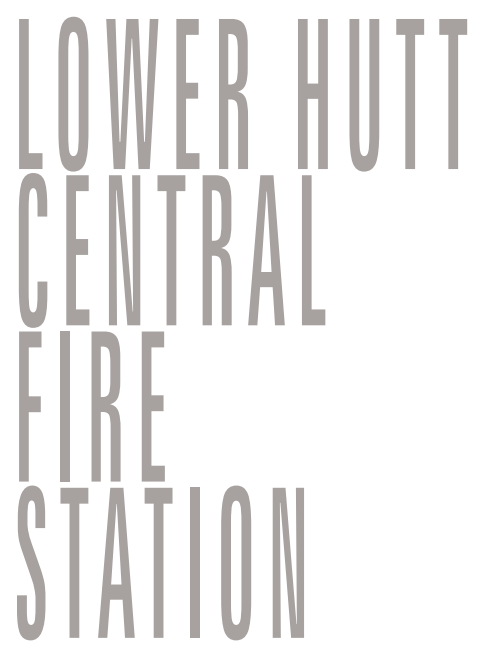

The Lower Hutt Central Fire Station (Former), Waterloo Rd, was built in 1955 (Naus and Dangerfield). Up until 2008, when the Post-War Modernist architecture was decommissioned (Naus and Dangerfield), it served the public, and held in high standing by the community. The building was also a first in technology at the time of its construction and is seen as a tribute to the architects (Naus and Dangerfield). Currently the fire station is managed by the Commissioner for Crown Lands for Treaty Settlement reasons and has a Category one listing on the heritage list (Naus and Dangerfield). The research proposes to retain the ceiling height of the appliance room where the trucks were stored, as well as the views around the building, for example the view through the window of the watch room into the appliance room. Less significant features are the walls in the West and East wings, the removal of these will open up the areas. The features to preserve are the external doors into the appliance room and the pole drop stations. It will not be appropriate to keep all the poles, but the openings through the first floor will be preserved. 


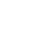




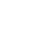


Site Analysis 
In summary the motives for the removal of certain features, or to retain them, are influenced by their effects on the atmosphere of the architecture. On some occasions the walls, floors and ceilings, which are described by this research as functional, can also have an effect on the occupants perception of the interiors. For example a greater ceiling height or thicker walls, can feel more imposing. Within historic architecture there can also be regulations established which can also protect certain elements which are deemed significant to the buildings history. These are set by the Hutt City and further discussion of this can be found in Appendix 1. There is also information on the organisations available for consultation of what, in the opinion of the Heritage NZ and ICOMOS, should be deemed significant to the architectural exteriors. 


\section{LTERATURE RELIEW}

INTRODUCING THE CONCEPT OF INTERVENTION THAT PROVIDES SUPPORT FOR HISTORIC ARCHITECTURE UNTIL ITS HERITAGE AND SIGNIFICANCE TO SOCIETY CAN SUPPORT ITSELF

"The shrinking of many European cities at the end of the second millennium is a clear sign that the design and construction of buildings is in steady decline. At the same time the alteration of existing built structures is becoming increasingly important" (Cramer).

$\bigwedge \begin{aligned} & \text { ew Zealand is considered a young } \\ & \text { country compared to Europe and } \\ & \text { for that reason we are able to take }\end{aligned}$ cues from overseas literature. The literature discussed early in this research will address the circumstances when working with historic sites, the later literature will be used to define an alternative solution to designing using the sites context. 
Johannes Cramer, Stefan Breitling, Fred Scott and Jennifer Hill are four theorists who consider similar architectural theories, based on site specific historic architecture renewal, but from different perspectives. They discuss site specific alterations; this is one type of methodology used as a design driver when designing for architecture. However, site specific design is limiting for multiple sites which represent different architecture aesthetics. The research aims to accept multiple design styles with its proposal.
Siteless: 1001 Building Forms, by François Blanciak, written in 2008, the author poses the question of "What would happen if architects liberated their minds from the constraints of site, programme, and budget?" (Blanciak) The book is filled with diverse forms and is concluded with a scaled test. Set on a site in Tokyo it shows what happens when the design is applied to an environment with its own parameters. This research intends to apply the same approach to the sites in the Lower Hutt. 
Case studies are used alongside the discussion of literature to further understand the writing of the theorists. Kintsugi and 3D printing are also evaluated for potential design instigators.

\section{Restored Expired Architecture}

Architecture In Existing Fabric, written by Cramer and Breitling, in 2007, defines the evolution of modified architecture. They reason its popularity is due to "great architects... [splitting] their attention between new constructions and a commitment to architecture within existing building contexts" (Cramer). This indicates that intervention is possible despite today's stigma that conforming to designing within existing architecture is restrictive. 
"Every design for an existing building will change it in some way. The change is intentional and accepted as such" (Cramer).

Cramer and Breitling believe in restoring historic architecture. They state that "buildings generally last longer than a human lifetime" (Cramer) and that " $70-80 \%$ of the built environment in 2030 already exists in built form today" (Cramer), hence modifying architecture is inevitable, as it is part of the process in the lifespan of a building. Having said that, when imposing change to a building's interior the designer is making the decision to never return it back to the initial state.

Cramer and Breitling recommend that a design which avoids unnecessary problems is the most successful. This research will investigate a sensitive intervention as a design which considers the historic building at odds with modern expectations.

"The continuation of existing form and architectural means is a simple approach to harmonising the new with the old" (Cramer). 
Another recommendation from Cramer and Breitling is the use of auxiliary constructions. The impact on the existing building can be reduced by introducing the programme outside of the old architecture. The building is broken up less during the alterations and avoids unnecessary demolition. An example of auxiliary construction being used successfully is in a 15th Century Cathedral in the Netherlands (BK Architecten). The cathedral was investigated to understand how the architects achieved a design sympathetic to the historic building that successfully introduced a new programme to the building. The design is successful in not compromising the historic materiality of the cathedral, and at a later stage can be removed without leaving a mark.

- A new flooring allows services to run throughout the building without disrupting the historic fabric,

- A hydraulic, free standing, lift has been installed to reach the higher levels, for minimal implications on the historic fabric.

- The new design is set out from the walls to avoid damage to the historic walls.

- An external architectural element has been introduced to accommodate the cafés kitchen. This removes the need for additional plumbing and wiring in the historic structure. 


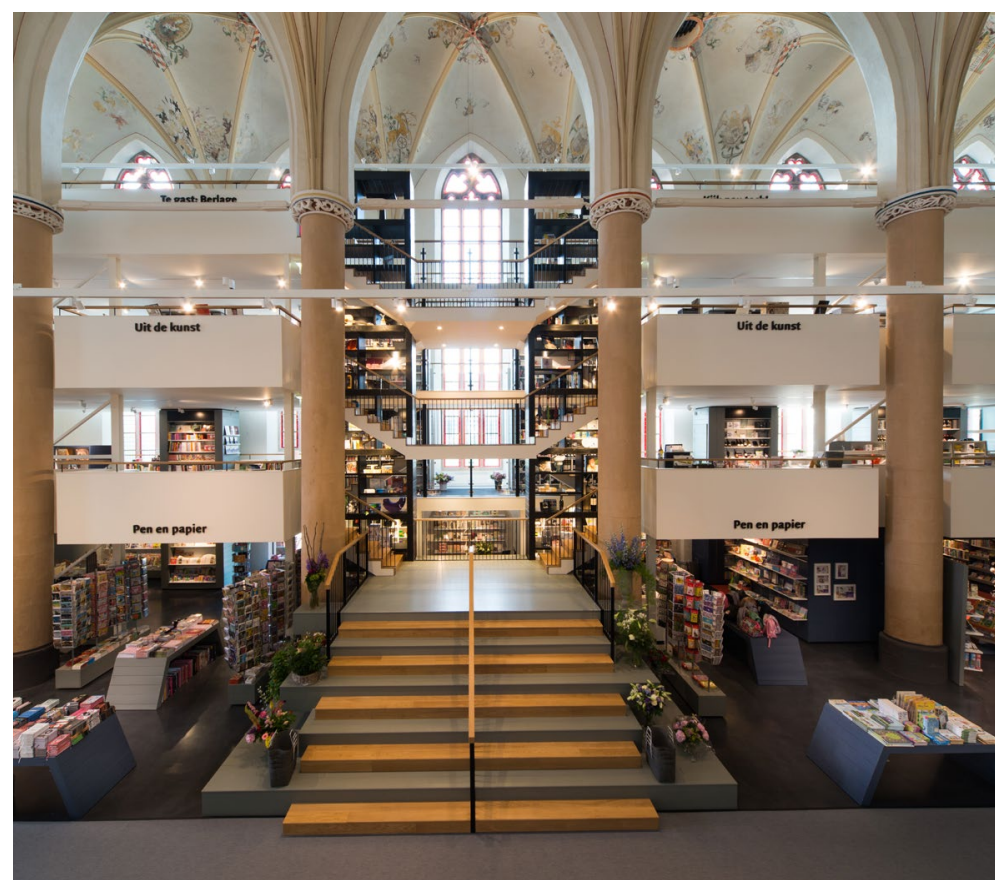

Figure.14. Bookstore inside the Cathedral, designed by BK Architecten.

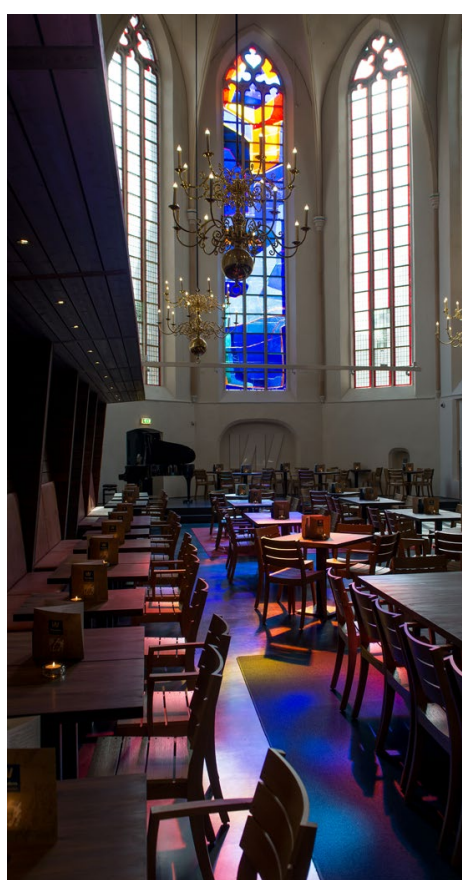

Figure.15. Cafe inside the Cathedral.

The words of Cramer and Breitling reiterate that there are "projects [that] clearly show how exciting a task, the development of existing buildings, can be in the hands of an ambitious designer" (Cramer). Cramer and Breitling also acknowledge there is the issue of difficult sites testing designers to the edge and the fall back is gutting the building and reducing it to an exterior shell. The outlook that this is acceptable is something this research will aim to amend. 


\section{In Support of the Architecture}

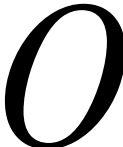

$\mathrm{n}$ Altering Architecture, written by Fred Scott, in 2008, opens with the bold statement: "all buildings, once handed over by the builders to the client, have three possible fates, namely to remain unchanged, to be altered, or to be demolished" (Scott). Scott wants what he considers is best for the architectures future. It is argued that restoration is a type of alteration, and when you chose to restore a building there is the question of which day do you restore it to? The date construction was completed or ten years later? If the time period carries uncertainty then the "restorative work is imitative and interpretive" (Scott), the work merely becomes another alteration in the building's life. An example of how this issue could be addressed is taken from a monument, designed by Robert Venturi and John Raunch, it is on the site of Benjamin Franklin's home. The building was pulled down in 1810 after Benjamin Franklin passed, a frame has been used to outline features of the architecture, it was felt that little more could be done when there were so few details available.
This style of refurbishment has since been emulated at other historic sites. In Wellington there is an example beside the Inner City Bypass, it is the site of Tonks' Well, one of the three known remaining wells in Wellington city. The ghost structure depicts the home from address No.5, which has been relocated from the site.

Another restoration example is the Neues Museum in Berlin, designed by David Chipperfield Architects (David Chipperfield Architects). The museum had suffered extensive damage during WWII. The architects aim was to recomplete the original volume of the building, the new main staircase repeats the original without replicating it, and the shrapnel damage still remains in the walls, even after the renovations. This is seen again with the Warehouse $17 \mathrm{c}$ renovations of a slaughterhouse, designed by architect Arturo Franco. The "theoretical vagueness" was a constant hindrance on the project and it was "decided to intervene in a radical manner without intervening." "Respecting the ruin... the new boosts the value of the old and vice versa." (Franco) Elements remain that tell the history of the building, such as markings on the floors

\section{Literature Review + Case Studies}




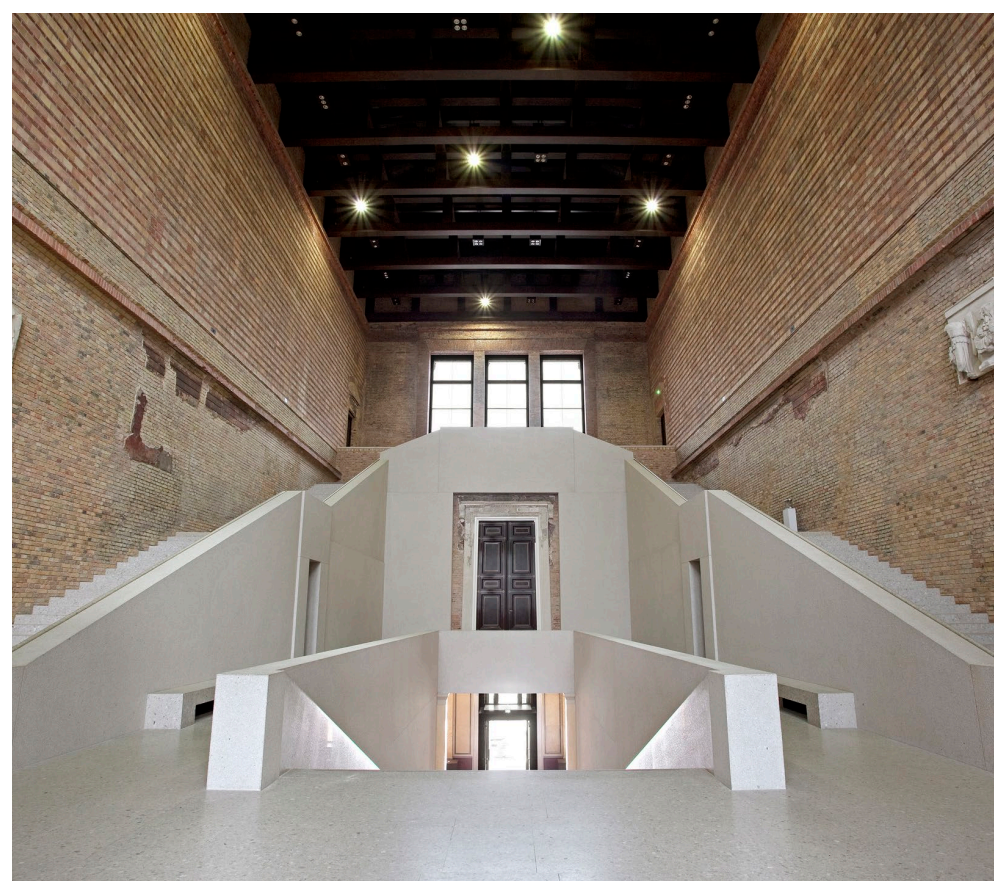

Figure.16. The main staircase in the Neues museum.

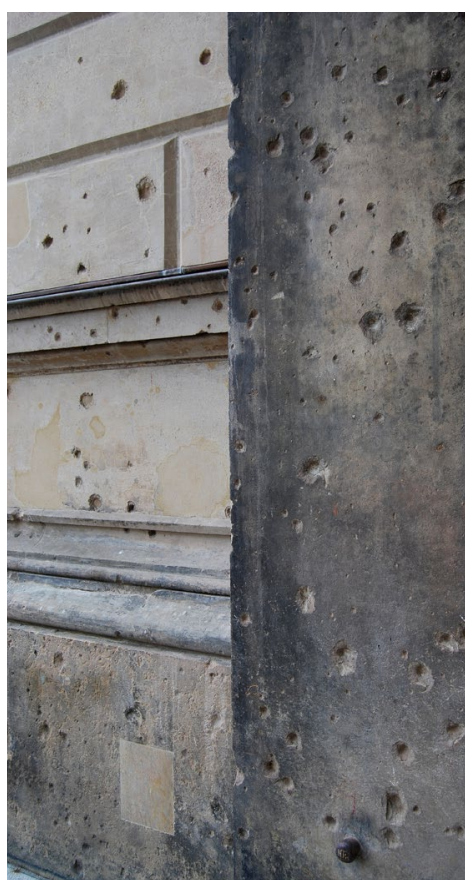

Figure.17. Shrapnel damage from WWII. 

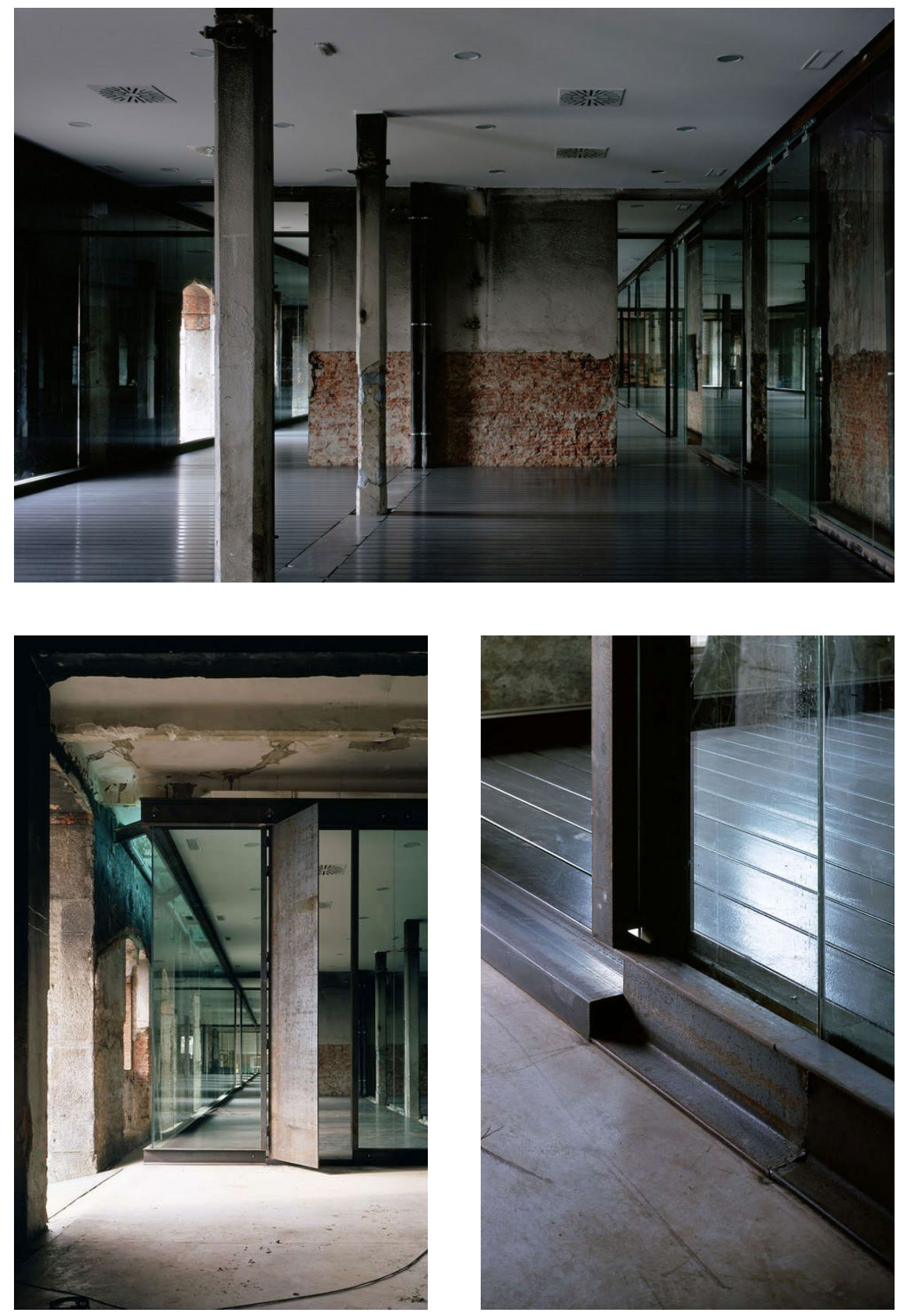

Figure.18-20.

Interior features of the $17 c$ slaughterhouse renovation.

Literature Review + Case Studies 
and walls made by the original machinery of the slaughterhouse.

Scott believes that "restoring a building nearly always involves modernisation of servicing" (Scott). $\mathrm{He}$ reasons that architecture from the Modernist epoch was designed to such precision for the intended programme that the building is incapable of ever achieving another programme, although mutation of its programme is possible; for example, King's Cross station in London transitioned from steam trains to diesel electric (Scott). The stations programme evolved with technology advancements but the architecture underwent less change. There is no alternative and it is implied that advancing the technology within a building is destructive. This is where Cramer, Breitling and Scott agrees with one another, that alteration can be done sympathetically or not. When work is performed on an older building it almost always requires some form of alteration, be it for the modernisation of the services or a change of programme, it is suggested that all these changes are irreversible. 


\section{KINTSUGI}

Tintsugi, meaning 'patch with gold,' (Roma) is the ancient Japanese art of decoratively

1 repairing a broken object. "The Japanese admired the glory of the passage of time," (Roma)there is an appreciation that nothing lasts forever; the notion of time being able to take away what is beautiful makes it more precious. This idea was passed onto a ceramic bowl, its fragility meaning it could break made it more valuable. A repaired bowl is viewed as reincarnation, as the pieces were mended the bowl was starting a new life.

The fine detail of the craft is so prominent but makes up such a small percentage of the reincarnated bowl's aesthetic. The act of repairing does nothing to affect the historic material, only allows the object to continue to present itself.

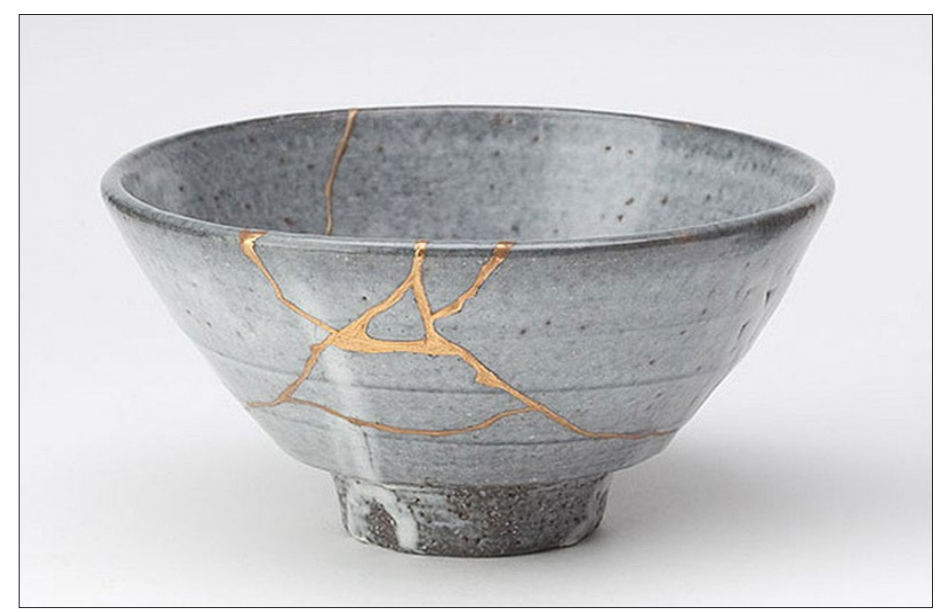

Figure.21. A bowl repaired with Kintsugi.

\section{Literature Review + Case Studies}




\section{HYBRID}

\section{REASSEMBLAGE}

$\prod \begin{aligned} & \text { ybrid Reassemblage: An } \\ & \text { Exploration of Craft, } \\ & \text { Digital Fabrication and }\end{aligned}$ Artefact Uniqueness is an article written by Amit Zoran and Leah Buechley, in 2013. The research project began with a desire to repair a personal object, accidentally broken. Comparisons are drawn from the restoration of both art and architecture; the article argues that the goal when restoring art is to preserve the original piece, however when restoring architecture it is not uncommon to see "modern extensions added to old buildings" (Zoran). Like the new design of the Neues Museum there is a view that there is no reason to pretend that something new is old, the addition to the building has purpose and that should be celebrated not concealed.

Zoran and Buechley suggest that digital fabrication can be an easy method to replicating their broken artefact. Digital fabrication presents the possibility of not only recreating the object but also developing extensions to the original form. This idea was applied to a set of vases, the difference between the old and the new is very clear; emphasised by form, material and the finishing. Instead of attempting to recreate the vases, the restoration draws attention to the damage; the vases no longer functions as it once did, instead they serve as a reminder of what they once were.
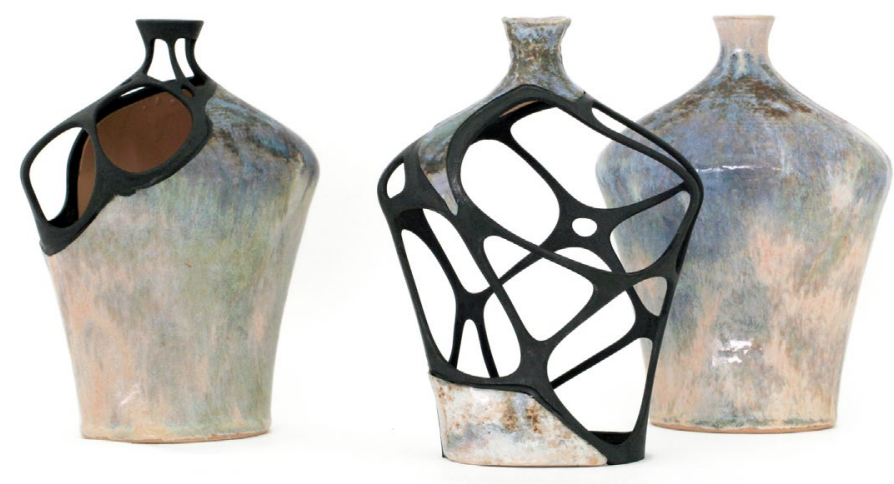

Figure.22. Vases produced as an outcome of the reassemblage research. 


\section{Methods of Alteration}

ix Degrees of Intervention, an article written by Jennifer Hill, in 2004, provides discussion on the various methodologies to rejuvenate expired architecture. She uses buildings in Sydney, Australia, as exemplars of six varying methods of construction a historic building can undergo.

"Ultimately the success of these projects is determined by the sophistication of their subsequent interpretation" (Hill).

Hill considers six methods of evading demolition.

- The Seamless Transition: a subtle change in fabric is the only portrayal of evolution from old to new.

- Restoration, Reconstruction and Intervention: the demolition and reconstruction occur to finance additional historic alterations, historic value is lost.

- Multiplicity of Layering Part Two - the old and the new: a complete redevelopment which carries little significance to the site's original building.

- Recovery: intervening with aging architecture to rescue it from demolition, elements can be beyond saving at this point.

- The Conserved Shell: is when the 'shell' of the heritage building remains while a new interior intervention provides the programme for the space. 
- Multiplicity of Layering Part One - shows years of use and change of programme. The Female Orphan School at Rydalmere was built in 1813.190 years of adaptation coexist within the building as the layers representative of its history. "Wall finishes [reveal] the variety of paint schemes from 1813 to the 1920's" (Hill). Other fittings, fixtures and finishes which remain also allow insight into the building's past as an orphanage and psychiatric hospital.

The work of intervention is based on an understanding of the situation, "a more intimate knowledge of a building's traditions can result in each of the layers being of its time" (Hill). The text supports the notion that alteration can be achieved both sympathetically and not. Hill proposes "the history of most buildings is a process of metamorphosis... and those transformations of their period also become parts of the history of the building" (Hill). The concept of layers representing history is suggested with reference to the Rose Seidler Museum. Hill feels that the appearance of the building after being "returned to its 1951 condition, belies the complexity of its history" (Hill) the restoration of the building involved the removal of layers of history, the history of a buildings transformation was present in the disturbed material layers. 


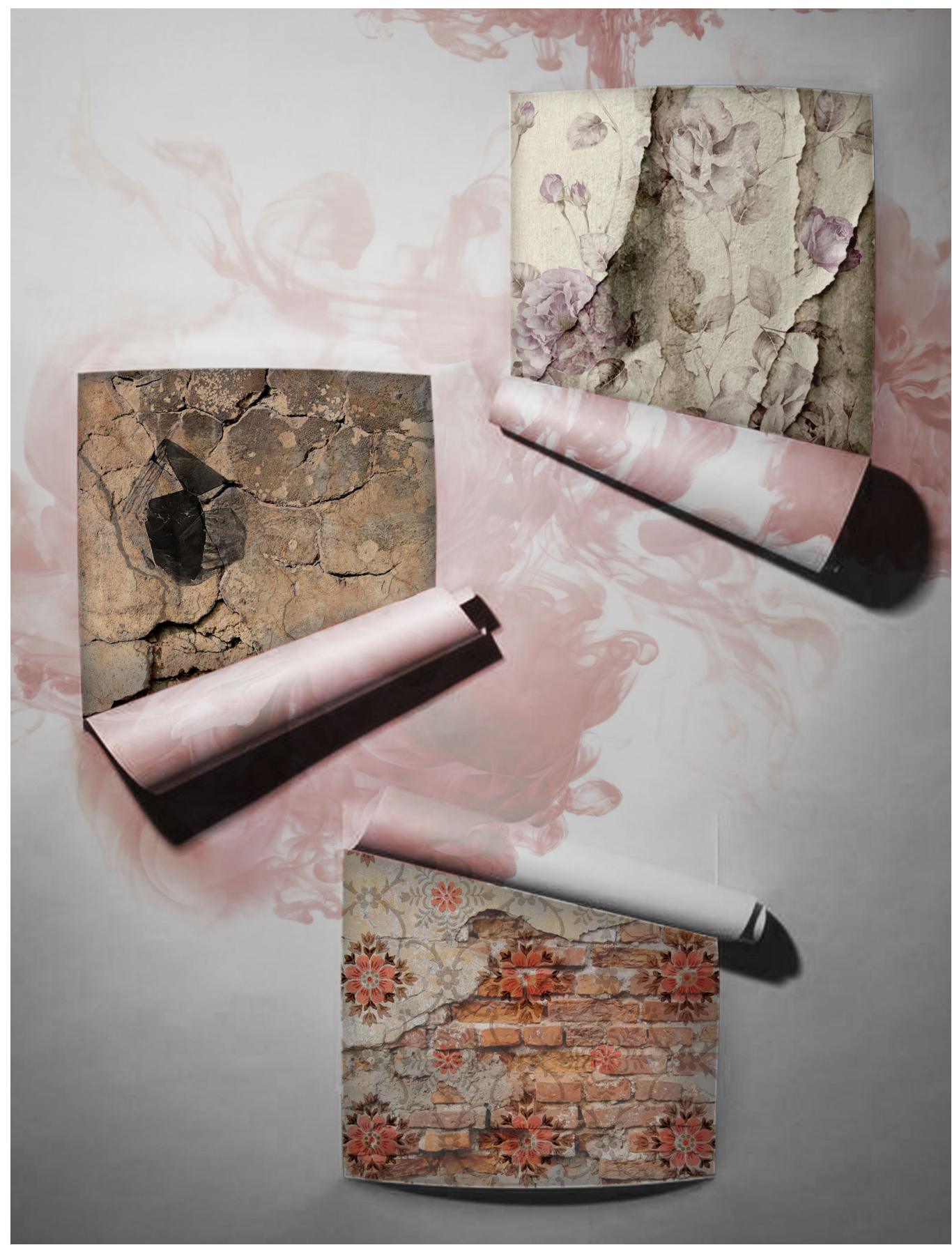

Figure.23. Author's representation of what materials may be exposed by the peeling back of historic layers within the interiors of architecture. 


\section{Site Specific}

\section{Renovation}

dditional restorations considered by this research present a
variety of projects where design specific to the architecture
are successful. The restorations of the 13th Century Dominican Monastery building where designed by ENOTA, in Ptuj. The building was abandoned in 1785, and alterations occurred in 2013.

Two other projects are:

- Palais de Tokyo, Designed by: Lacaton and Vassal, Location: Paris, France, Built: 1937, Alterations: 2002.

- Castelvecchio Museum, Designed by: Carlo Scarpa, Location: Verona, Italy, Built: 1355, Alterations: 1957.

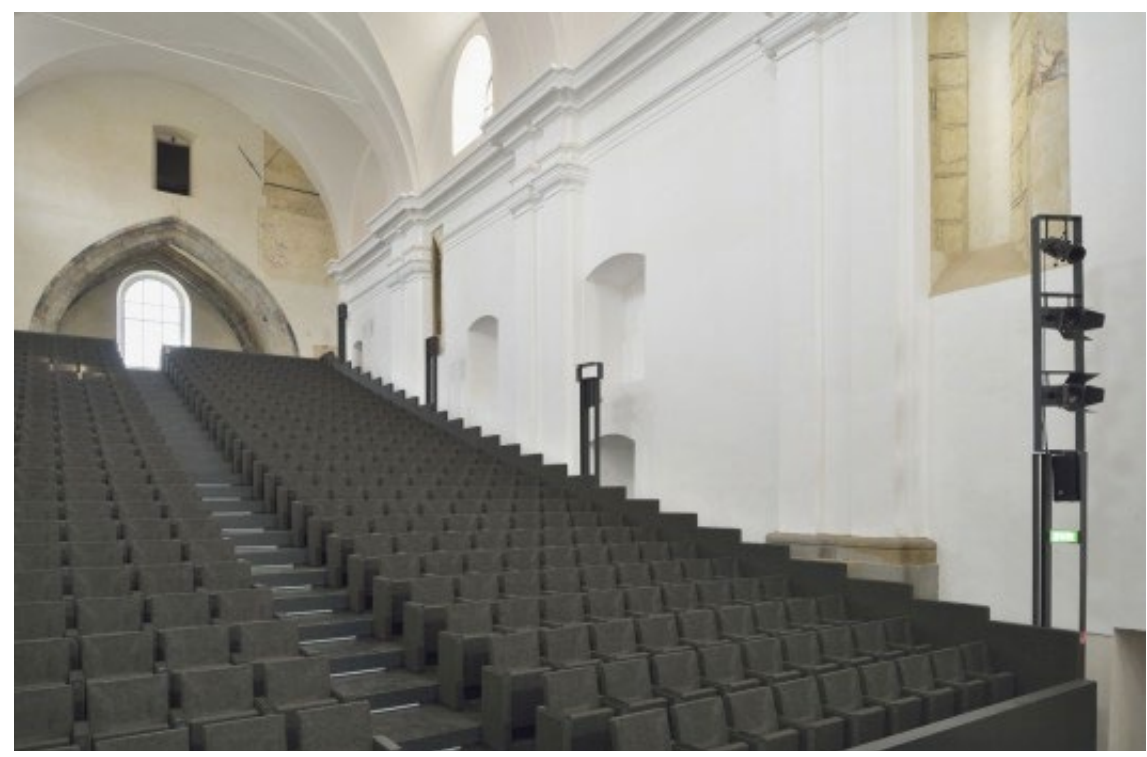

Figure.24. ENOTA contrasts the aged stone with white a design in the Dominican Monastery. 


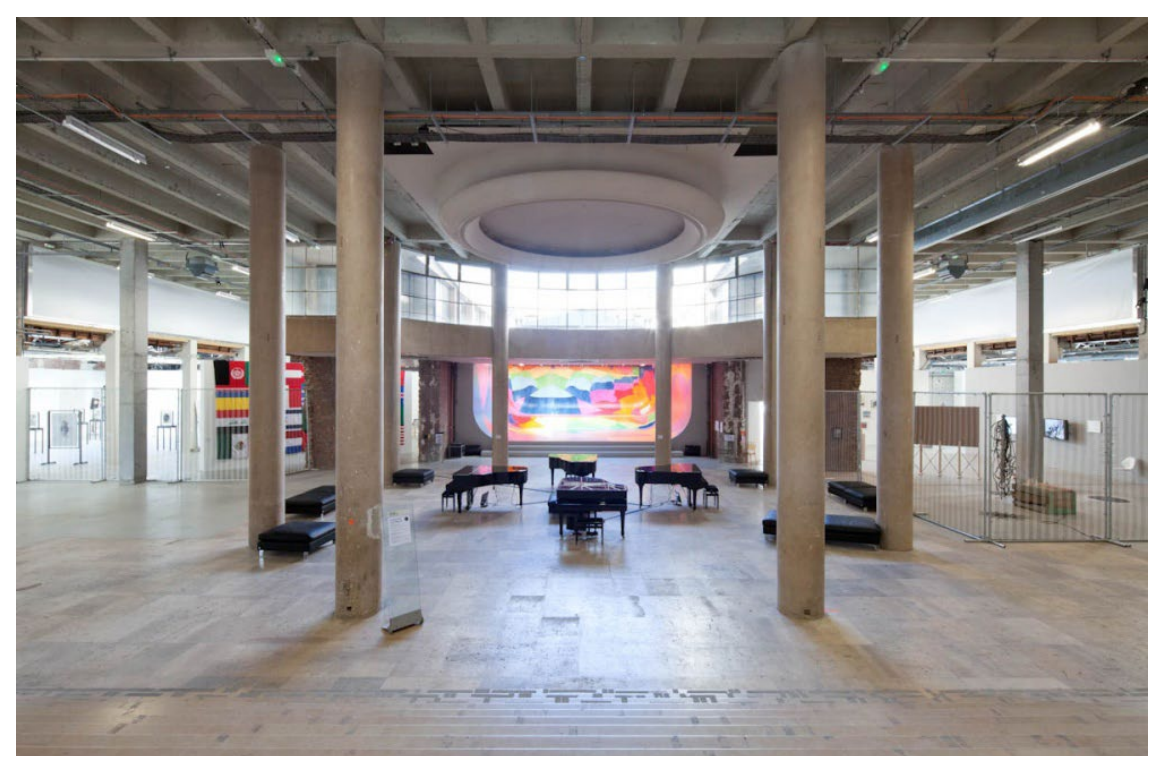

Figure.25. The entrance of the Palais de Tokyo.

Figure.26. Scarpa's design recreates where the statue would have been prior to the deterioration of the architecture.

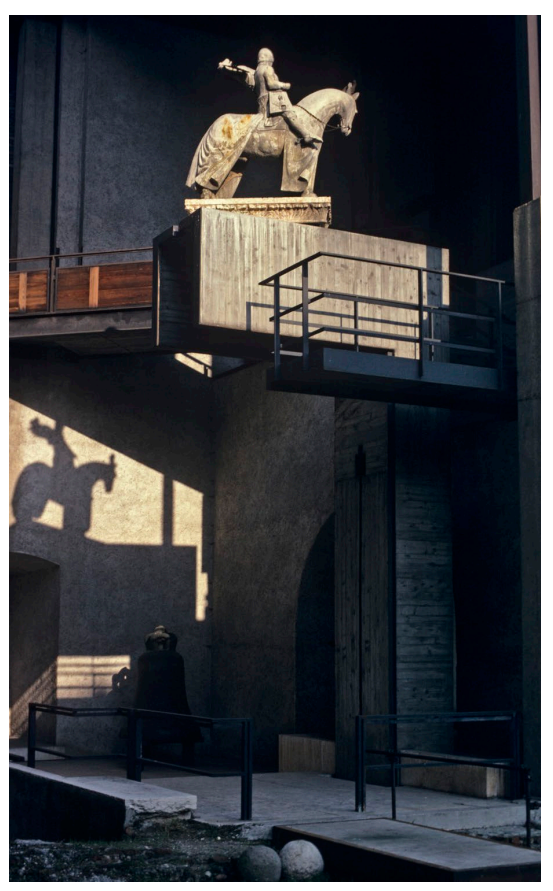

Literature Review + Case Studies 


\section{Siteless Interior}

he following investigation responds to previous
literature, it is aimed at understanding the
concept of 'siteless architecture.'

Designs addressed by the earlier literature were each developed specific to the site. The complication of this is that the design outcomes are not transferable across different sites; this has occurred for various reasons relating to the architectures age, the severity of deterioration and the programme of the building. To address this literature which considers the theory of "architecture out of context can generate new ideas; hidden, non-obvious ones" (Nebojić) is now presented as a solution for the interior intervention.

Siteless: 1001 Building Forms, written by François Blanciak, in 2008, is self-described as being a "link to the future of the profession" (Blanciak). The text provoked two questions for this research; how does no context work? And where does the form come from? Blanciak explains the design approach of the forms in the book, "the traditional sequence, programme plus site equals form, is...intentionally inverted," (Blanciak) meaning his design commences with the form. In the production of the forms produced in the book "the possibility of tabula rasa" (Blanciak) is tested. "Prospective of a series of forms that focuses on the nucleus of architecture, the building as a unit" (Blanciak).

\section{Literature Review + Case Studies}


Architect Frank Gehry is acknowledged as a former employer of Blanckiak. Considering Gehry's approach to architecture, similarities can be found between the two architect's styles. An answer to the question of "how does no context work?" might come from the 1980's, when Gehry's work was described as being "made out of defamiliarised architectural conventions" (Gehry). It has been described that "there is an idea that unites Gehry's buildings with their locals and vice versa," "he adapts the programme...to the site in such a way as to make it impossible to say with any kind of certainty what comes first" (Gehry).

The Function of Form, written by Farshid Moussavi, in 2009, questions that "if not function, what does form follow?" (Moussavi) Moussavi discusses how many "theorists of modernism" have tried to answer this however when providing a solution, they make three assumptions; "first, that society is defined by a unitary culture; second, that physical form must be preceded by a fundamental principle...; and, third, that form either epitomises or responds to a single, ideal meaning, identity or possibility" (Moussavi).

Today "cities are characterised by different and multiplicity," (Moussavi) this has "increased the demand for built forms that provide higher levels of performance." (Moussavi) This is mirrored on the interior which is "expected to provide specific answers to user demand and the need to improve out well-being" (Spanjers).

"Any building would be obliged to refer... to its site a specific place serving a general and therefore siteless function” (Gehry). 


\section{Discussion}

T hile architecture has managed to achieve interesting and innovative responses by eliminating context as a design driver, there is the prospect of accepting the same design principles to achieve interior designs, within historic architecture, which disregard the site context and offer a stay of demolition.

This research concludes that by choosing to design with disregard to the site context the designer must then find a new source of inspiration. While the literature, from Cramer, Breitling and Scott, considered the methodology of designing for historic architecture, its consideration of site did not offer guidance for potential solutions for new outlets for design inspiration.

Jennifer Hill's observation of the layering occurring during the aging of architecture is a point of interest as it brings into question the type of fabric introduced by a new design. The existing layers might come in the form of a solid surface, such as wood floor boards, to a more malleable material like "the variety of paint schemes" (Hill) and wallpaper peeling off the walls. Retaining the historic material is important as Spanjers tells us that "intact historic interiors can tell us more about the culture, the fashions and habits of a certain place and time than indepth scientific studies" (Spanjers). 
This research proposes that the new form to be introduced to the architecture will disregard site context and regular architectural conventions; instead it will adopt the view of layers within architecture and use this as a design driver: a "building is never finished" (Spanjers) and the proposed design will introduce another chapter to the buildings history.

The following chapter recognises other influences for this research. It will include the economic benefits and a proposal to fold the layers described by Hill. 


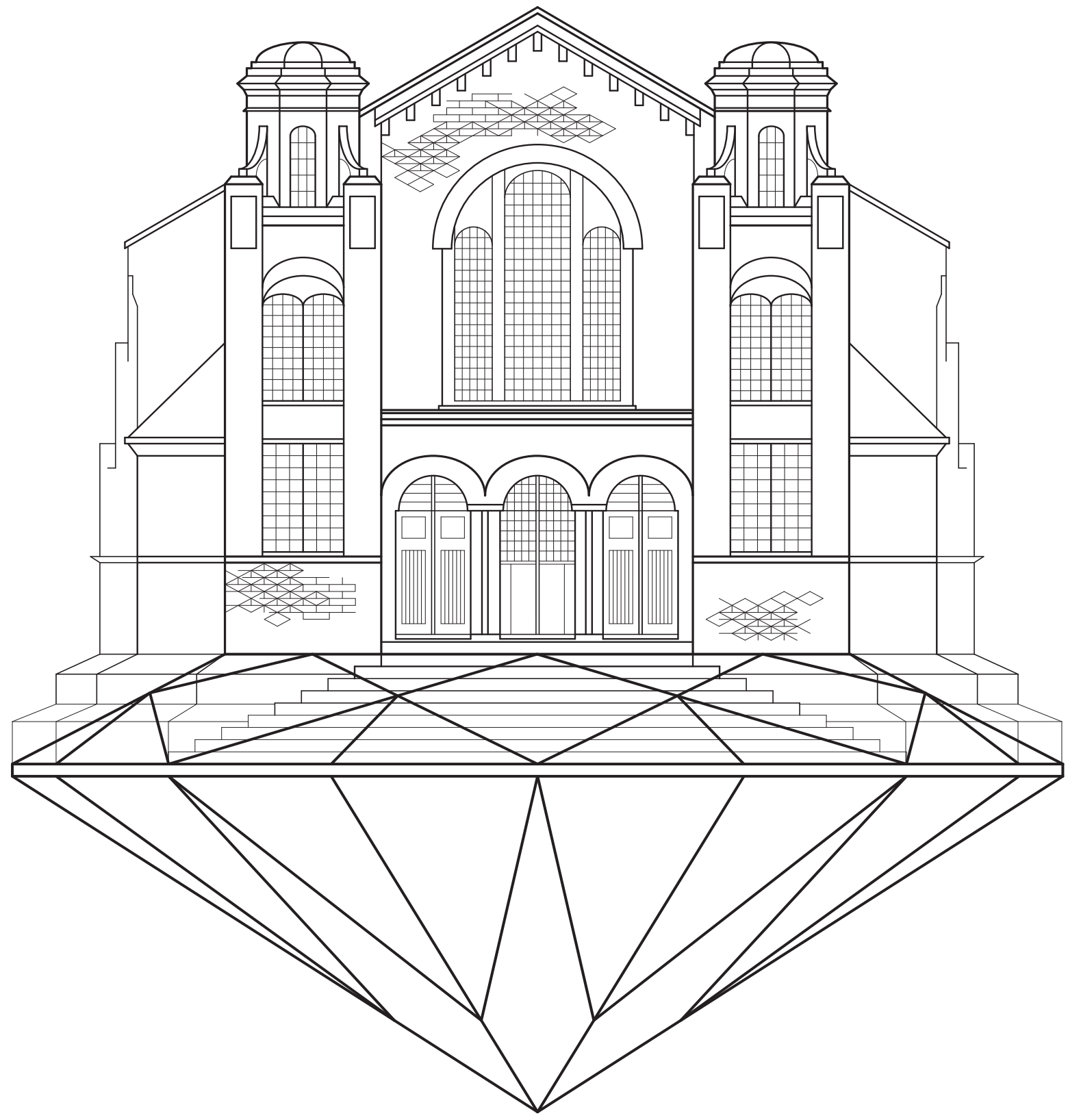

Figure.27. Author's image to depicted architecture balanced on its own financial worth and heritage value. 


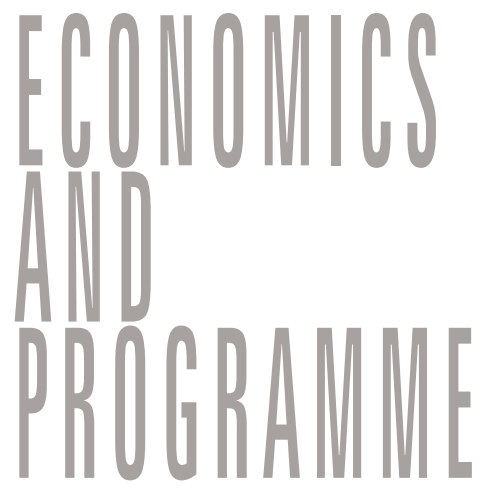

There is also the economic benefit of rehabilitating heritage architecture to consider. In Architecture In Existing Fabric, Cramer and Breitling argue that developing an existing building is more economical than building a new structure. Rationale is that it is easier to assess the possibility of alterations in the future: "the construction has aged, undergone repairs and proved its durability" (Cramer). The second rationale is finances; if the use of the old building is compatible with the new development they predict that savings of up to $40 \%$ can be made (Cramer). 


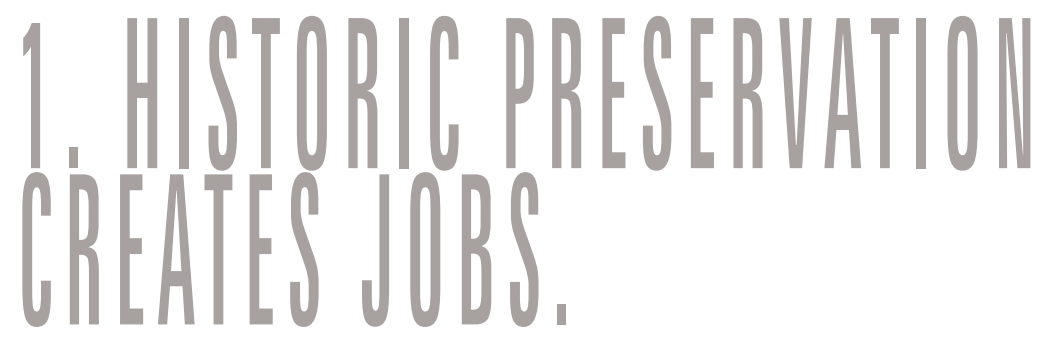

Donovan Rypkema is an American economist who is an advocate for restoring heritage architecture, his literature supports these statements. In his book The Economics of Historic Preservation: A Community Leader's Guide, written in 2014, he lists 100 reasons for why, in his opinion, historic architecture should be preserved, ending with "100. Historic preservation makes sense" (Rypkema) In a talk at Victoria University, in 2012, Rypkema broke his research down into five major measurables of heritage economics: job and household income, centre city revitalisation, heritage tourism, property values and small business incubation (D. D. Rypkema).

The area of interest for this research is what heritage buildings can provide for businesses. Rypkema lists " 14 . Older buildings provide excellent incubator space for businesses of all types" (Rypkema) and "19. Locating new businesses in historic structures leaves more money available for employment and future expansion" (Rypkema). These reasons assist in designating a programme for the design by suggesting that is cannot be specific. Instead the design must serve multiple programmes to provide for as many 
businesses as possible. It is anticipated that the possibilities of the new programme could range from a retail store, small offices, or even gallery space; each of these programmes have varying needs. The challenge will be for the design to adapt to accommodate all of these.

It is appropriate to acknowledge here that if the buildings from this research were not demolished because they are not programmatically viable anymore, they would likely have met their demise due to unsubstantial earthquake strengthening. It is being suggested that by removing much of the insignificant material from the interior, with the removal of walls, floors and ceiling, would facilitate easier access for earthquake bracing. With the creation of a new spatial relationship between the historic material and new design, this would address both issues. Many interiors have to be removed to enable earthquake strengthening, so why not find a beautiful way to make that happen?

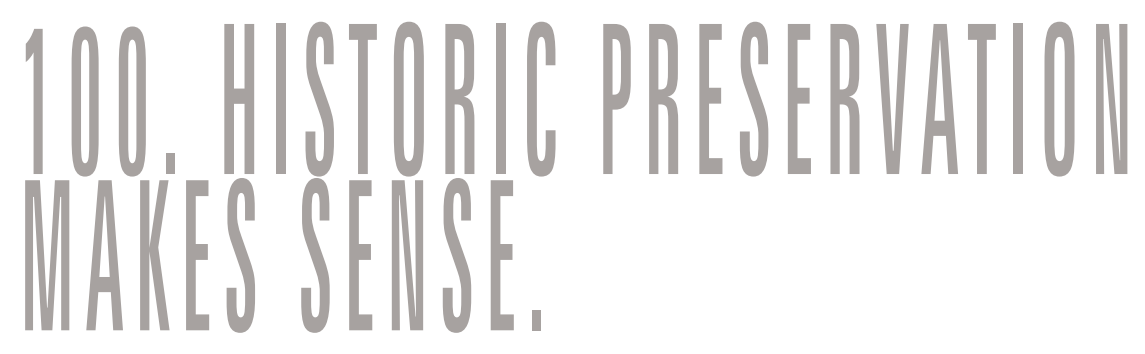


Literature Review + Case Studies 


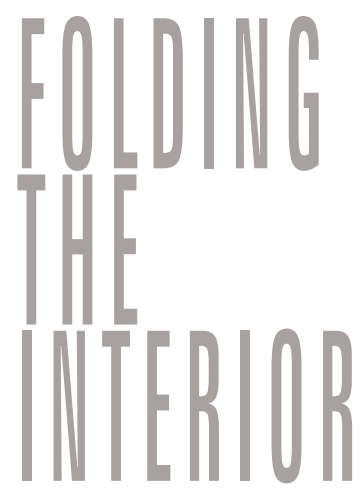

"The notion of surface has evolved into a formal trait in avant-garde architectural discourses" (Vyzoviti).

Between each of the layers, attached to the walls of the aged architecture, the deterioration is notable in all the selected sites in Lower Hutt. Paint has cracked and is flaking off the walls, the glue behind the wallpaper has dried detaching the paper from the layer beneath, fabrics have worn thin and tears are evident: all these feature the prior use of the building. The peeling layers are exposed, the lightest pressure puts creases in the vulnerable materials. This research will orchestrate its own series of creases and folds in the layer being introduced to the interior of the architecture.

Folding in Architecture brings together a series of essays by architects such as Frank Gehry and Peter Einsenman: two of Blanciak's former employees. Folding of Architecture precedes Blanciak's Siteless literature. The introduction notes that the architects "used metaphors of folding... to explain their morphology but none took recourse to digital visualisation and mapping as an explanation for their

\section{Literature Review + Case Studies}


shape or form." (Lynn) It also discusses that there was a "desire for architectural complexity in both composition and construction" (Lynn) noting that the digital design was not introduced during the early stage of design is significant to this research as it attempts to recreate the motivations architects felt for designing with disregard to the site. This research acknowledges that there have been significant advances in technology which will enable it to utilise digital visualisation in the preliminary design stages to rapidly produce design forms.

In the revised edition of Folding in Architecture, printed in 2004, Mario Carpo reviews the literatures impact and continued significance in a second introductory essay. He explains that the original text "was regarded as the quintessential architectural embodiment" (Carpo). Carpo deduces from the literature that there is a "notion of forms that can change, morph and move: a new category of objects defined not by what they are, but by the way they change and by the laws that describe their continuous variations" (Carpo). The research recognises the excitement in this as something the new folded design could also achieve using "a multifaceted approach towards detail, structure and form" (Carpo). Folding in Architecture is an important text for this research as it

"Folding is a process, not a product;... which can nevertheless induce the perception of motion by suggesting the 'continual variation' and 'perpetual development' of a form becoming" (Carpo).

represents architects use of folded forms in realised architecture. It takes the forms from Blanciak's text one step further.

It is important to acknowledge here that this research is not the first time origami has been used as a technique for initialising a folded form. Origami - Folded Plate Structures, Architecture, written by Buri, Hani and Yves Weinand in 2008, is a research paper which proposes "methods to generate rapidly complex folded plate structures that can be built" (Buri and Weinand). They write that "origami gives birth to an astonishing 
formal richness and variability. Complex geometries are generated in an economic way." (Buri and Weinand) This research recognises that here the resolved forms are aided by computer modelling. The nature of the proposal requires the "generation method of the geometry [to] be close to architectural design processes and use devices as section and plan to define the folded plate structure" (Buri and Weinand).

Origami is recognised as an aesthetically attractive form achieved through the art of paper folding. A report written by Jesse L. Silverberg et al. discusses the opportunities when working with an origami form and how the patterns are composed using the tessellation of a single component and a fold pattern that only has two stationary positions, open flat and folded completely onto itself (Silverberg).

Folding Architecture, written by Sophia Vyzoviti in 2003, describes the folding process as experimental. She explains "our interest lies on the morphogenetic process, the sequence of transformations that affect the design object" (Vyzoviti, Folding Architecture). A few of the methods of this process are listed as: the folds, pleats, creases, scoring or cutting of the material. Vyzoviti observes that we "appreciate the function of folding as a design generator by phase transitions, that is, critical thresholds where qualitative transformation occurs" (Vyzoviti, Folding Architecture). In Vyzoviti's second book, Supersurfaces, written in 2006, the "paperfolds are investigated as physical objects... and how they can be productive within a design methodology" (Vyzoviti, Supersurfaces: folding as a method of generating forms for architecture, products and fashion). The designs are broken up into methods for creating each form. This research notes the variation of form modelled using the same fold pattern. These texts are similar to Blanciak's as they propose potential forms for architecture, however Vyzoviti goes one step further to explain to her audience the process of the form's creation. This is significant to the research in its own manipulations of the folded layer of design.

\section{Literature Review + Case Studies}




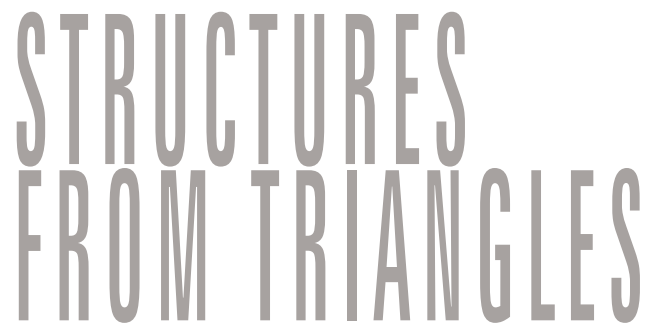

The research acknowledges the presence of geodesic architecture. The first well documented geodesic domes were built in 1965 by a community, and were named Drop City. There are other interior designs which have since used triangle faceted surfaces.

- Swarvoski Crystal Dome, built in 2010, has an interior of faceted triangular mirrors creating a kaleidoscope effect.

- A New Zealand design which used parametric modelling to calculate the dimensions and angles of the form is located at the Te Wananga o Raukawa, Built in 2012, the form provides a space of rest and tranquillity.

- In 2014 Autoban designed the fit out of the Heydar Aliyev International Airport in Baku. The design incorporates wooden cocoons that are flexible in the uses they provide. 


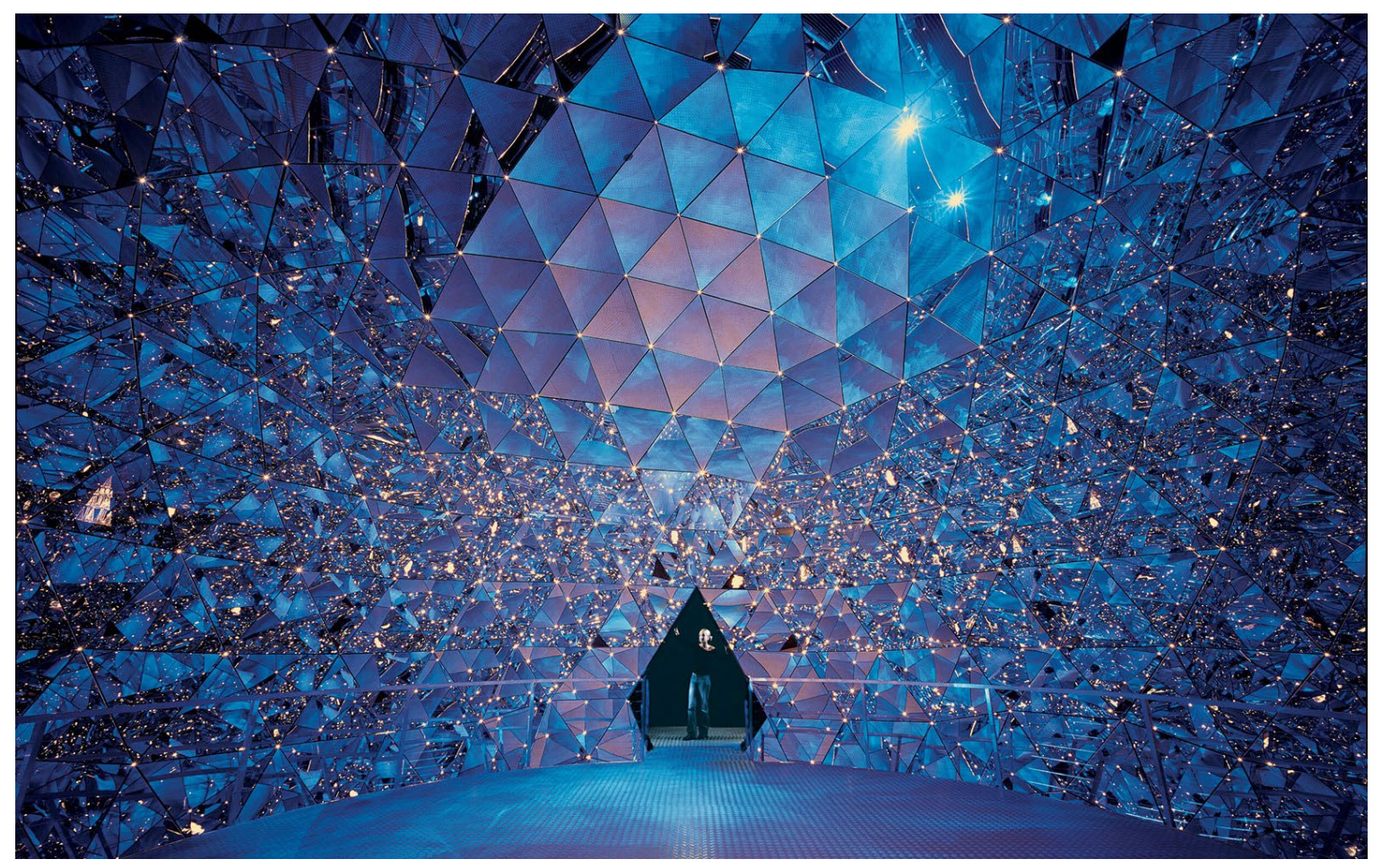

Figure.28. Inside the Swavoski Crystal Dome.

\section{Literature Review + Case Studies}




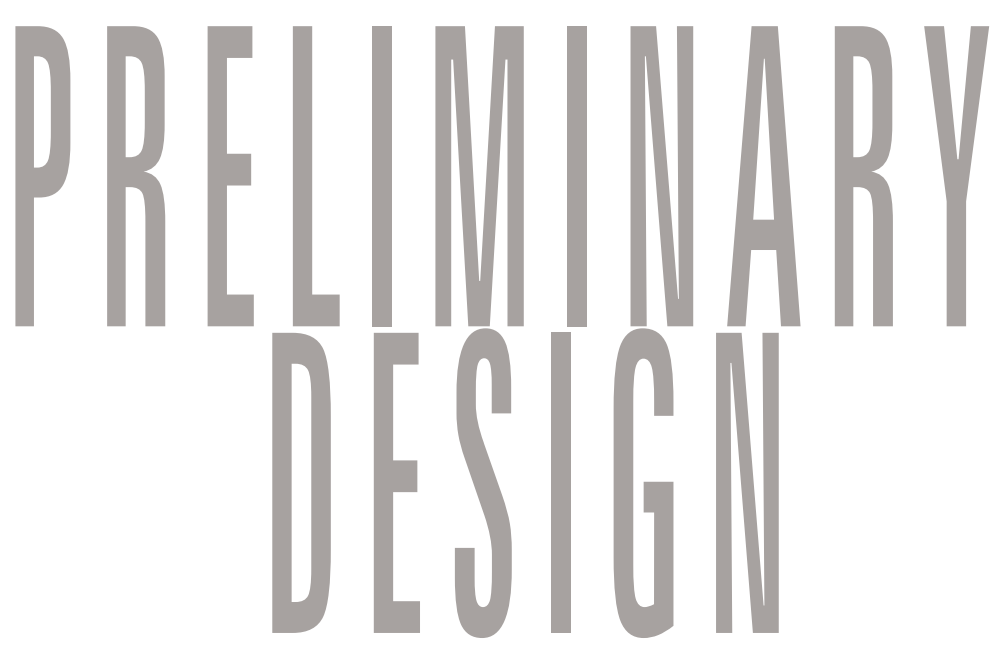

7 his section outlines the initial research related to producing folded forms, the implications of the forms are then discussed at the first site, the Methodist Church.

Three different folding techniques were experimented with: pleating, patterns which fold around a point, and origami. Commonly reflection was used in all the tested iterations. 


\section{SERlES OME}

A-POC

DEATS PLEASE by Issey the body. The pleats are worked into Miyake is a clothing fabric, and there is no additional material collection that was designed used to hold the folds. The fact the pleat alongside Miyake's A-POC research is designed into the product means there (Miyake Design Studio). Computer technology was developed to manipulate a single length of thread into a clothing product, using just one process. For PLEATS, folding is used to create a malleable material that can form around is no additional weight and the design is simplified. The wearer's body is the reason for the form existing, the garment can expand to accommodate the body's movement. 


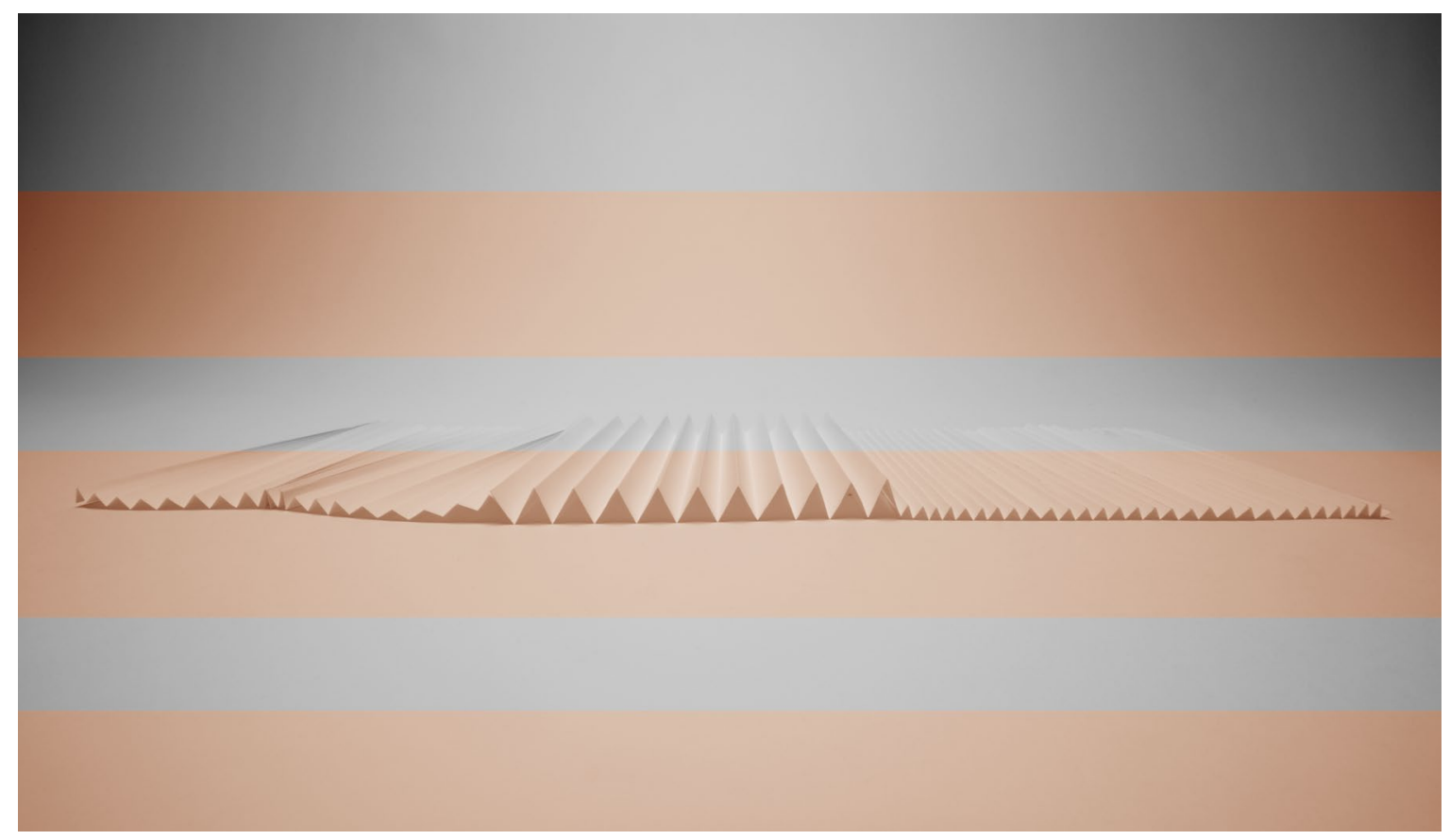

Figure.29. Paper folds using pleating in Series One.

\section{Preliminary Design}



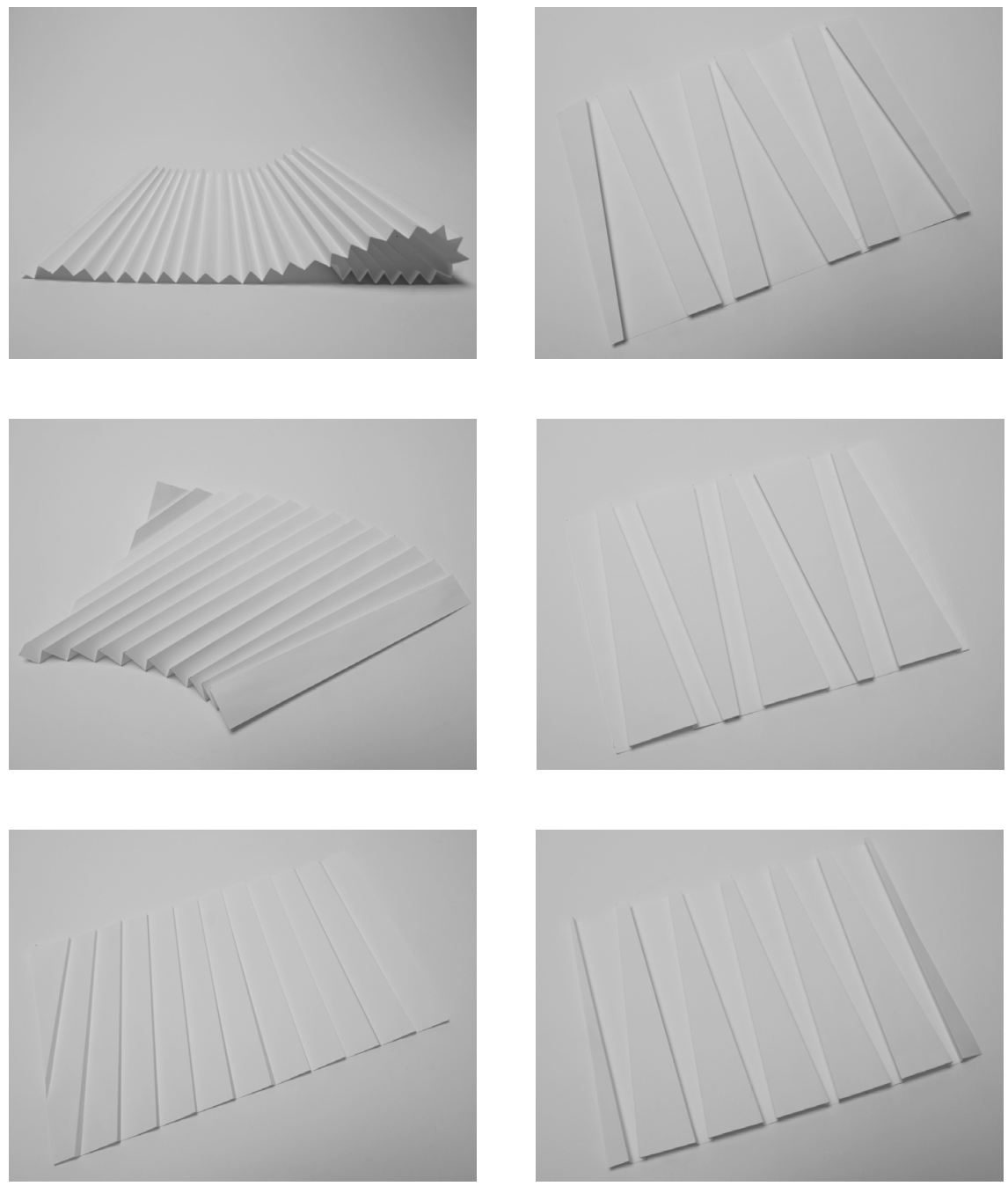

Figure.30-35. Continued paper folds using pleating in Series One.

\section{Preliminary Design}




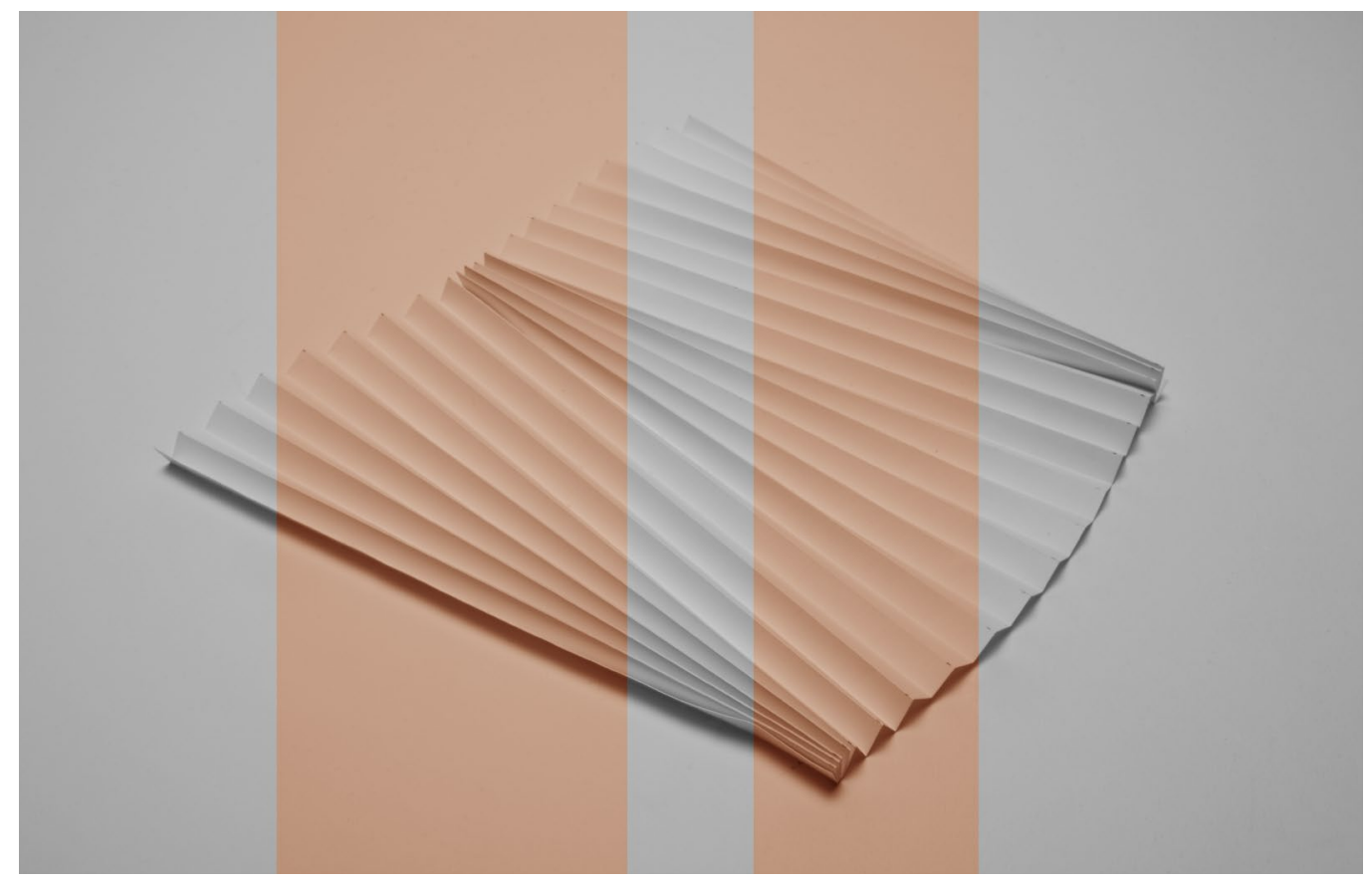

Figure.36. One paper fold design from Series One which combined pinching of the material in three places.

\section{Preliminary Design}




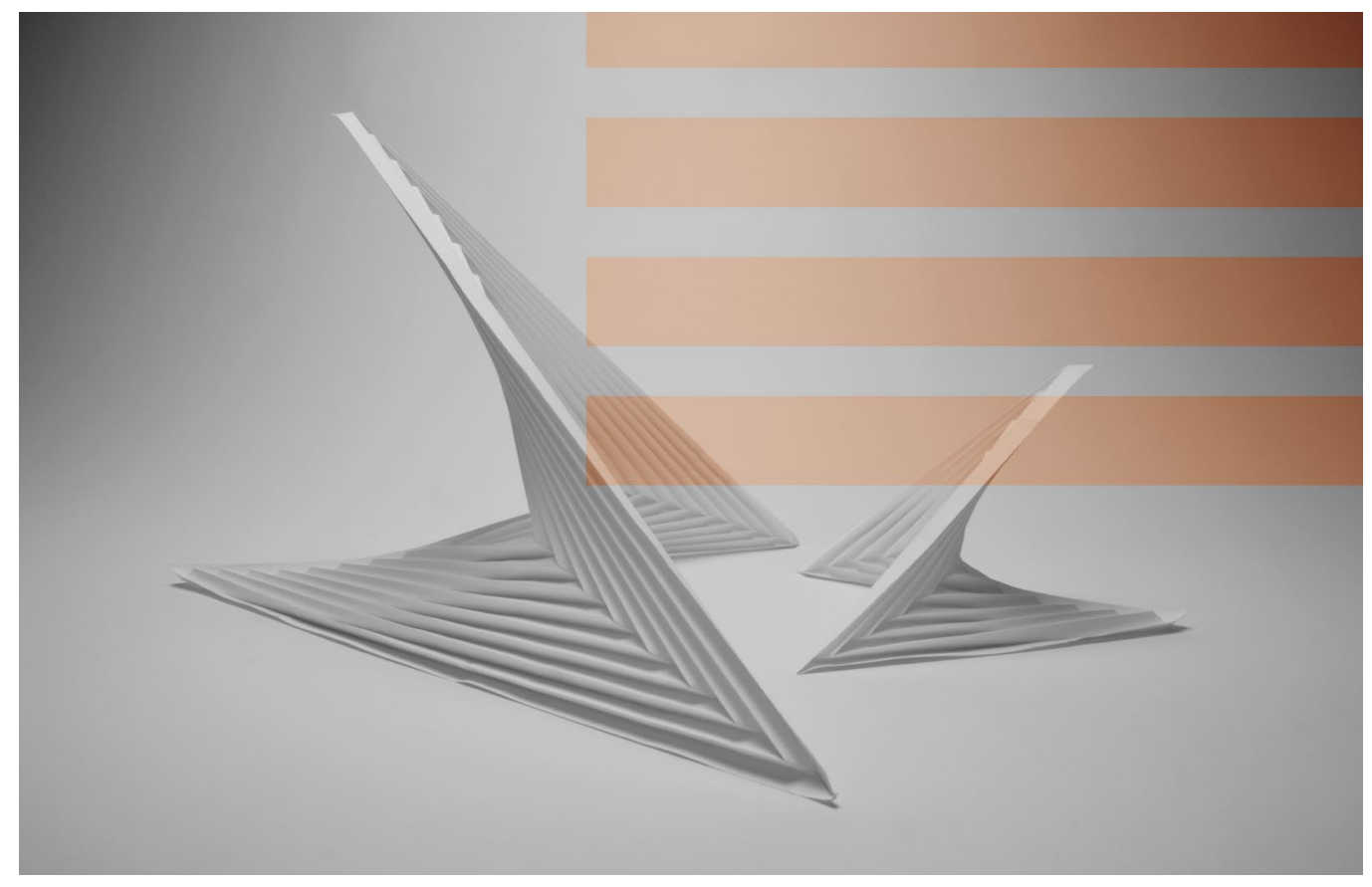

Figure.37. Forms created using the pleating in Series One.

\section{Preliminary Design




\section{SERIES TINO}

Folding Around

a Point

B

radford Hansen-Smith is a researcher who works with folding patterns around a point. He divides the paper into equal sections using a base shape of either a triangle, a square or a pentagon, and finds organisation using reflection and more triangles (Hansen-Smith).

He removes a section to change the pattern to a shape with one less side, for example the pentagon shape to a square. This creates creases over the paper, and the placement of the creases is organised by the previous divisions. The folds give way to forms that Blanciak would attest to being inhabitable forms.

Hansen-Smith then goes on to test these theories alongside the randomness of crumpling paper. He believes that there is a form of organisation that can be related to random crumpling. There is a centre point that the crumpling originates from, just like the folding from a centre point (Hansen-Smith, Regularity and Randomness). 


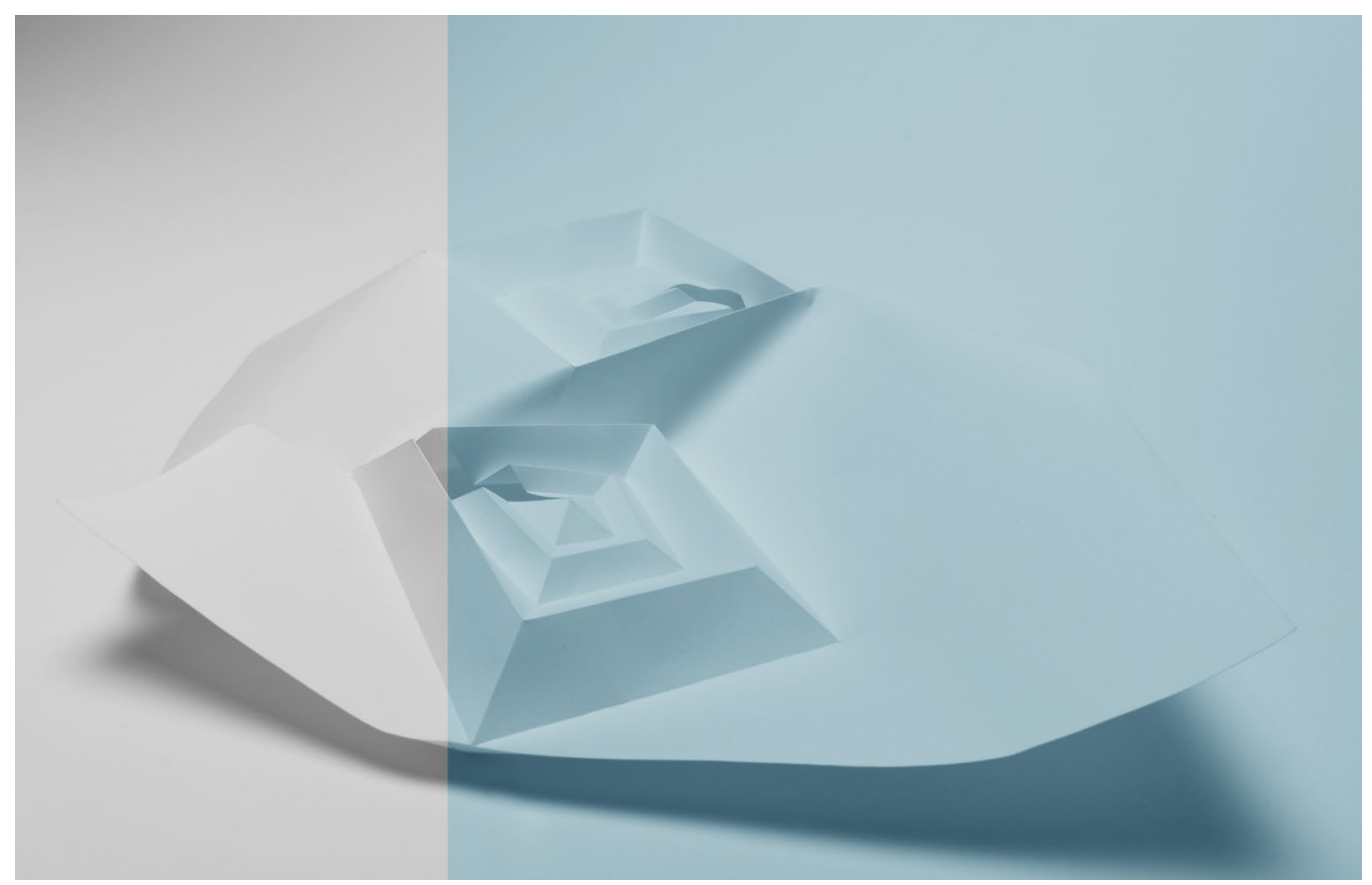

Figure.38. Paper folds in Series Two.
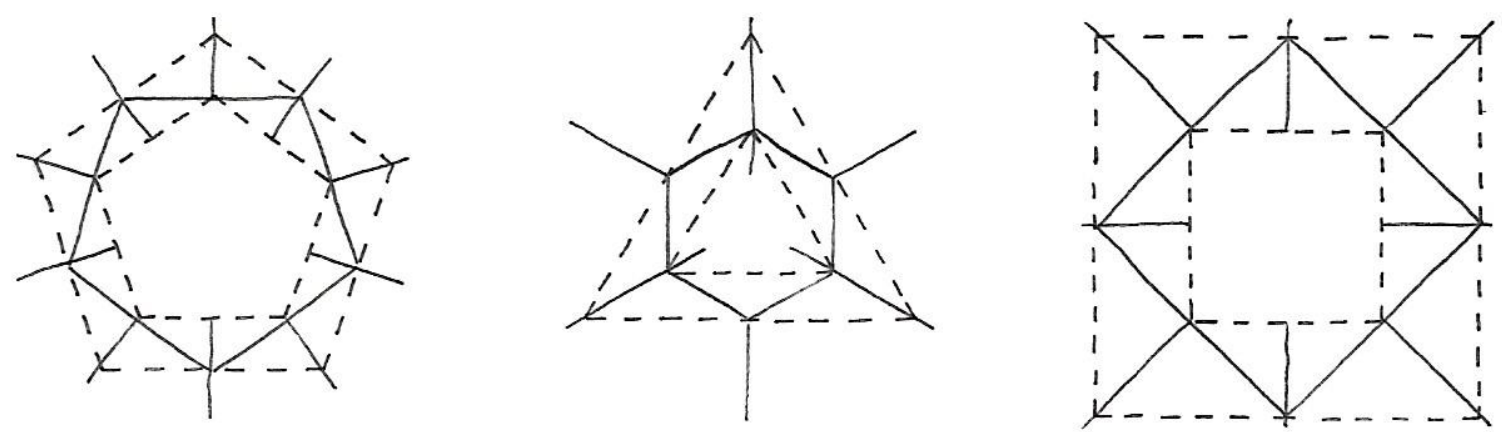

Figure.39. Author's own sketches of the Series Two fold pattern. 


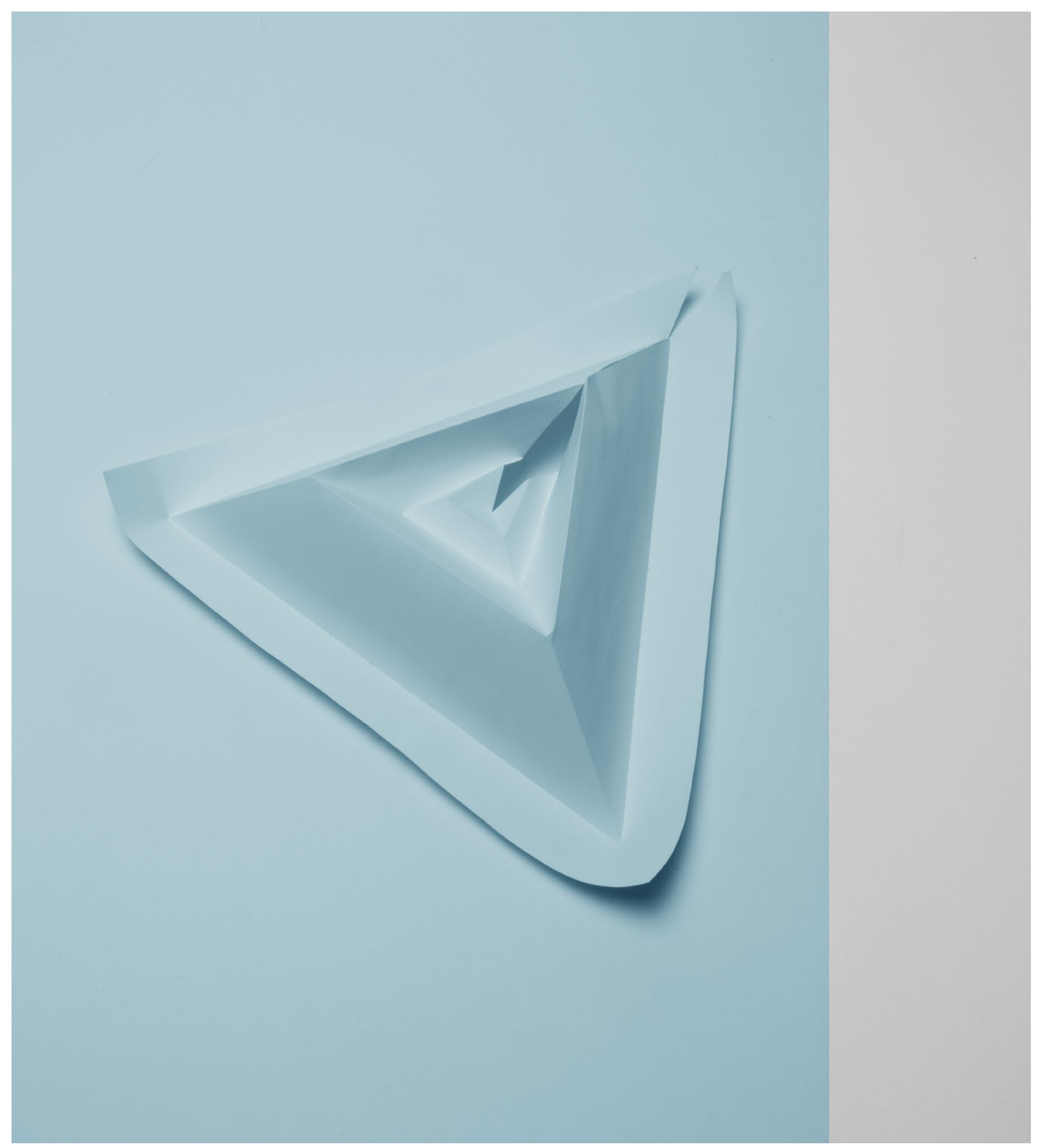

Preliminary Design 


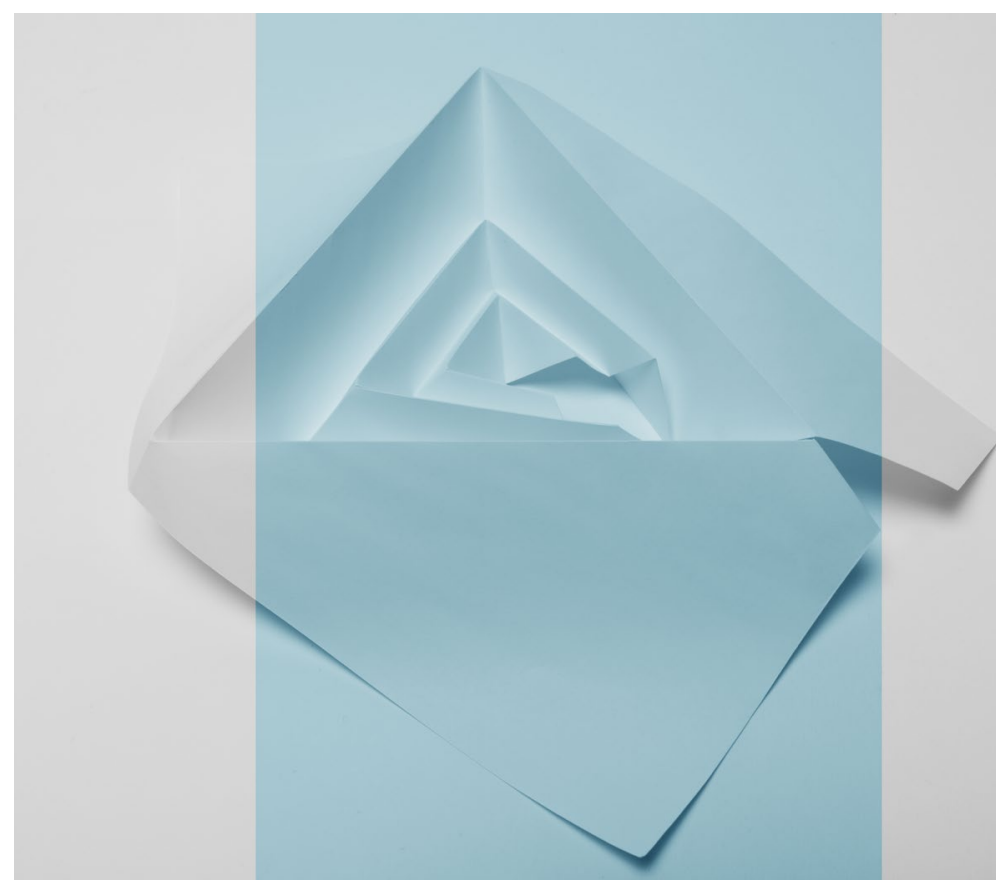

Figure.40-42. Paper folds in Series Two.

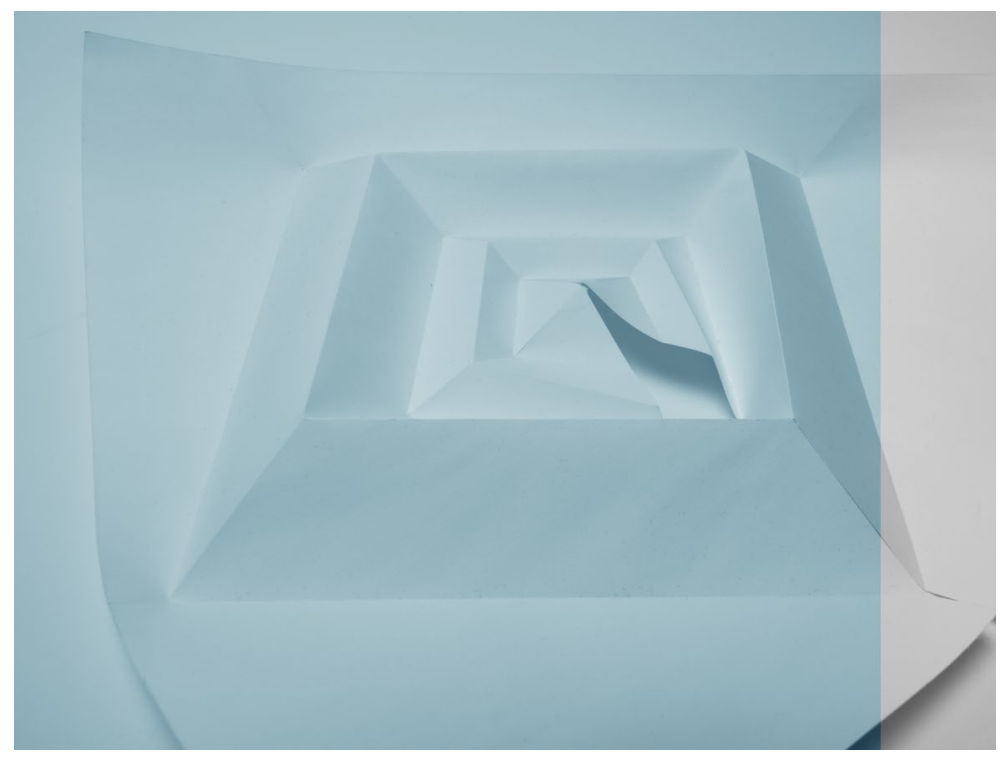

\section{Preliminary Design}




\section{SERTES THREE}

\section{Origami - Folded Plate}

Structures

rigami - Folded Plate Structures,
Architecture, by Buri and
Weinand, also identifies and provides a detailed description of three patterns they believe "to be particularly interesting for architectural and structural applications: Yoshimura pattern, Miura Ori pattern and Diagonal pattern" (Buri and Weinand). These forms are derived from a series of pleats and diagonal folds using the diamonds shape and a parallelogram. 
Figure.43-44. The first

origami pattern trialled in

Series Three.
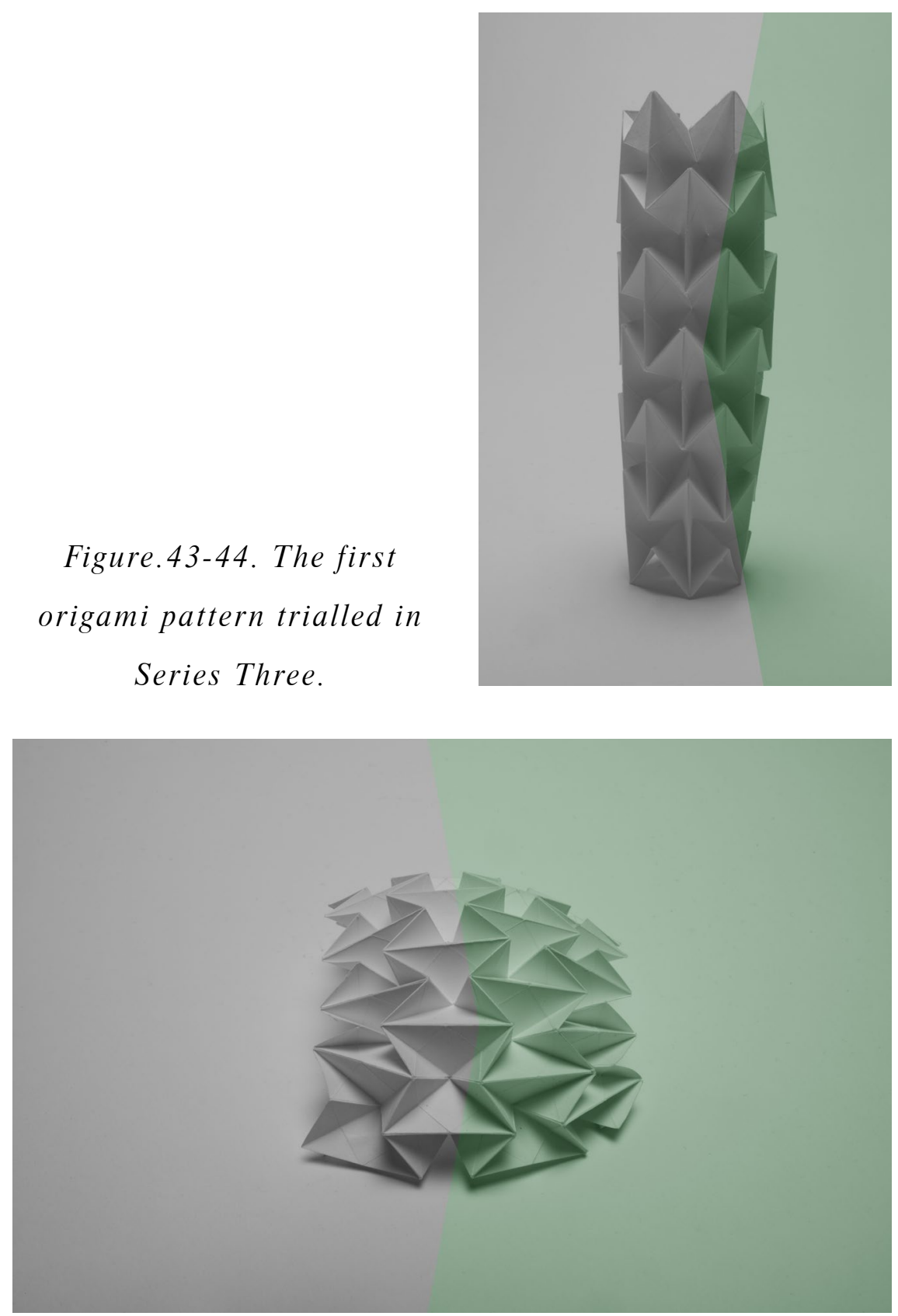

Preliminary Design

83 


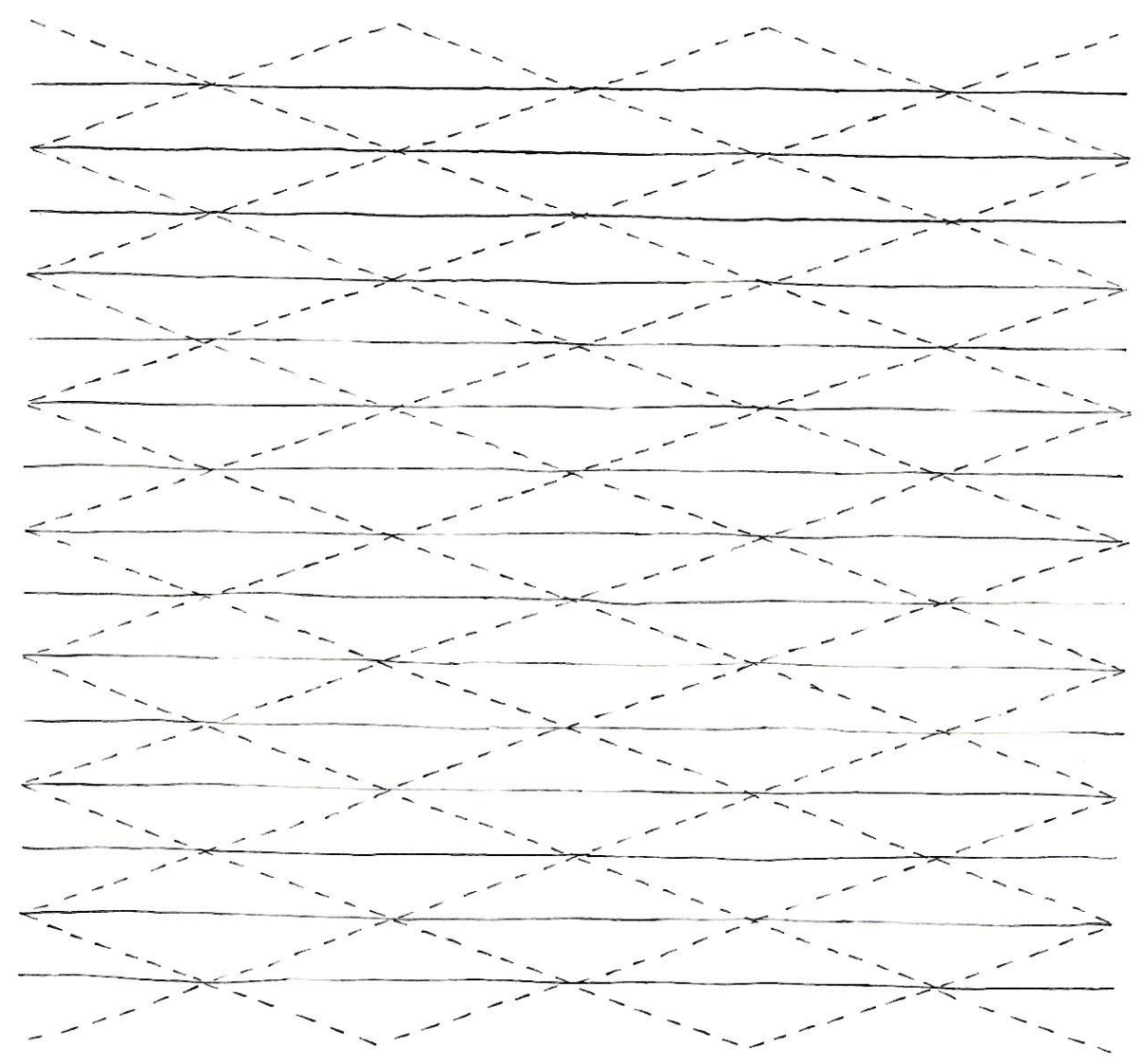

Figure.45. Author's own sketch of the second origami pattern, the design incorporated mountain and valley folds as represented by the dashed lines (valley fold) and solidlines (mountain fold). 


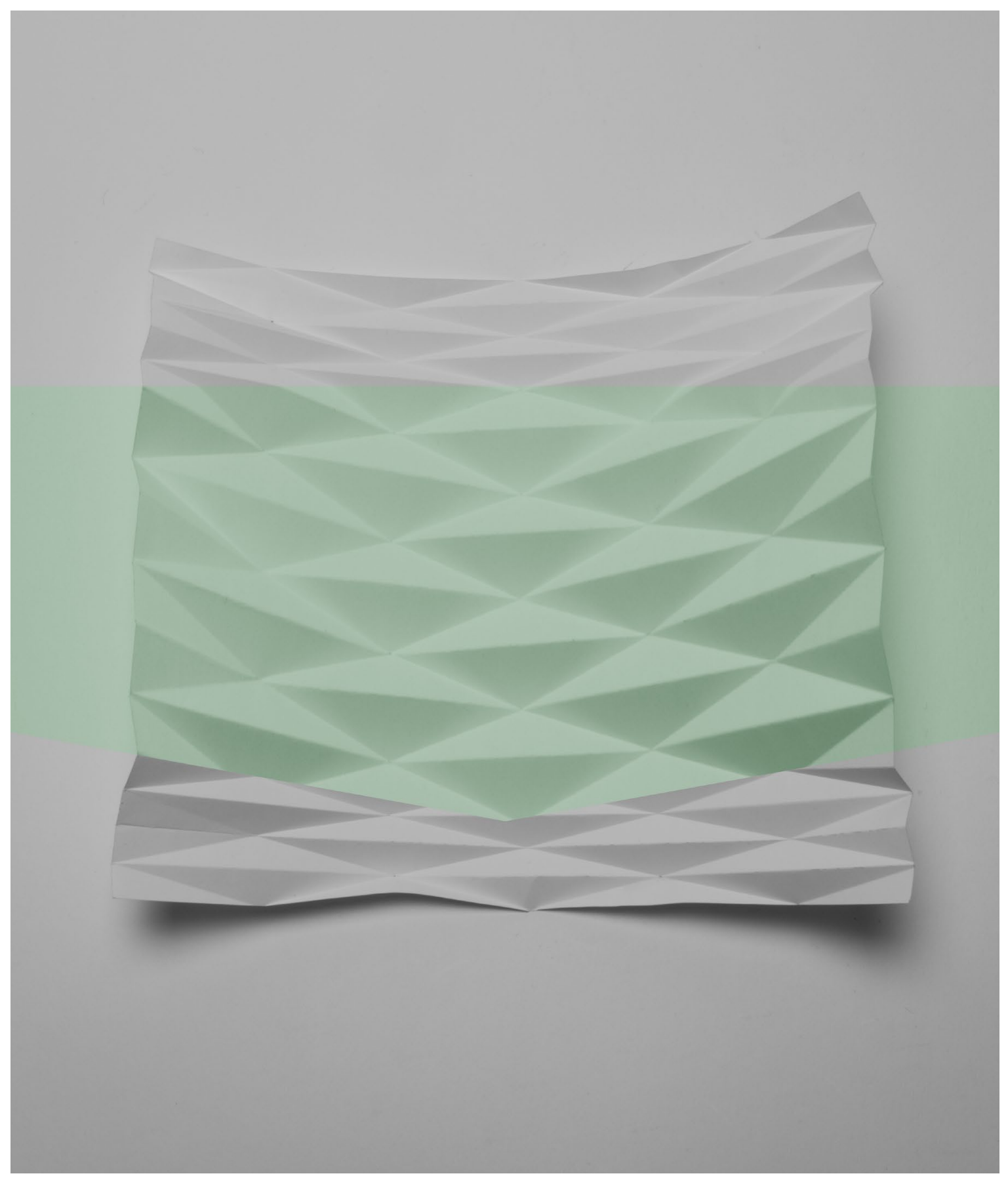

Figure.46. The second origami pattern trialled in Series Three.

$$
\text { Preliminary Design }
$$



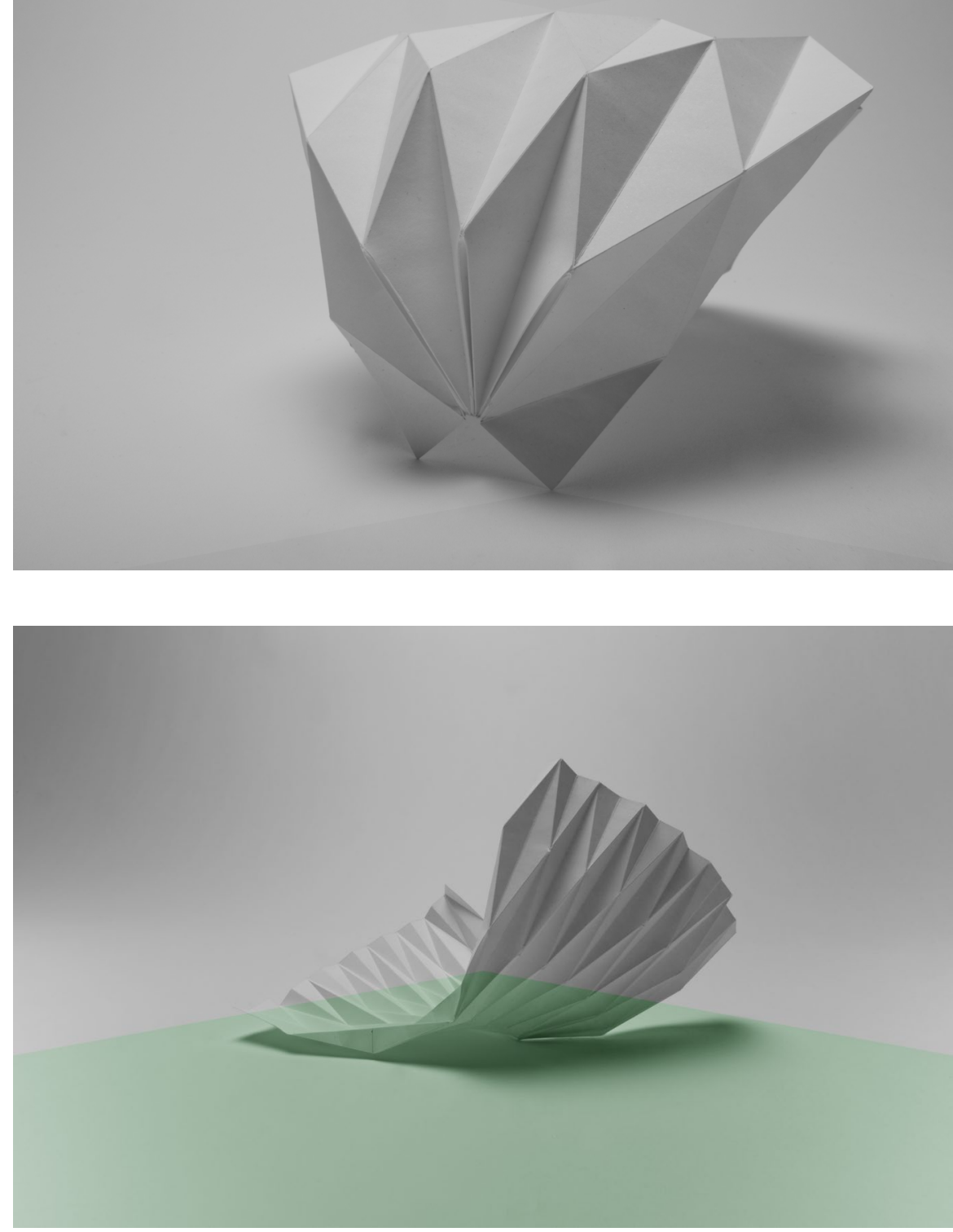

Preliminary Design 
Figure.47-48. Two paper folds using the second origami pattern, trialled in Series Three, combined with pinching of the material.

\author{
Preliminary Design
}


7 he iterative process, followed by trialling the theories of other designers and researchers, led to the production of many folded forms, some of which were more inhabitable than others. The forms from Hansen-Smith's research produce designs more like a terrain; they are habitable pathways which could be used to create interesting circulation within the architecture. However this is not the desired outcome for the research, as it is creating a warren of small spaces which was earlier identified as a cause for building abandonment. The pleats analysis produced a series of surface treatments. It could be interesting to see these applied to the designed form at a later development stage. The origami forms create spaces that can be perceived as interiors. The flexibility of the folds allows these forms to expand in size within larger areas and shrink to fit into small spaces, responding to the architecture's interior conditions identified in the site analysis. The folded origami forms support themselves and do not require a structure that engages with the existing building, reducing damage to the historic surfaces. At this stage of the research the origami methodology is recognised as the most successful design
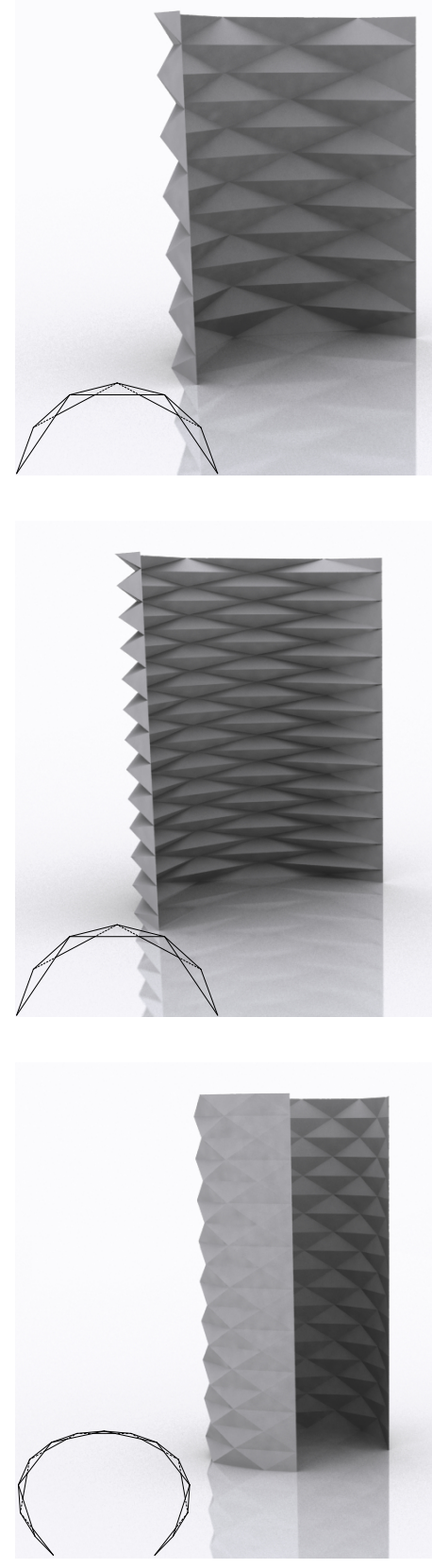

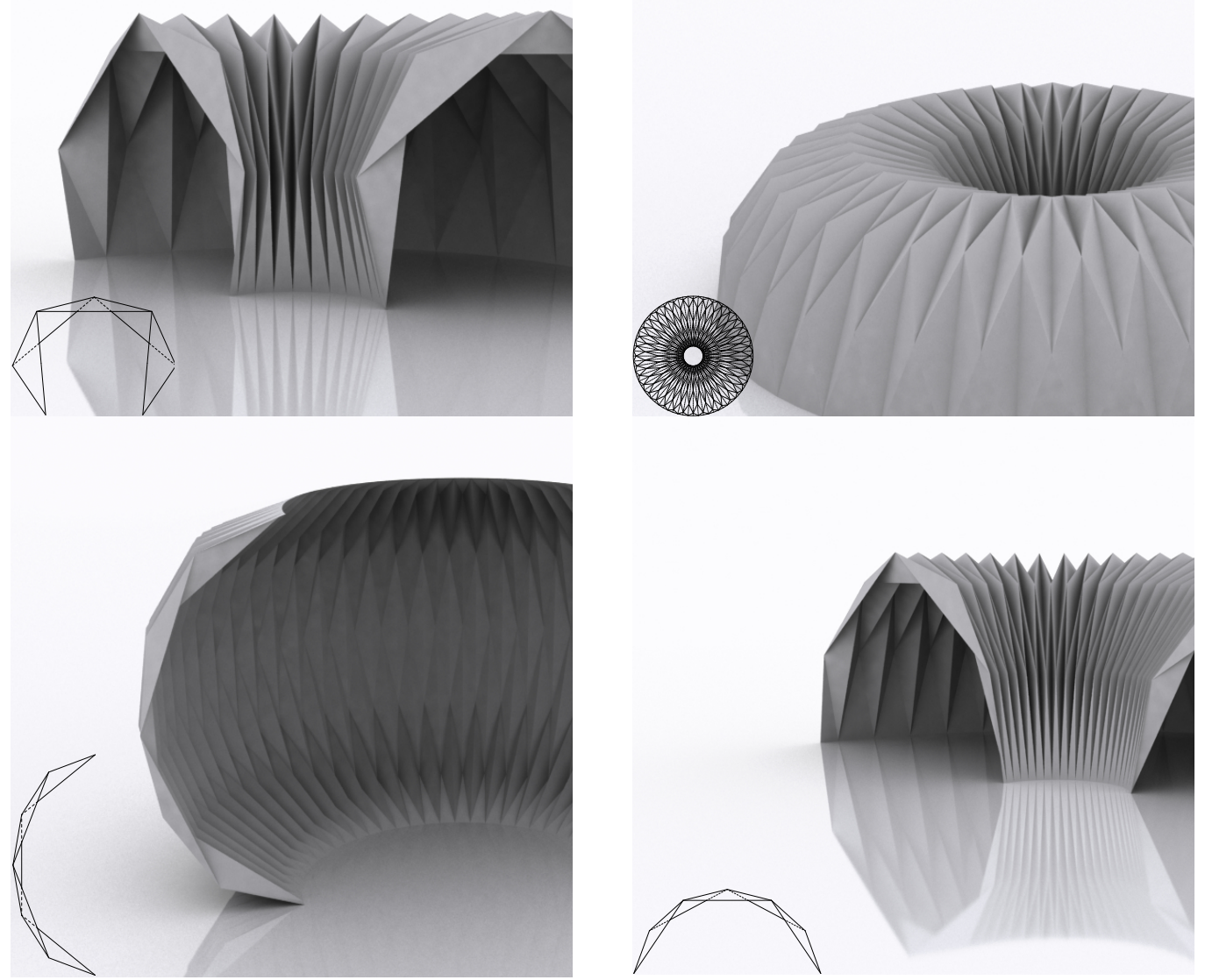

Figure.49-55. Renders from parametric computer modelling.

to inhabit. The new interiors created by the forms are each individual spaces and can be organised inside the architecture to provide as many 'rooms' as required and allow the circulation to be as open or as dense as desired by the new user.

7 arametric computer programming was used to rapidly produce a series of forms using the origami fold pattern.

\section{Preliminary Design}



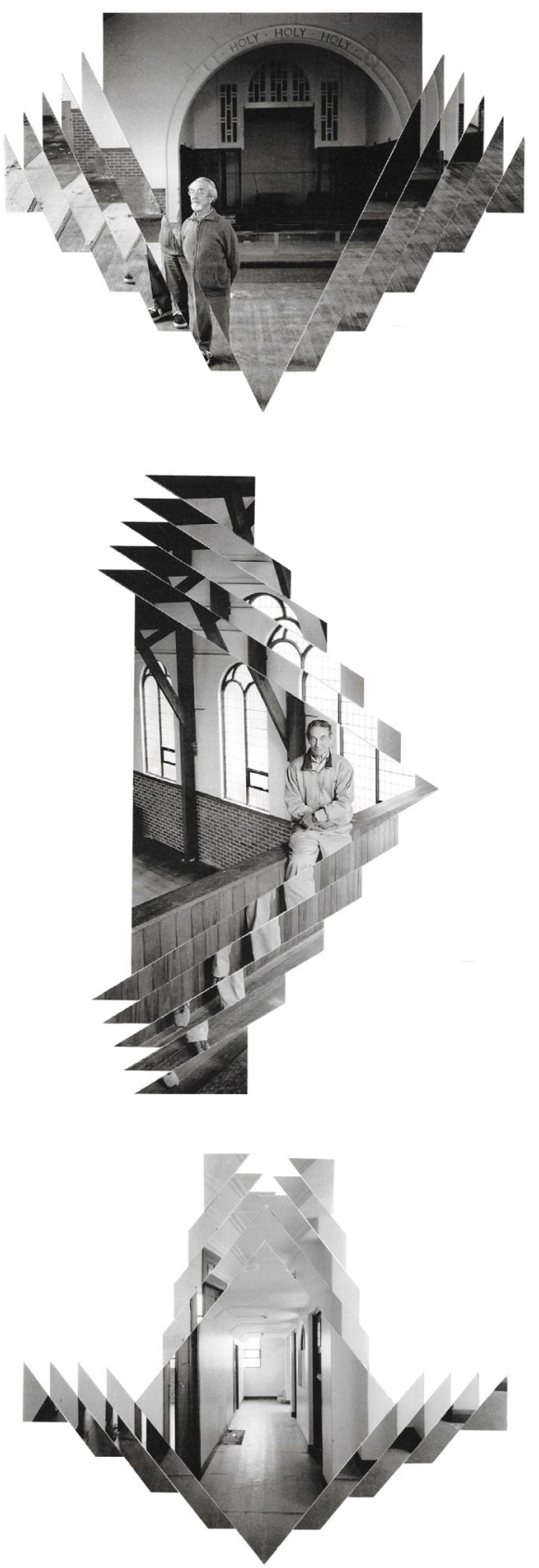

Figure.56-58. Author's collages using photos by Mark Beehre.

\author{
Preliminary Design
}




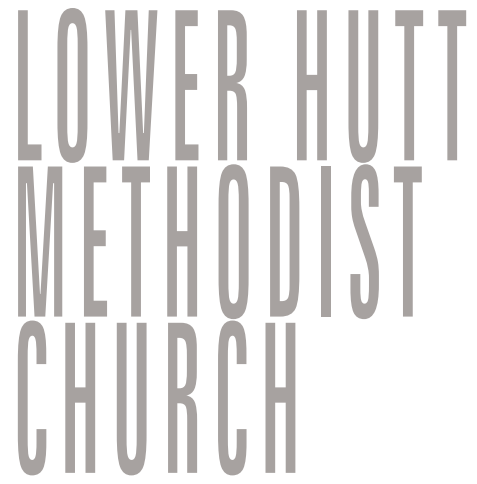

The paper folding led to the development of one template manipulated into various forms. The template was then imposed on the first site, the church. Being a space of religion there is considerable social attachment remaining within the building walls. The site analysis identified significant areas the design would need to negotiate sympathetically. These include the vestibule, the alcove where the organ once sat, and the balcony which overlooks the space the pews occupied. 
Developing on from here the research will consider the effects of the form in the space: how the users will interact within the new folded form and how they will circulate outside it. It will also expand on the materials used to construct the design. The initial forms were constructed using one sheet of material, as in Issey Miyake's clothing and the design researched by Buri and Weinand. Material research will test the viability of applying the same methodology to the habitable form as a possible technique to influence the appearance of the design. This research will follow consideration of possible dimensions of the form to prove the designs worth to its occupants. 


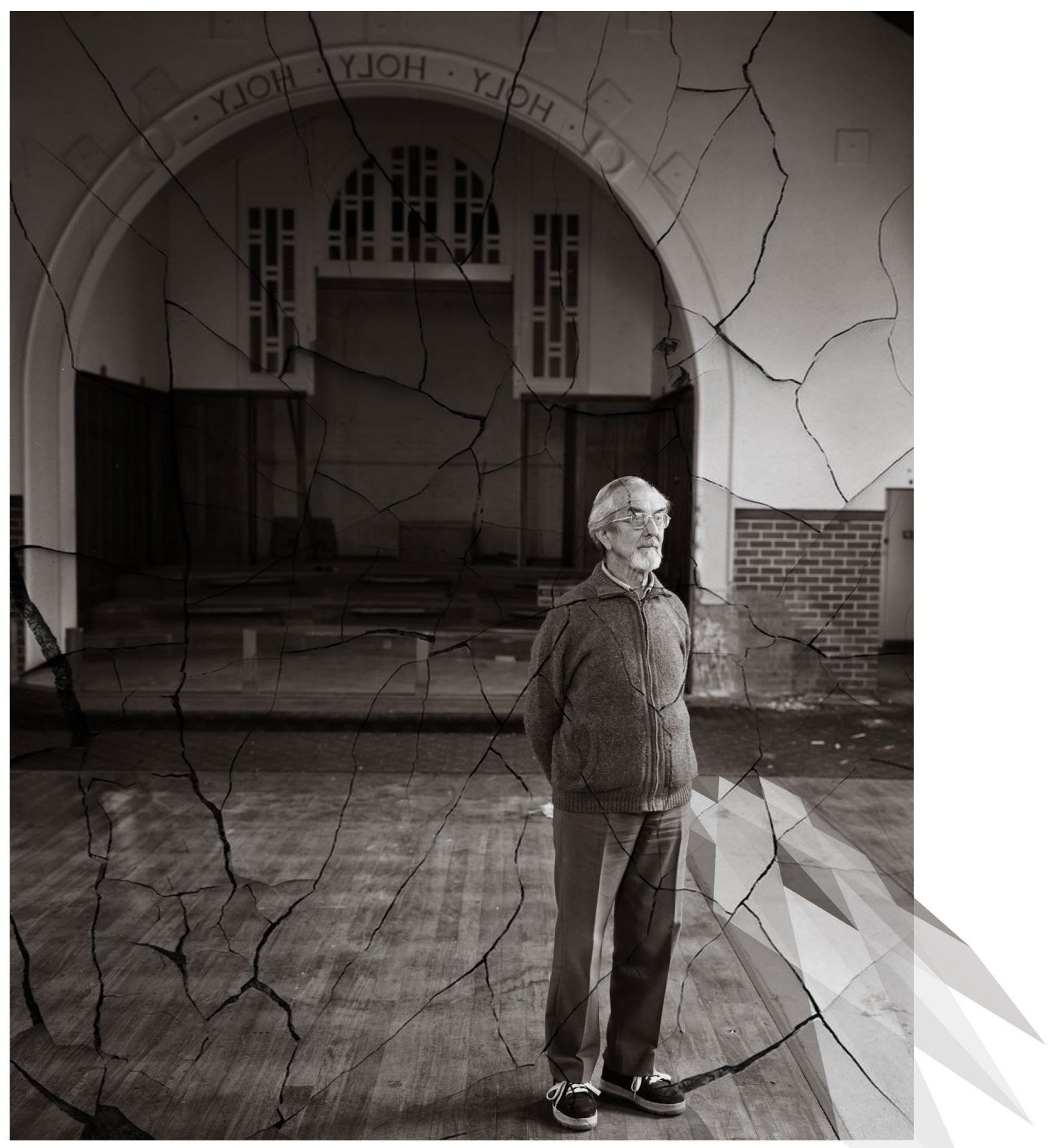

Figure.59. Showing the worth of the design within the church, where it can be most usefull, in this case repairing the damaged flooring. 


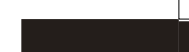




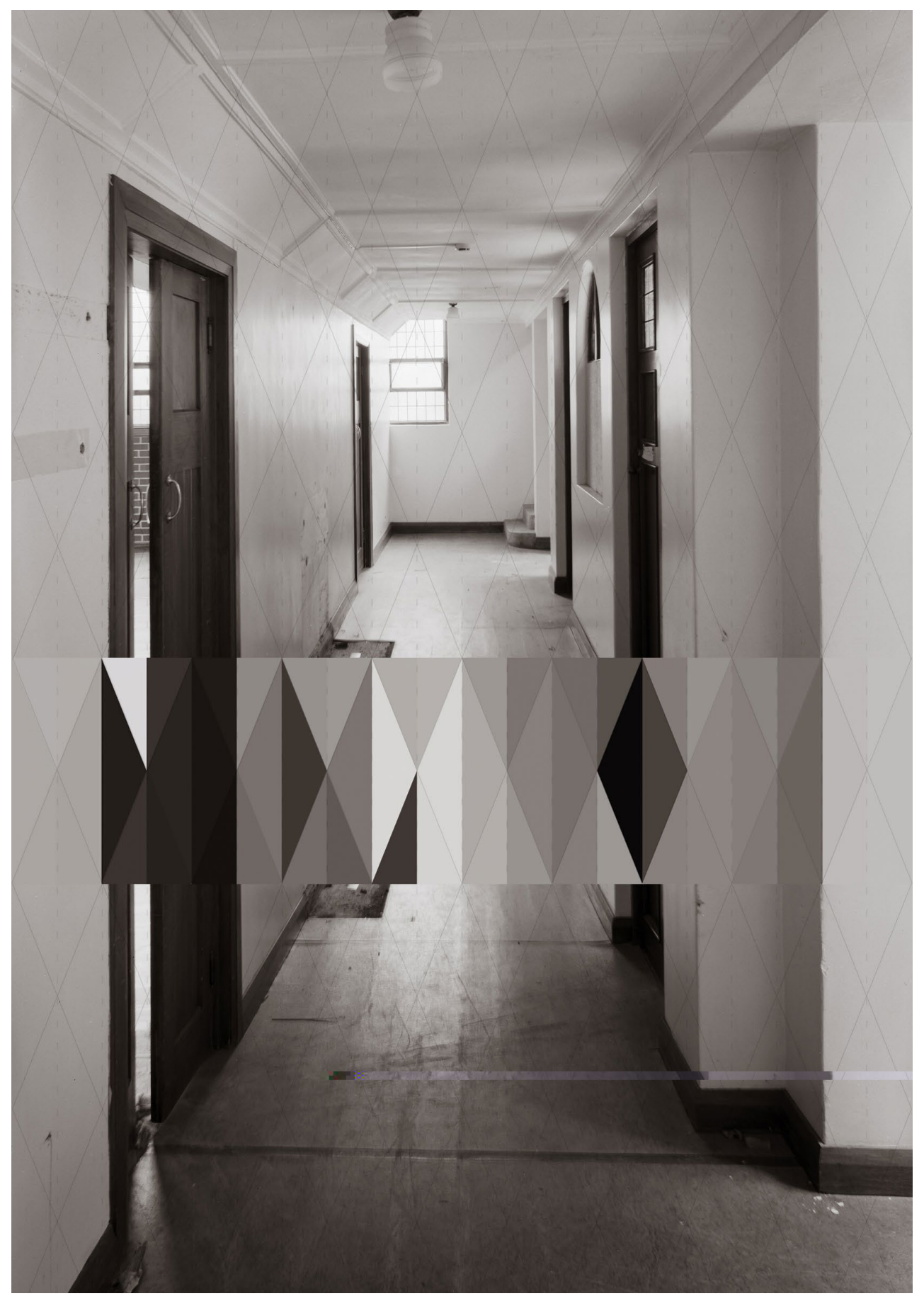

Figure.60. Considering the effects of the design within a narrow space such as the vestibule. 


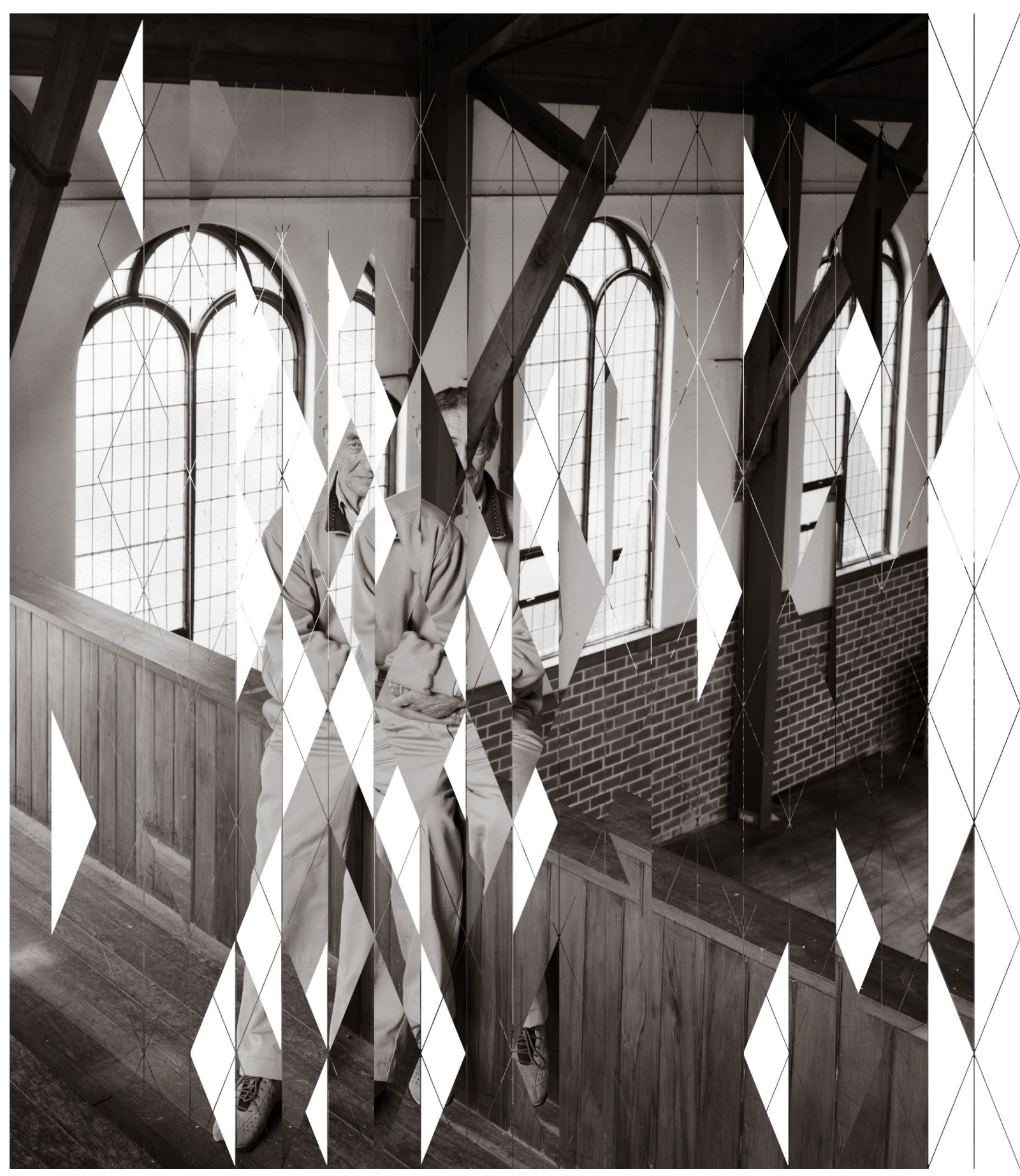

Figure.61. One way the design can control what the occupants see within the architecture. 


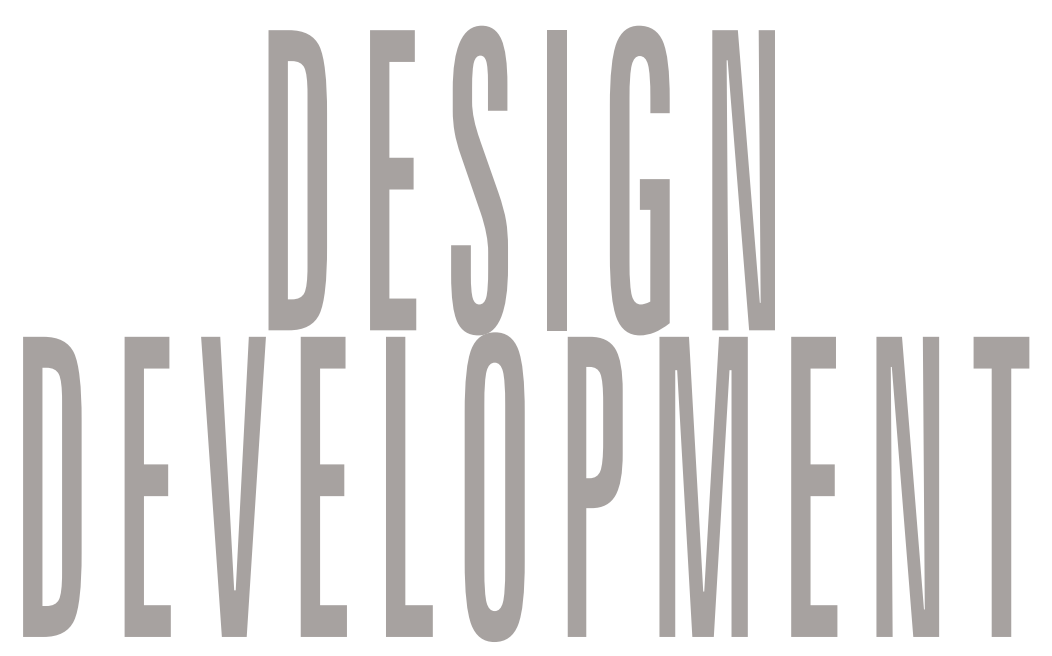

THE IMPLICATIONS OF

INTRODUCING FORM TO A SPACE

This research considered successful interior refurbishments, which incorporate inhabitable forms, such as the Ekimetrics Office in Paris. The 19th Century building was renovated in 2014, by Estelle Vincent. The design occupies one level of the building and establishes itself through the use of 'pods' installed within the space.

The repercussions of the additional form are positive; their interior provides an area for a specific programme while the outer surface of the form serves the interior in a positive way, such as the museum gallery. In some situations it provides a successful circulation path, and for other designs it offers a secondary programme. 

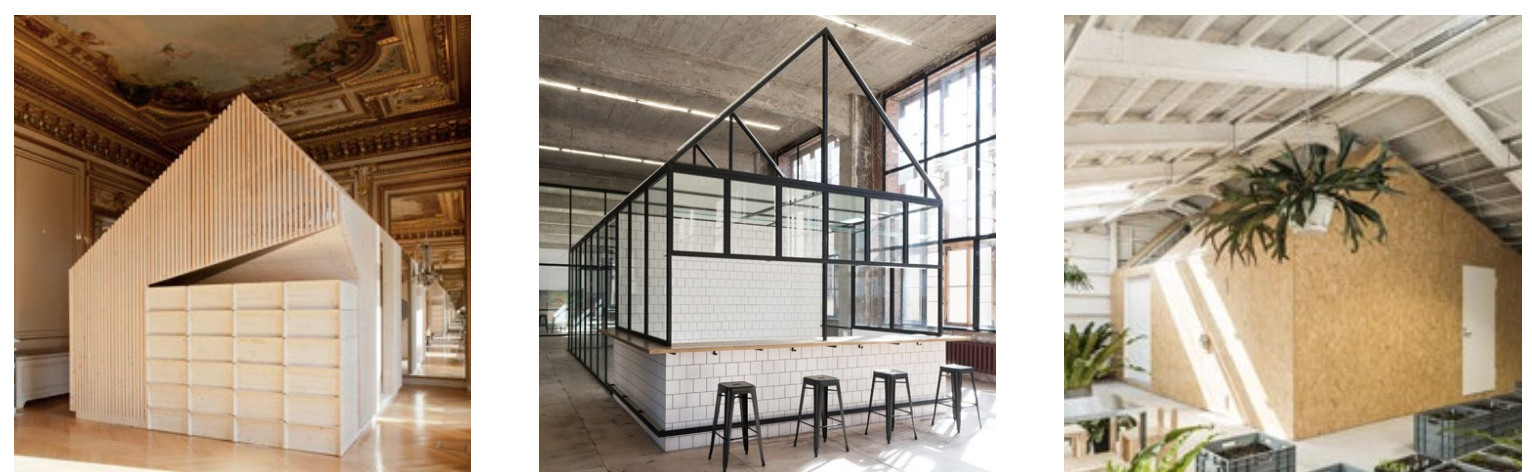

Figure.62. One pod from the office design by Vincent.

Figure.63. The Archiproba glass kiosk.

Figure.64. The Chipbaord shed designed by Schemata Architects.

Other uses of interior installations considered were;

- The renovations of a 1920's telecommunications building into offices, in Moscow by Archiproba. A glass kiosk has been used in the design as a meeting room and café. The seating for the café extends outside of the design.

- And the conversion of a Tokyo factory into an artist's studio, by Schemata Architects. The top floor of the factory is designed with a Chipboard shed used as an edible herb garden, while the remainder of the floor is a personal design space for the artist. 


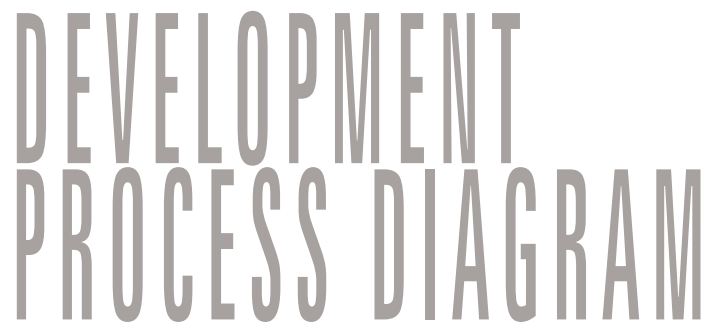




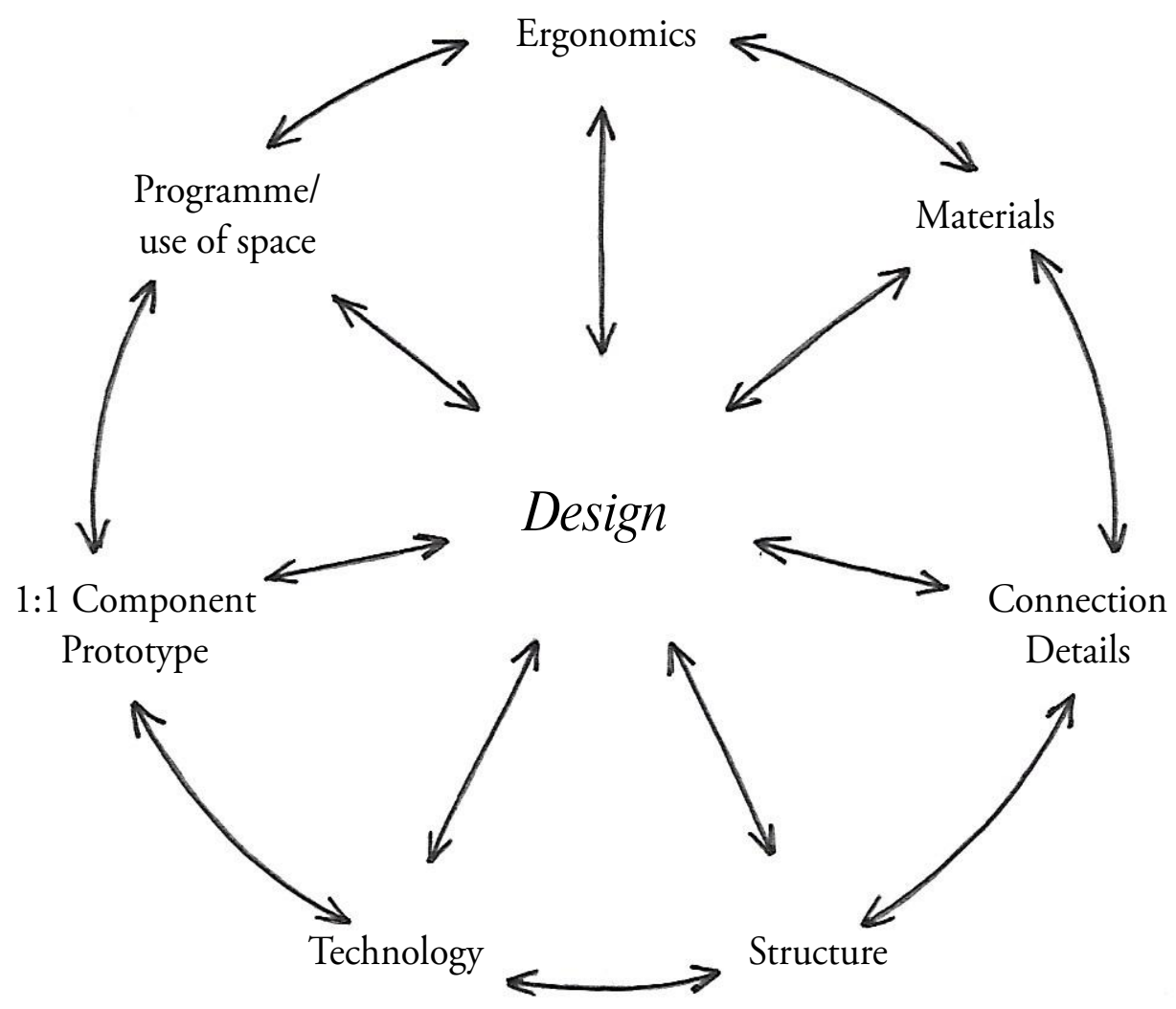

Figure.65. Diagram of the development process. 


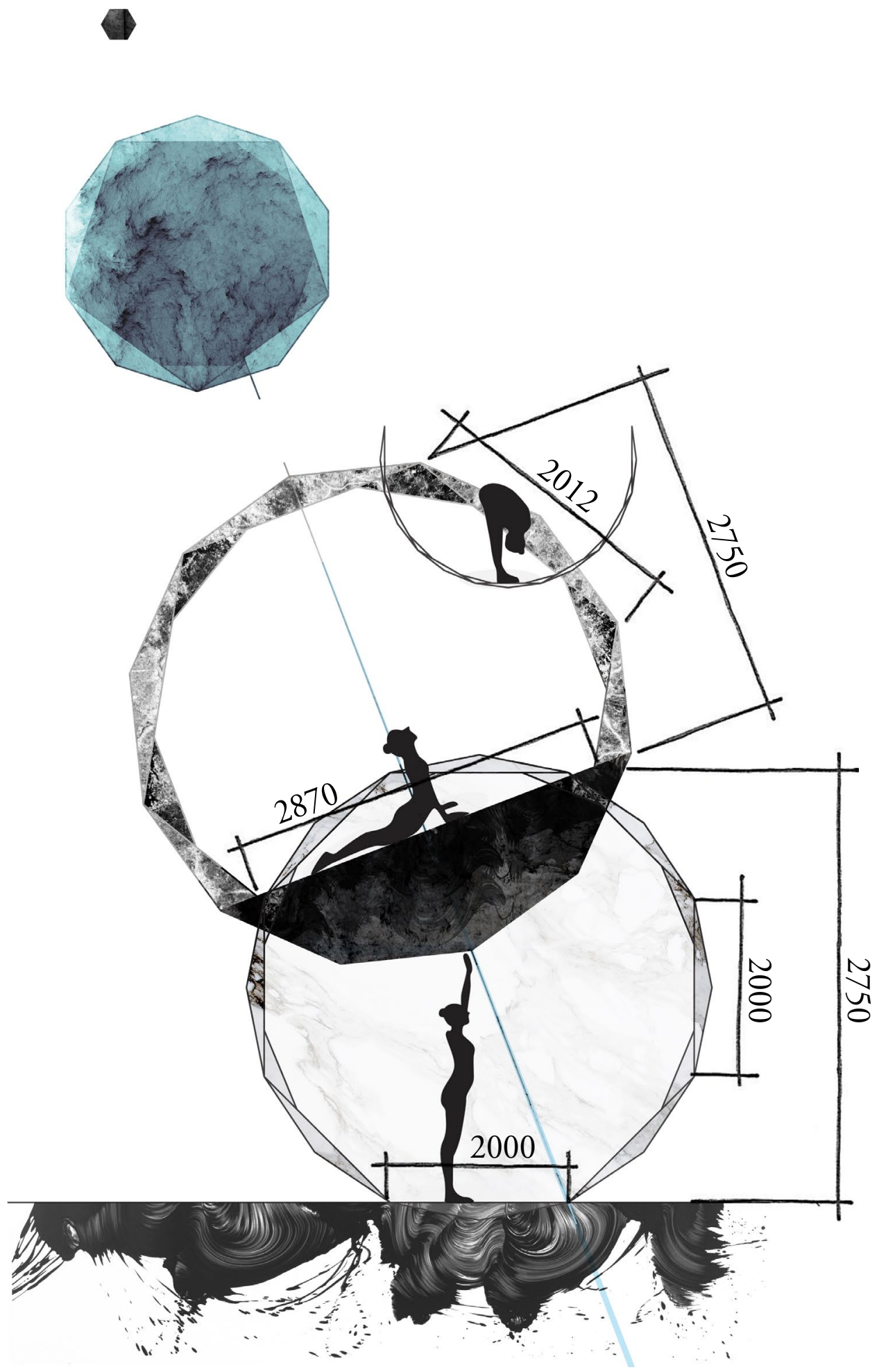

Design Development 


\section{ERfollOIIIS}

With this new knowledge the research considered the scale of the proposed form and how it would feeling imposing itself as a new layer within the interior of a building.

The folding net was explored further. Observations noted that narrower triangles changed the angles of the folds, which in turn changed the radius of the form making for a wider space to occupy. The development of the form in section view resulted in a triangle $201 \mathrm{~mm} \mathrm{x}$ $2012 \mathrm{~mm}$ in size, which gave grounds for material development.

Figure.66. Sectioned image exploring dimensions of the triangle and the spatial effects of the dimensions. 
The form and materials investigation was developed concurrently as an iterative process.

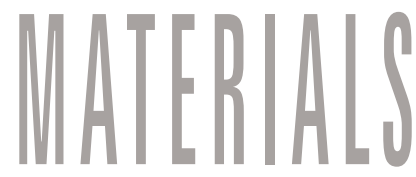

While establishing dimensions of the form, materials were taken into consideration. In particular the effects they would have on the design and how they may interact with a new useage applied to the form. The material research was accompanied with the design of possible connectors and technology opportunities.

Initial material research investigated continuous sheet material. The challenge of the single sheet construction was the dimensions required of the material and the possibility of sourcing locally to reduce the carbon footprint of the design. The scaling up of a paper origami form also carried with it a great deal of uncertainty, especially the weight of the new material, the strength of the structure, and ensuring the creases held. A sheet metal was considered. It had been observed that the strength of paper increase with the folding process and it was thought that the same principles may be applied to a thin malleable material.

In discussion with Jeongbin $\mathrm{Ok}$ the possibility of a new material composition was considered. These studies were vital in realising the possibilities and constraints when working with sustainable material s. Research showed that due to the uncertainty of the life span of interior design the materials involved should be sustainable. The concept of sustainability was outlined by the recyclability of the material, its carbon footprint and the production process of the material. Inspired by Graham Wiles' Cardboard to Caviar Project, materials were approached with the question of 'what can be done to them after?' 

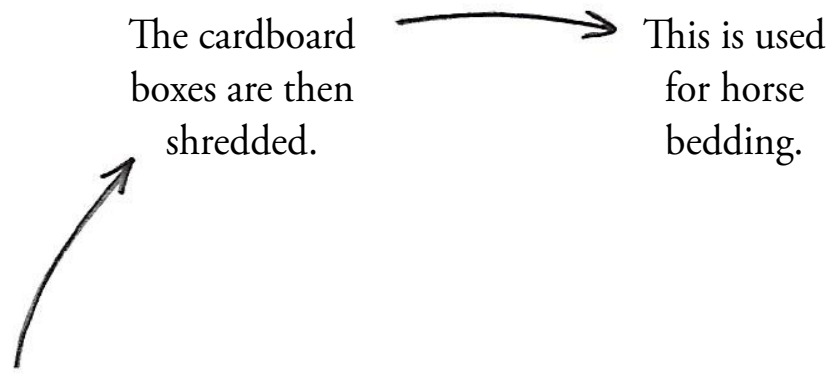

The caviar is distributed to restaurants in cardboard boxes.
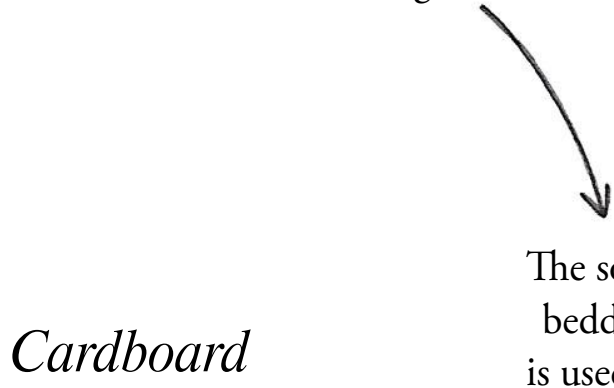

The soiled bedding is used for composts.

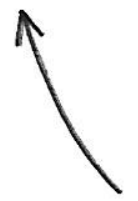

The fish lay

Worms from eggs, otherwise known as caviar. the compost are fed to fish.
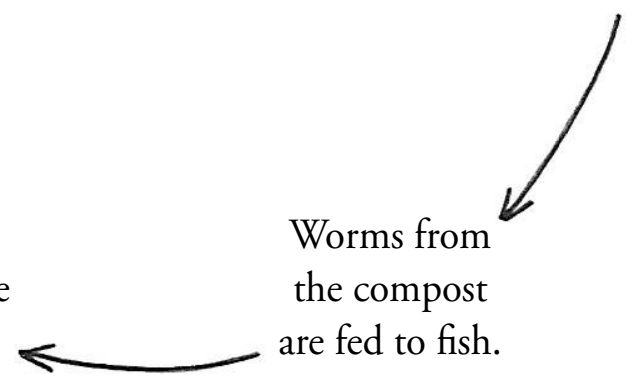

Figure.67. Graham Wiles diagram reproduced by author. 

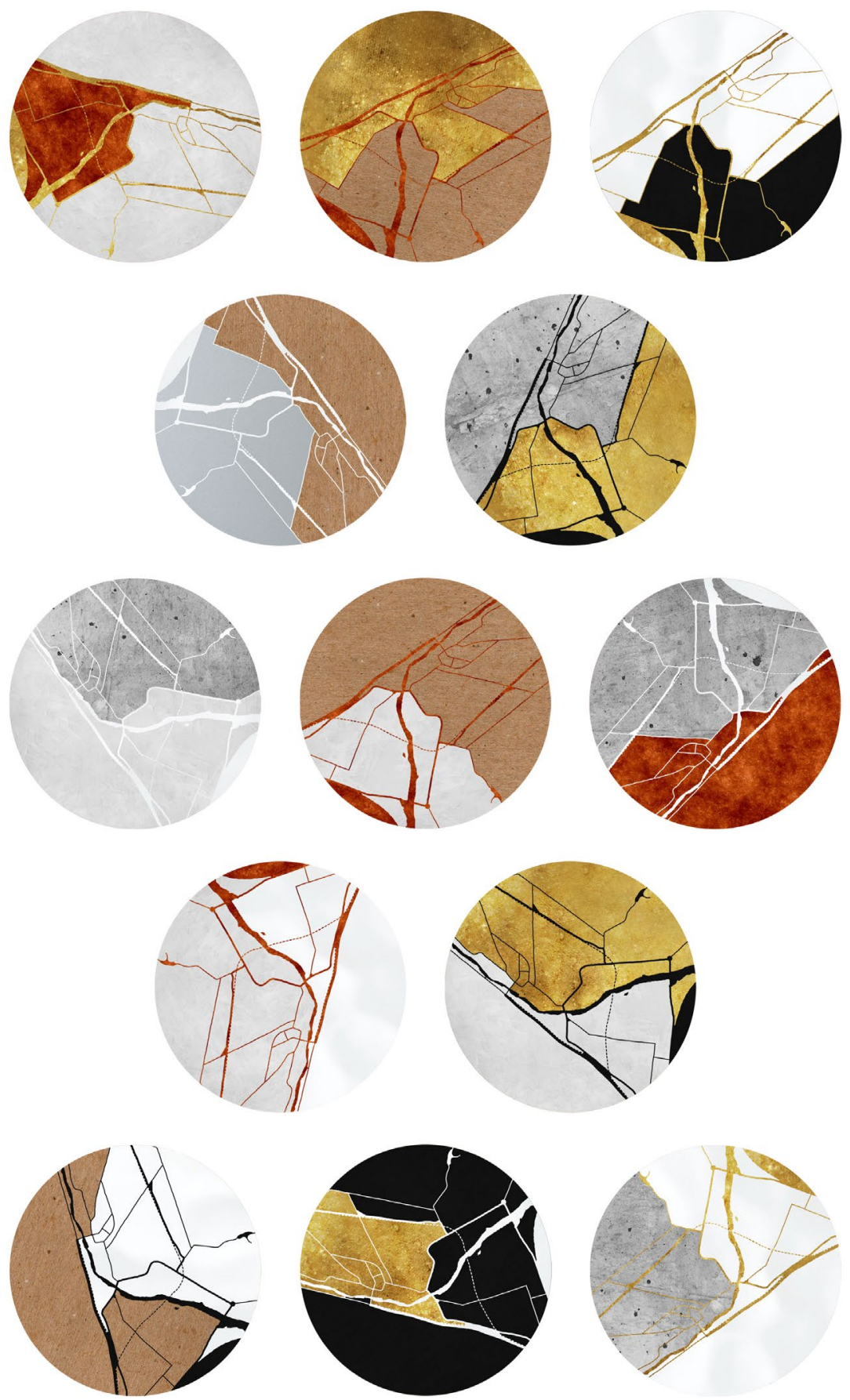

Figure.68. Initial material aesthetic exploration using the Lower Hutt Region Map. 
During the research period with $\mathrm{Ok}$ thought was put into the fabrication of a material specific to the design. Originally, the motivation of this was producing a material that was malleable enough to fold, yet strong enough to support its own weight.

One material considered was polycaprolactone. Thematerial is manufactured in small pellets and has a melting point of 60 degrees Celsius. This is low enough that the pellets can be softened in a cup of boiling water then removed and moulded into a form; this process can be repeated as many times as desired. A process which used boiling water to recycle a material was deemed more considerate to the environment than one which required machinery or chemicals.

Further discussion led to the consideration of which materials should be blended together to achieve the desired material properties.
- Polypropylene was suggested as it can be translucent, there is the potential for flexibility and a glossy surface, and is available in pellets.

- Meliflex is also transparent and flexible and it has a high UV resistance.

- Oshenite is a natural mineral powder sourced from Florida. The addition of the mineral increases the acoustic properties of a material, as it creates air pockets in the material. It also reduces the ratio of plastic by up to $40 \%$. It also has a high fire resistance. This prompted the question of whether a different mineral powder could be sourced in New Zealand to achieve the same results.

- The addition of a highly conductive metallic powder would also mean the material could conduct electricity without wiring.

- Given the semi-permanent nature of interior design, the type of stimulant that might trigger the decomposition of the material was considered. 


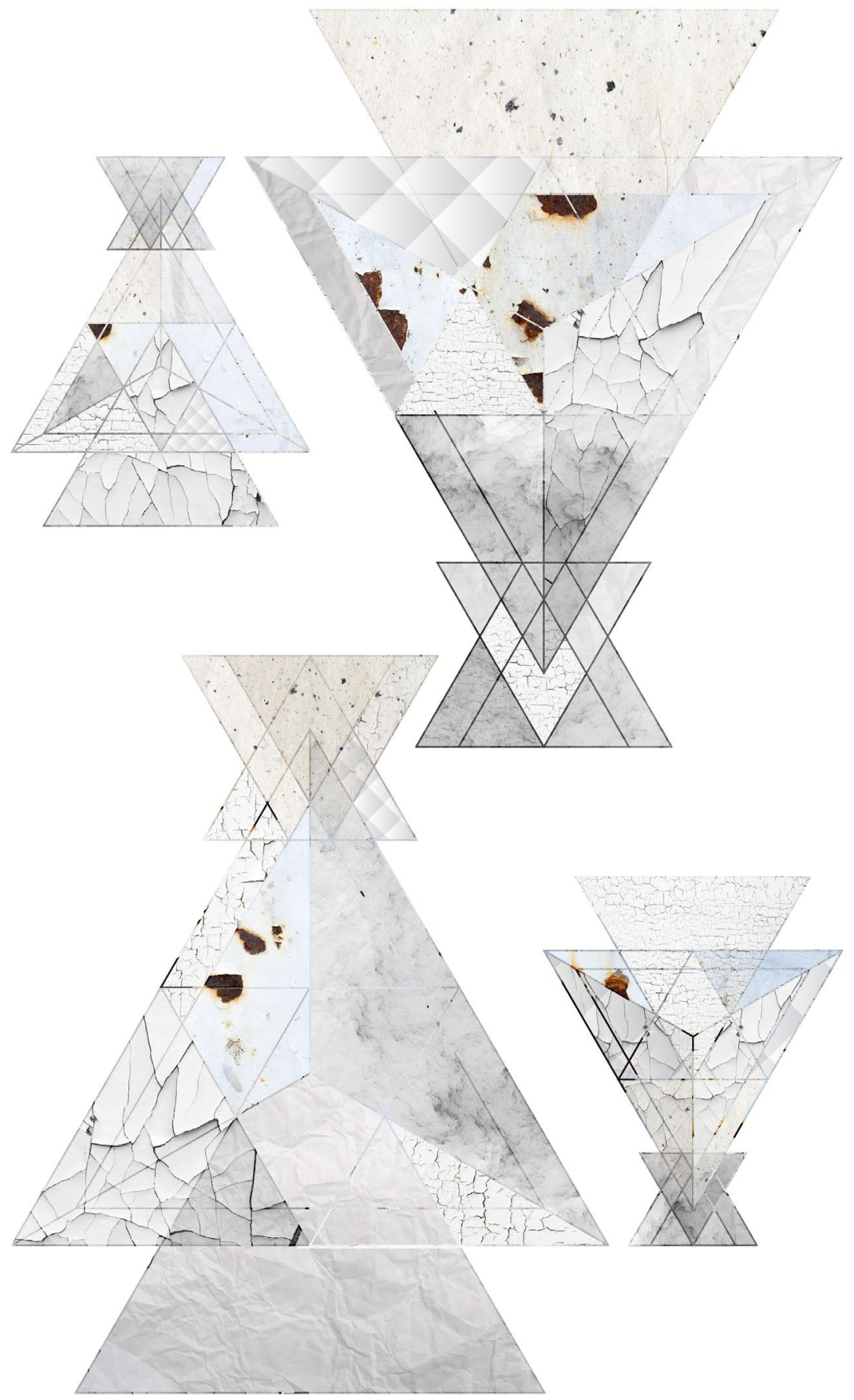

Figure.69. Continued material aesthetic exploration considered translucencies. 
Pre-existing materials were also considered for this research. They were PET acoustic panels and cork sheeting.

- PET panels are a material made from 60\% recycled materials, and there are also companies who have systems in place so the material can be returned, if unmarked by adhesives, and recycled to be reused in the same product.

- Cork is a rapidly renewable material that could be used as a skin over the frame of the form.

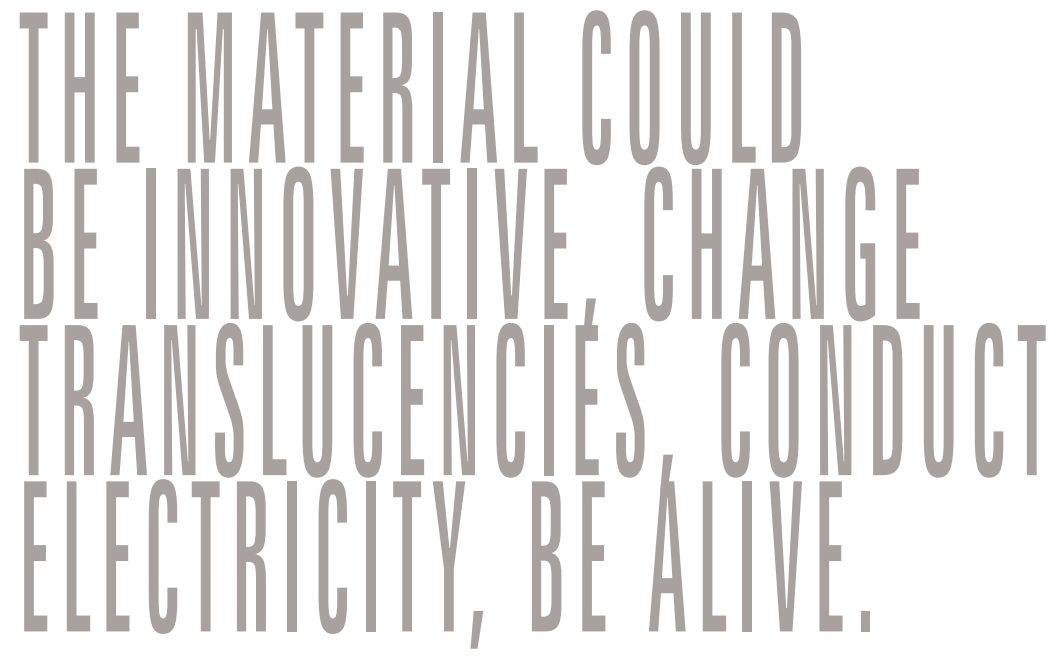

Design Development 


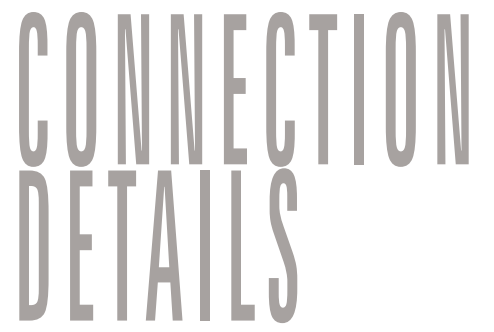

The connectors shown in Figure.72. depict brackets and hinges designed to join sheets of the forms material. There were two types of connections designed in the early stages.

- One type proposed was a solid, flat, joiner to connect rectangular pieces together, which folded along the diagonal.

- The second concept proposed was a hinge or angled bracket to establish a connection between triangle shaped pieces. 


\section{STRUTIURE:}

There was consideration to vary the material of the form. Sections would be constructed out of a stronger material to act as a frame for lighter weight materials to be used in other areas.

It was proposed that inverted folds became unconventional beams which reflected an observation made by Jeremy Gilbert-Rolfe in Frank Gehry: The City and Music (Gehry). He noted that by using unconventional forms for architecture, unconventional building techniques are adopted as well. 


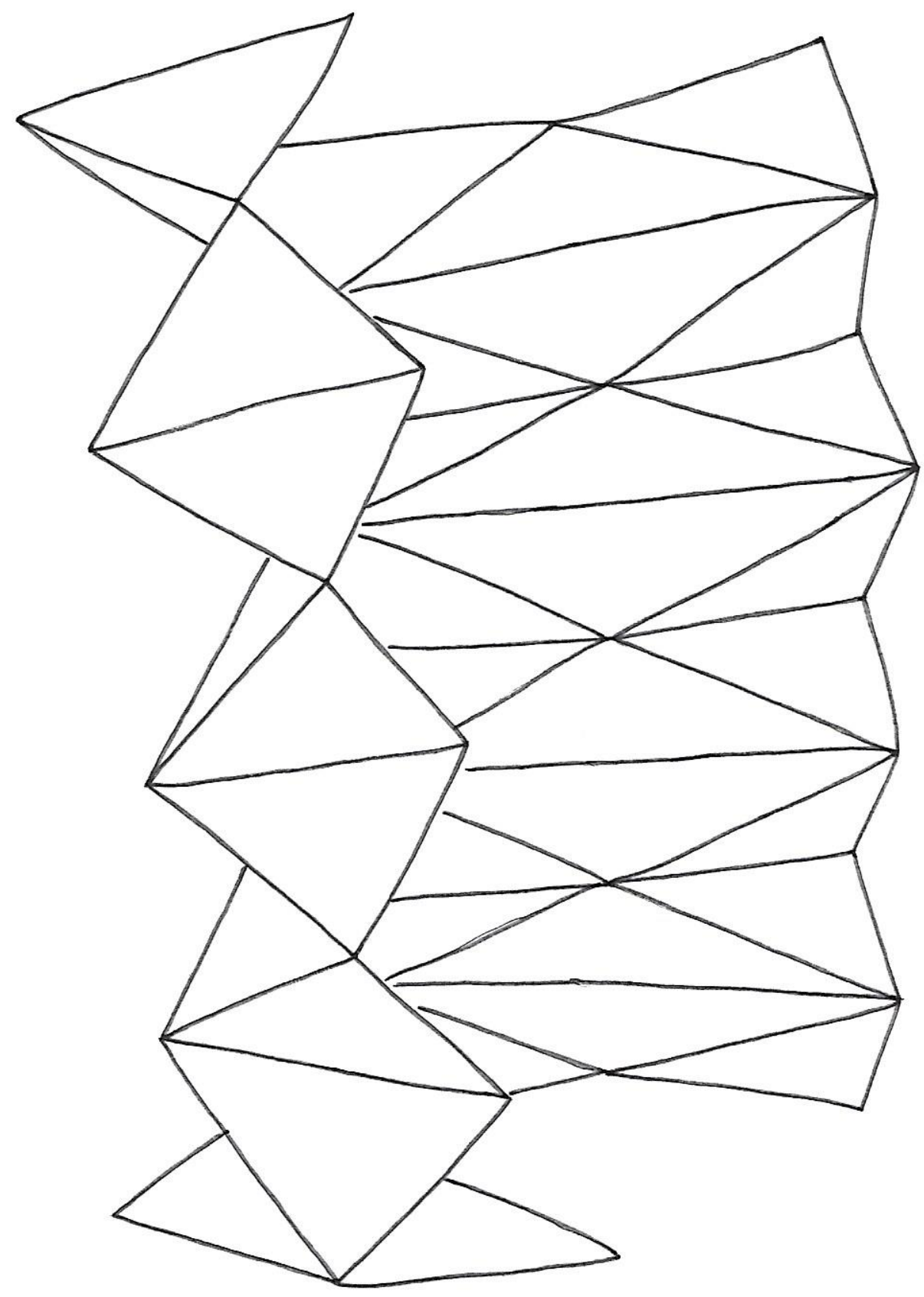

Figure.74. Sketch of one form the design could produce.

\section{Design Development}




\section{TECHNOLOGH}

The assumption has been made that in architecture there is, almost always, lighting mounted from the ceiling. The existing wiring is proposed to be used to supply power to the design. The current detailing in the frame will allow easy access to all wiring, which will enable changes to be made to accommodate technology advancements and any change of programme to the form. 

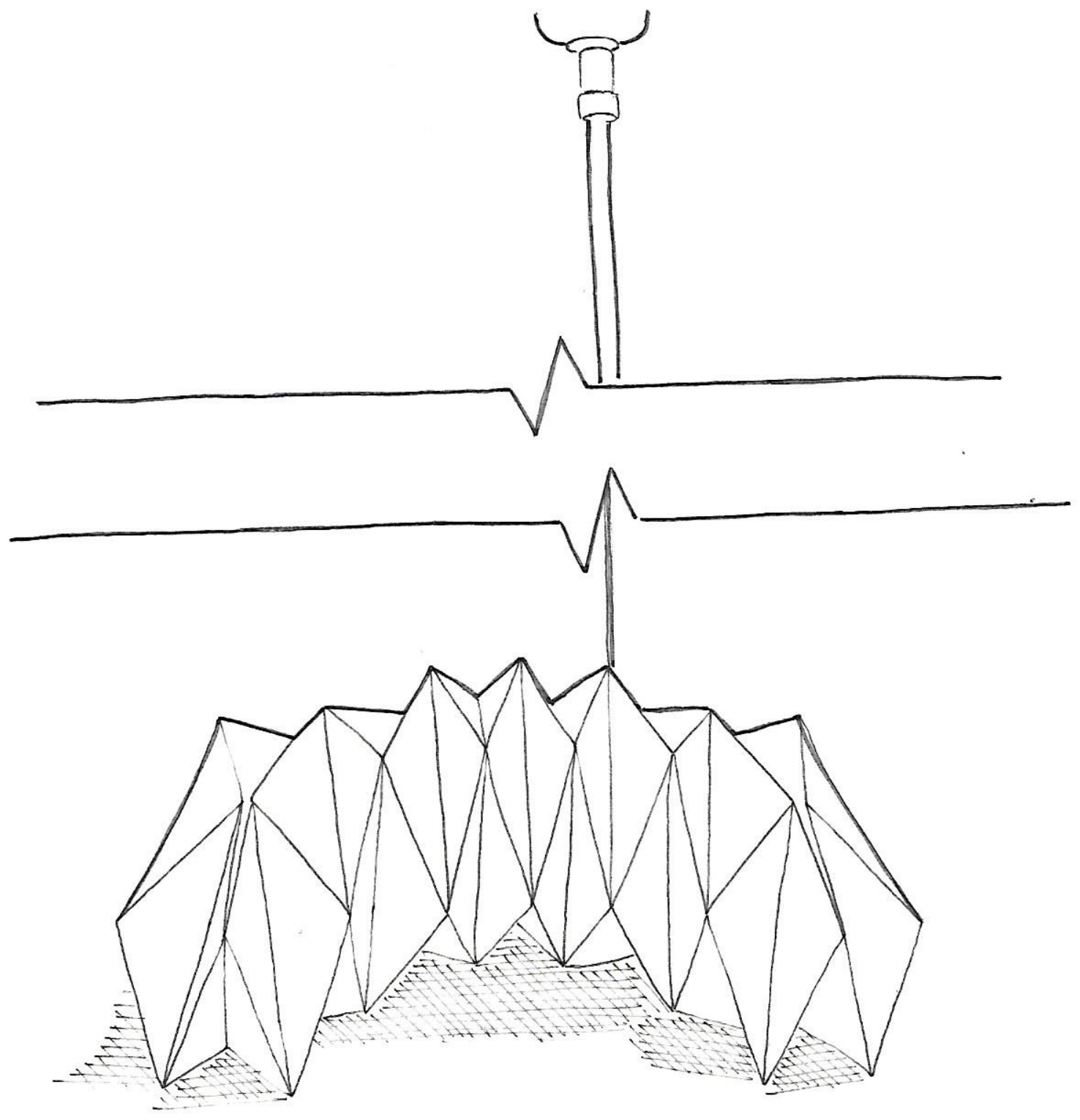

Figure.75. Sketch idea considering the use of power supplied from the preexisting ceiling light wiring. 


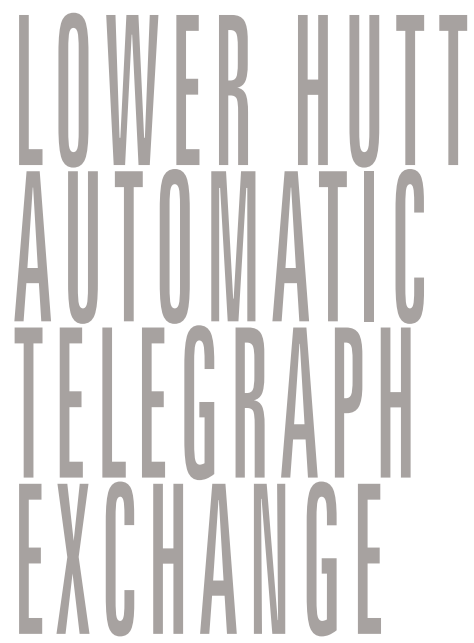

Reflecting on the Telegraph Exchange the researcher finds there is not a defined programme to introduce to the architecture. The site analysis observed that there are elements within the aged architecture that will require protection from the new users of the building. Equally, at times, the users may need protection from the deteriorated conditions. At the second site there is currently a proposal for changes to be made to the interior, with the removal of the original spiral stairwell. While this research has been advising a new programme to be installed within the proposed new layer of intervention, it also presents the possibility of accommodating architecture in need of protection. With another layer of the Telegraph Exchange's history due to be removed, the research proposes that the intervention could be used as a form of barrier between the users of the space and the stairwell. The old stairwell no longer meets code but is significant to the time period the architecture was built in. With additional access to the above floor already existing, the removal of the stairs will not make way for new design, and will only dissolve history. 


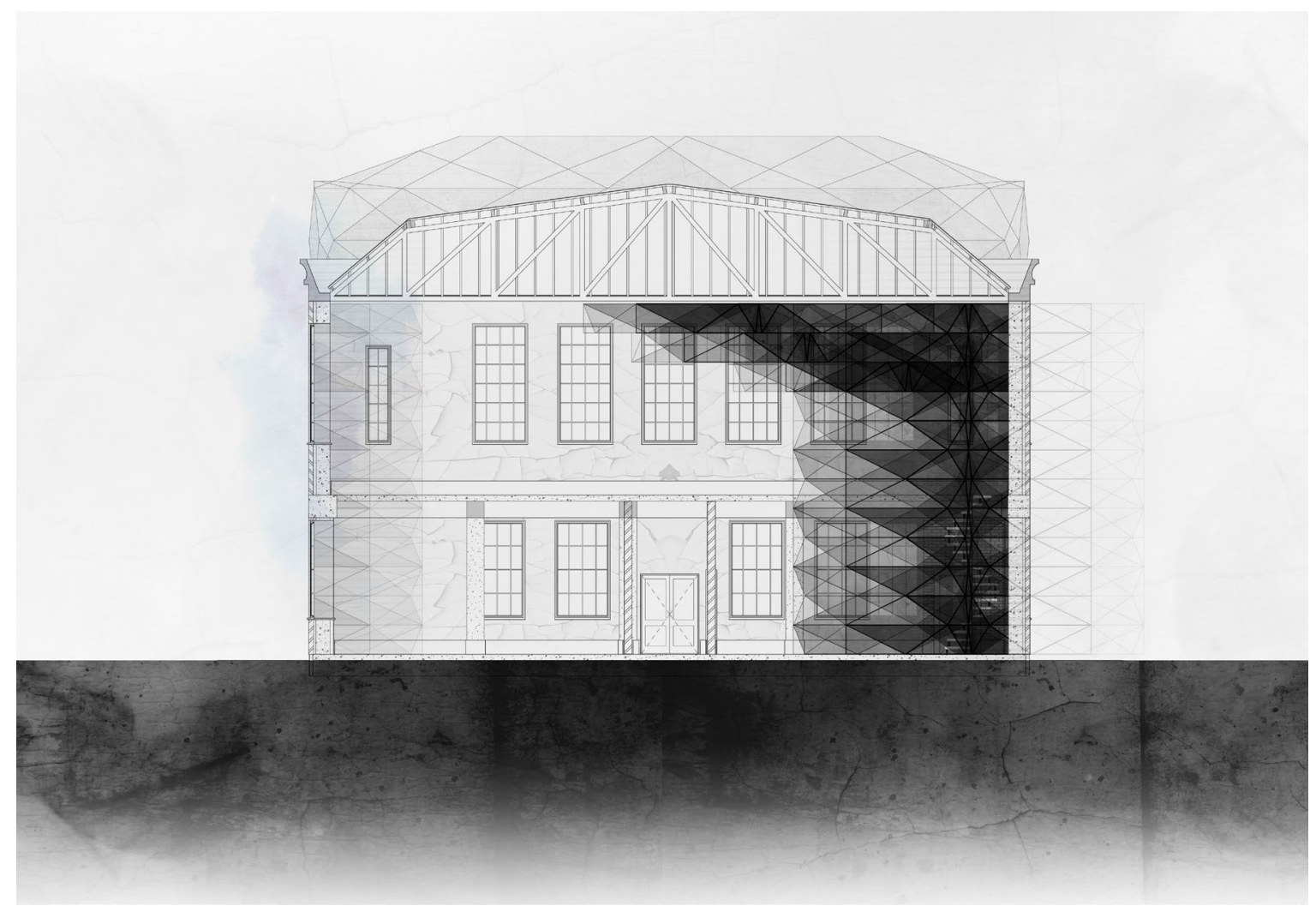

Figure.76. Section image depicting the design protecting the existing stairwell. 


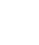




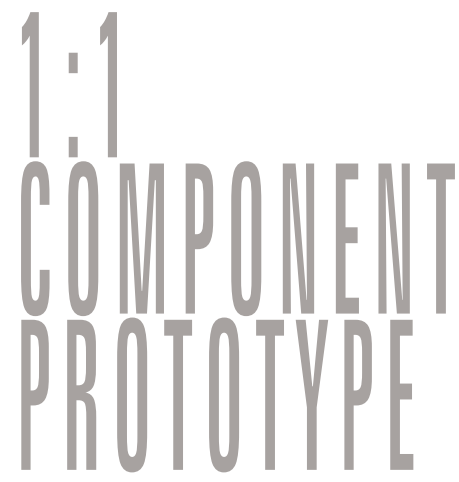

The process of modelling at a 1:1 scale meant working with industry manufacturers. Material tolerances were discussed; what thickness of material is appropriate and the available finishes. Joint tolerances was also a consideration for constructing at full size.

The current detailing of the frame will allow easy access to all wiring, this will enable changes to be made to accommodate technology advancements and any change of programme to the form. 


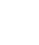




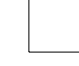

. 


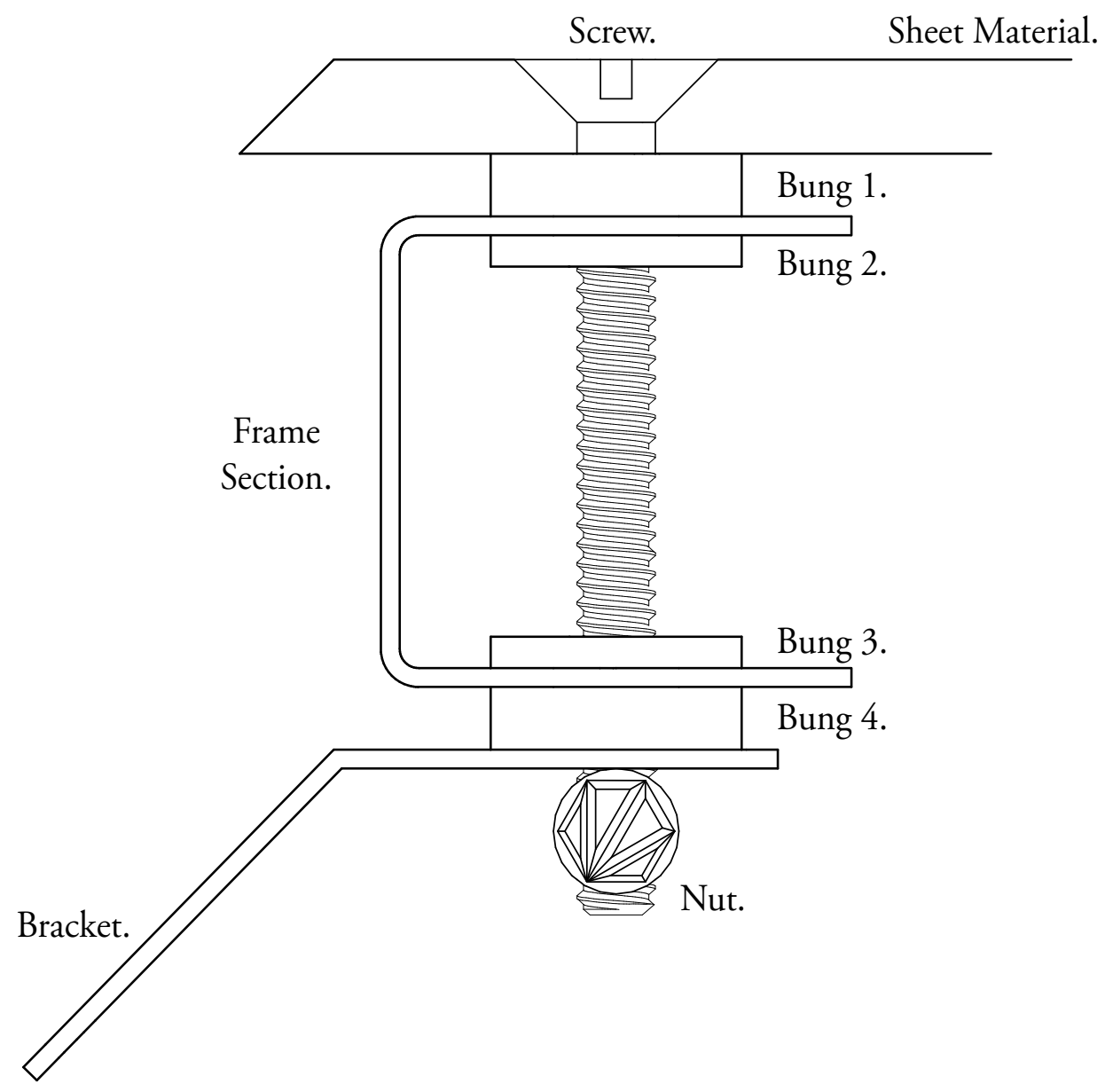

Figure.88. Section of the final bracket design with the material connection. 
Figure.89-91. Photographs of the 1:1 component prototype including LED strip lighting inserted into the 'C' frame and $3 d$ printed bungs for tolerance. 


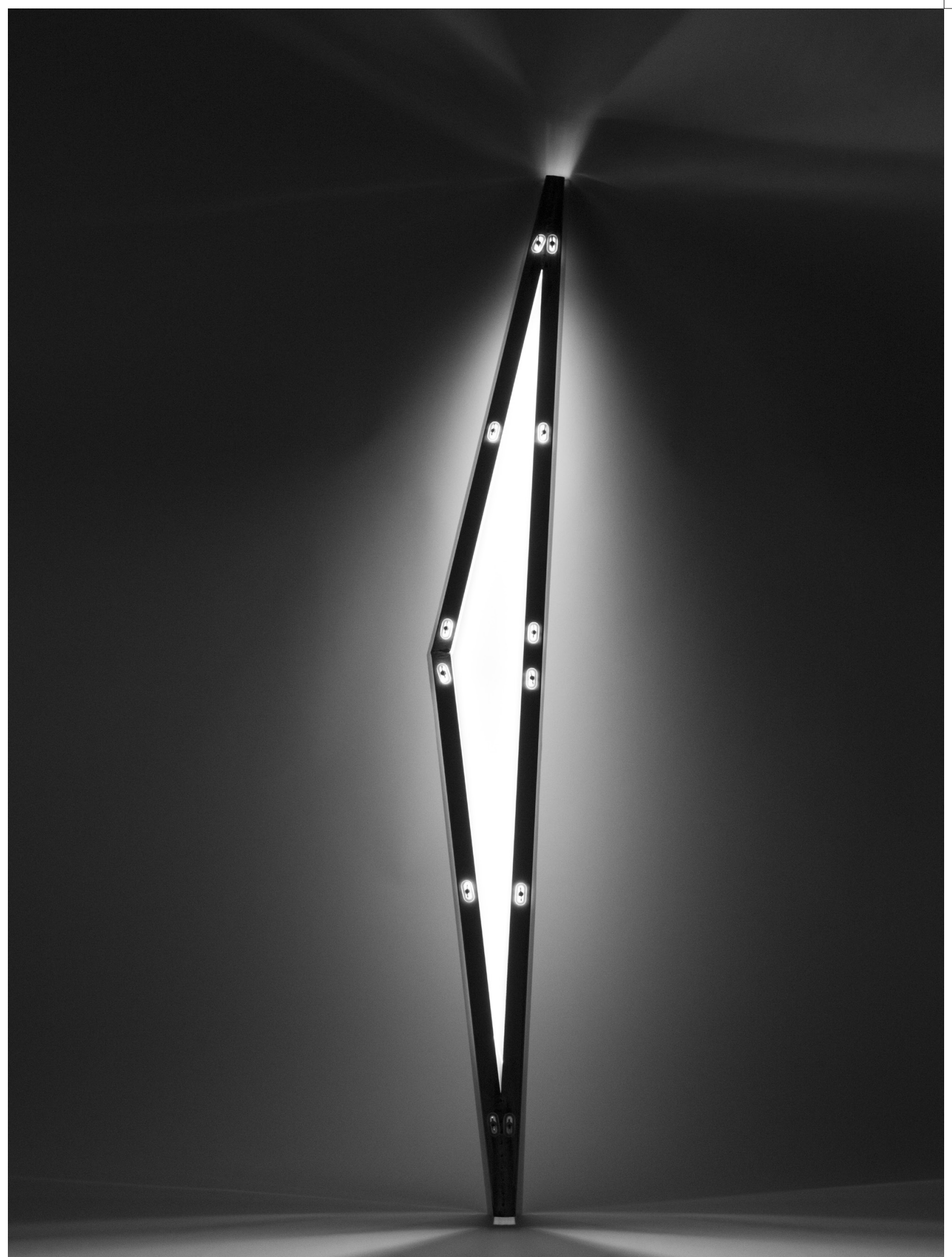




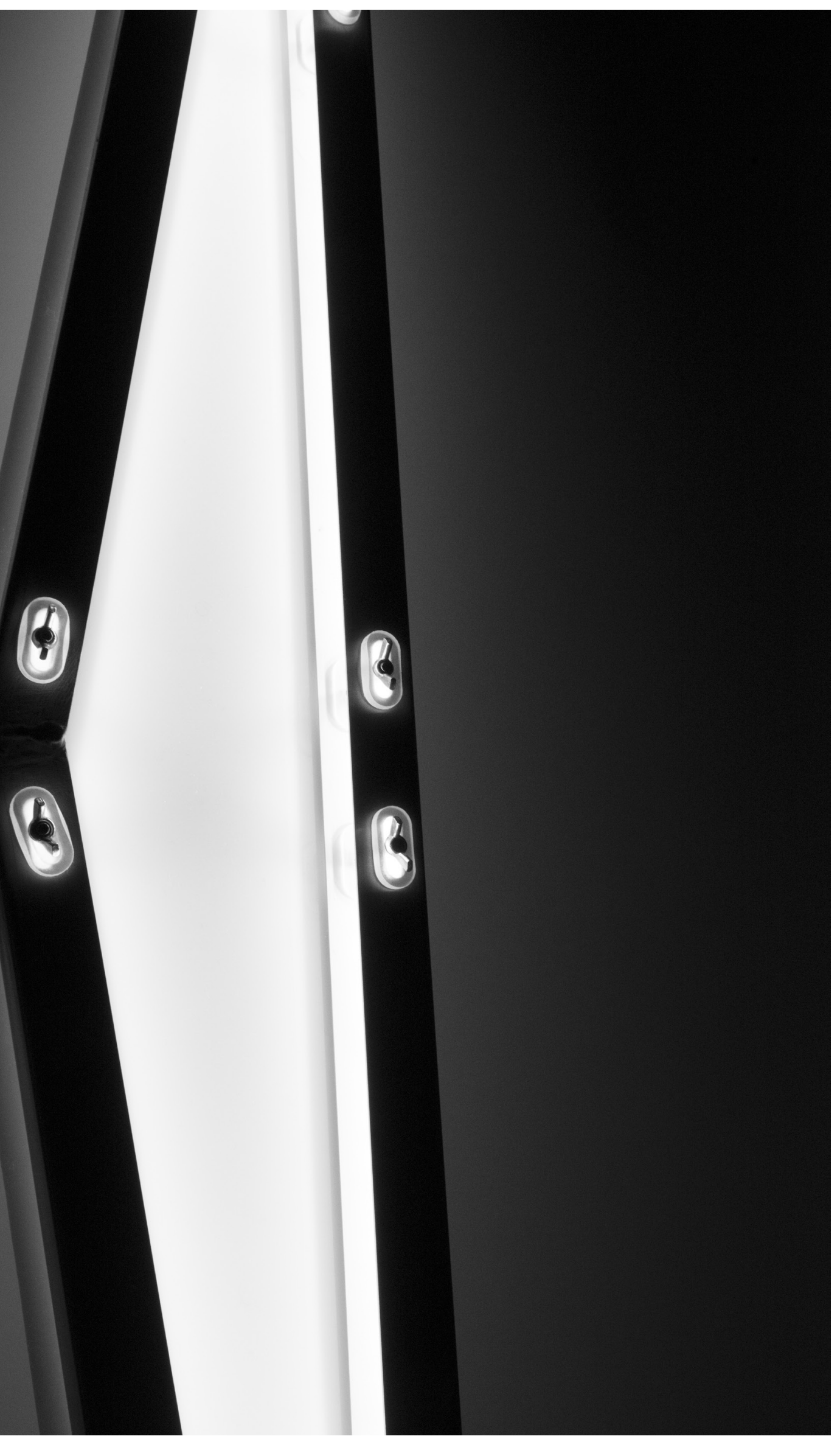




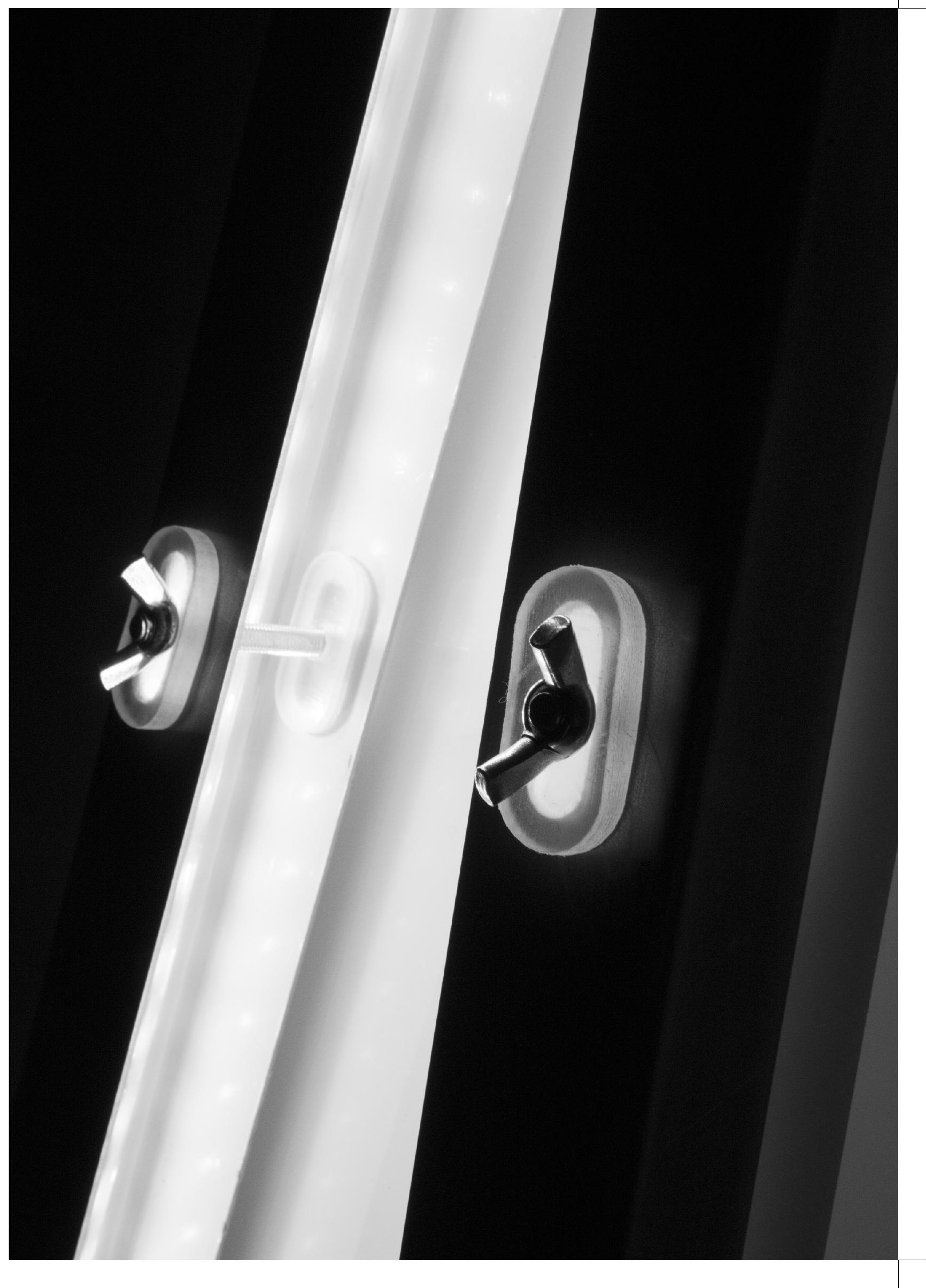




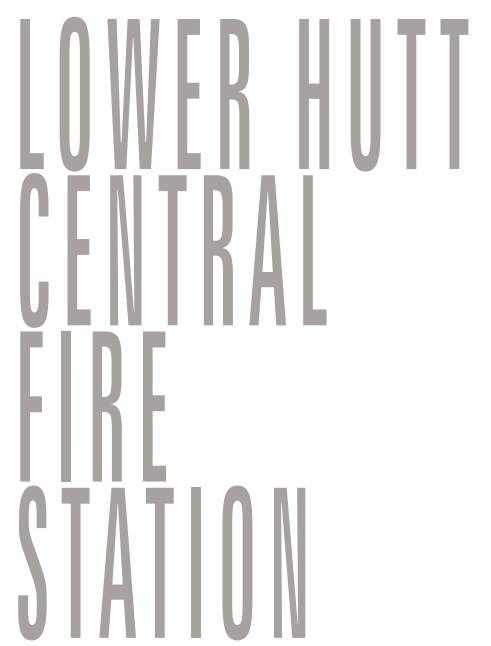

Introducing the research's design into site three, the former Fire Station, brings back into question the programme of the design; what is appropriate for the new design?

Inspired by the floor plans of architects Kazuyo Sejima and Ryue Nishizawa, the fire station intervention creates habitable spaces whilst also developing an area on the outside of the design to be occupied. Specifically, the 21st Century Museum of Contemporary Art Kananzawa, described as "an iconic enclosure containing "white cube" galleries of various sizes, with secondary functions in the interstices." (Detail: Inspiration) The author recognises the use of thoroughfare areas as secondary gallery spaces.

The developed design is positioned to protect elements such as the poles at the pole drop station, other forms convey the dialogue of the rush of movements when the sirens rang. The product of multiple divisions the space presents the question of what type of programme could fill such as area. The nature of the materials mean the design need not block sight lines, only provide barriers between the areas.

\section{Design Development}



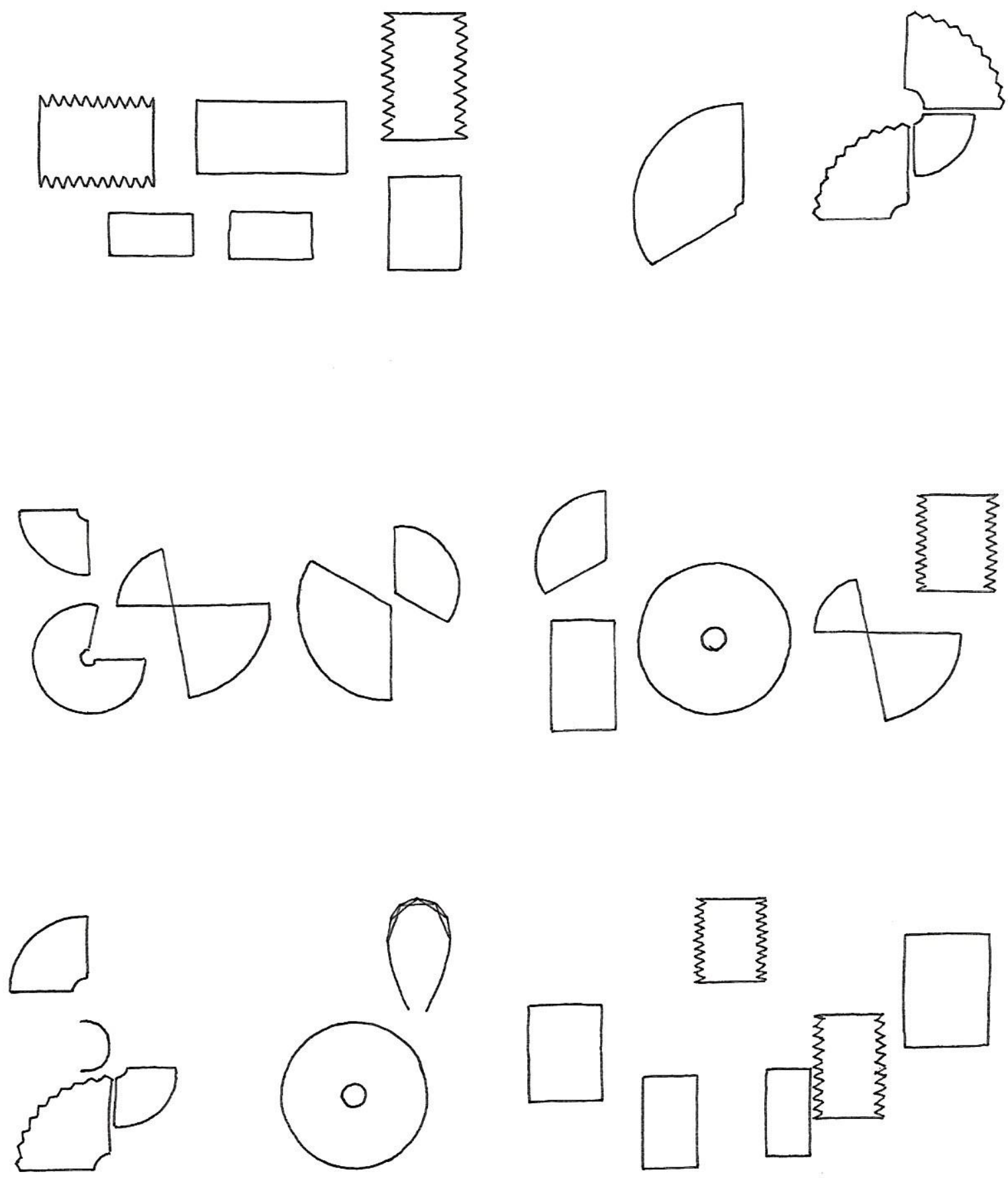

Figure.92. Sketch interations of potential floor plan designs involving various forms and layouts. 


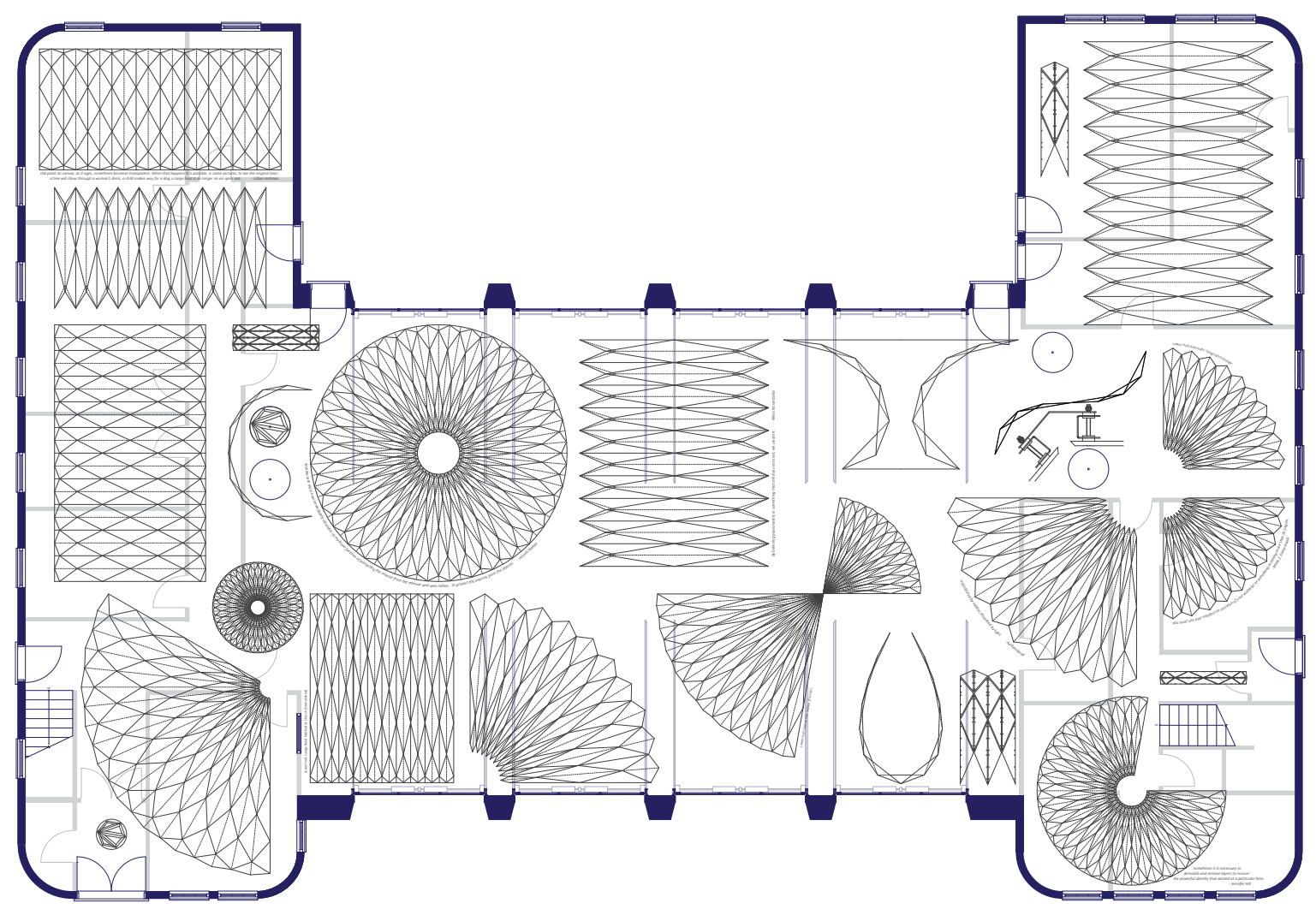

Figure.93. The design occupying the fire station floor plan. 

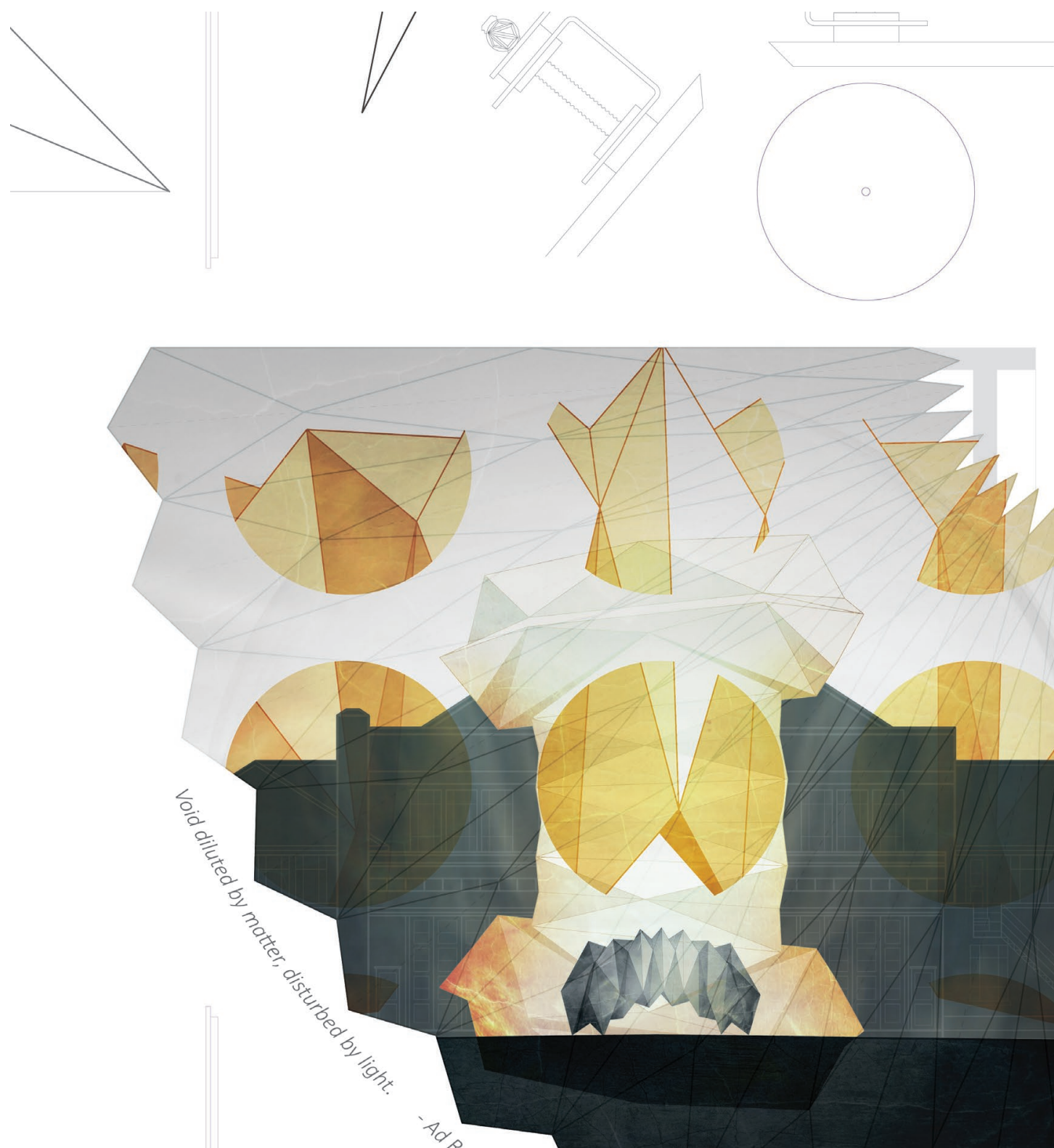

Figure.94. This image portrays the potential the design has to bring new
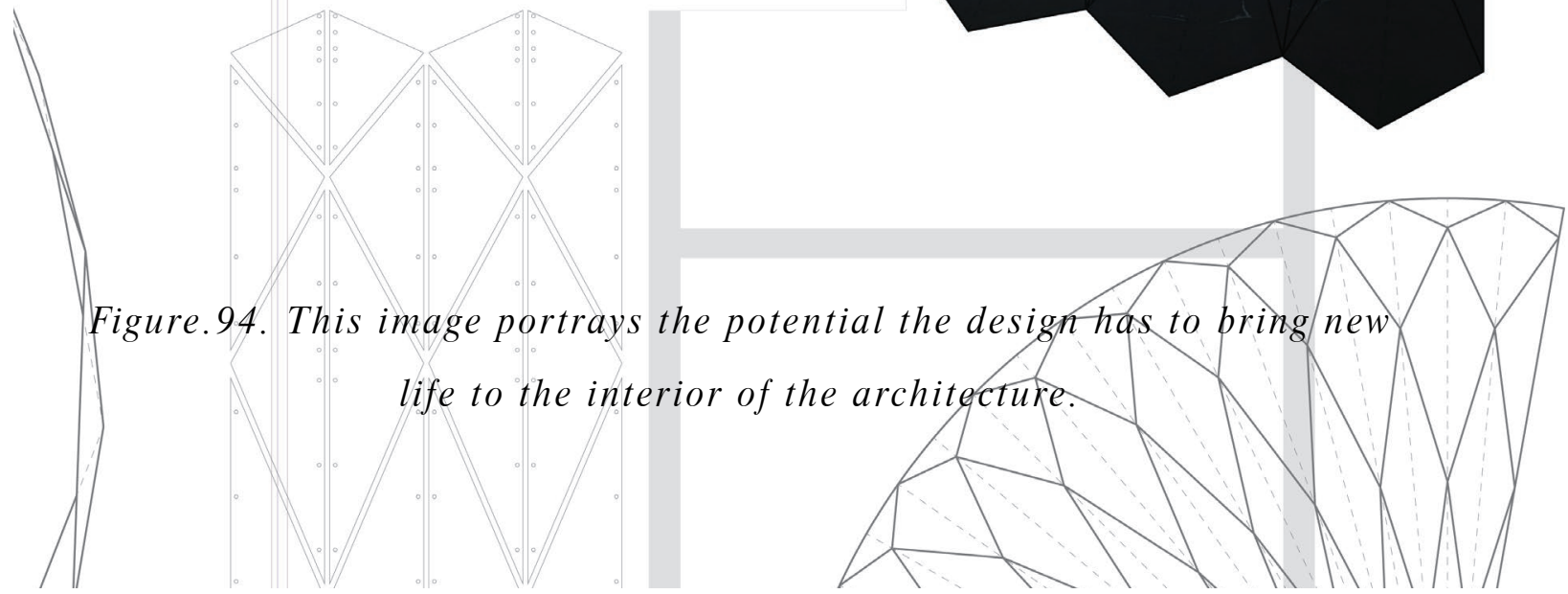

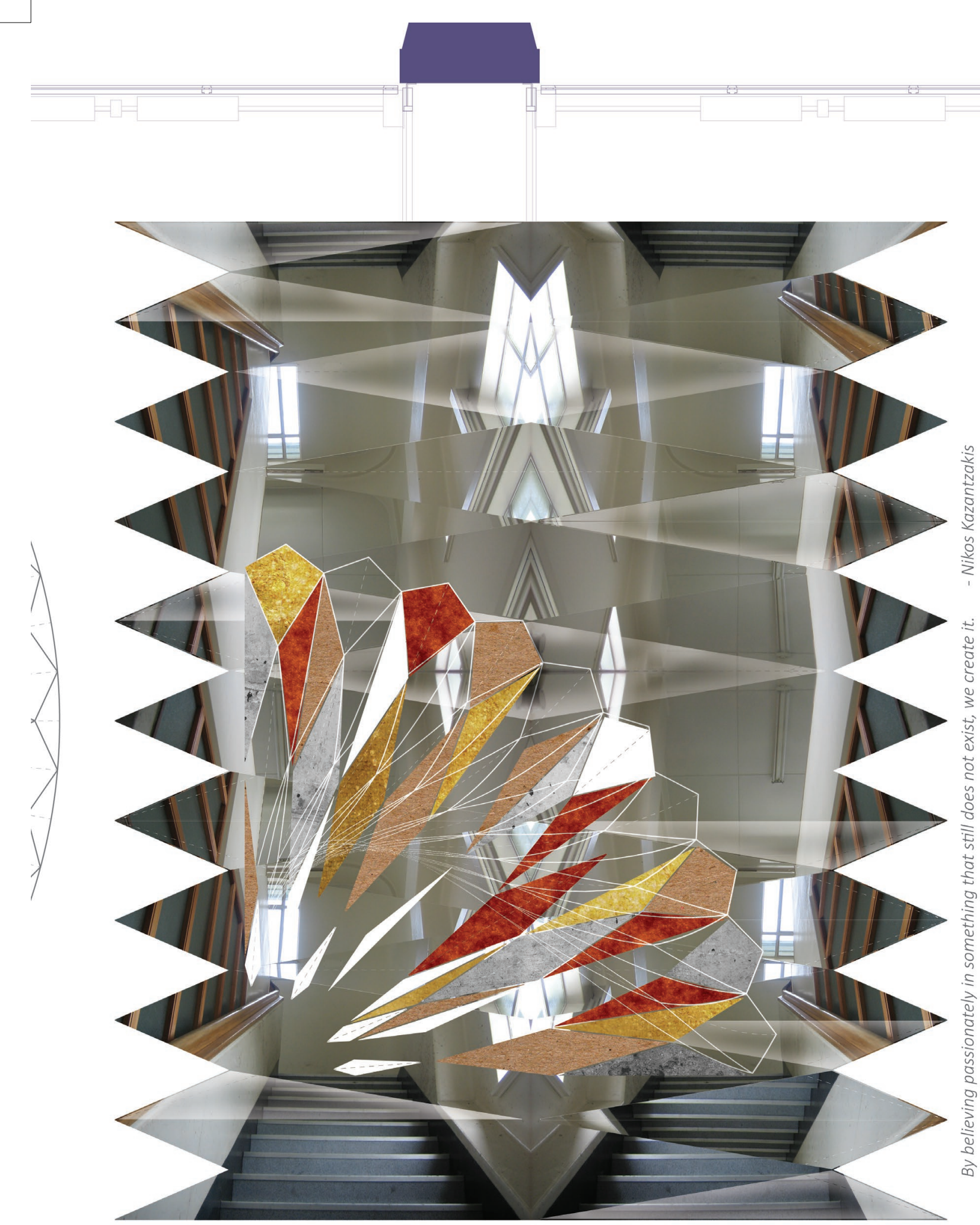

Figure.95. The design influencing the occupants experience of one circulation area in the firestation.

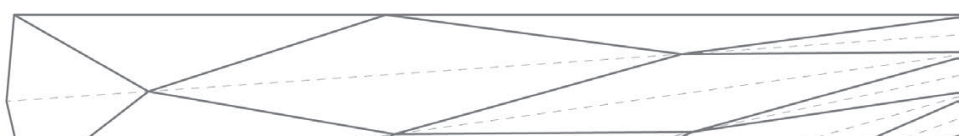




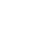




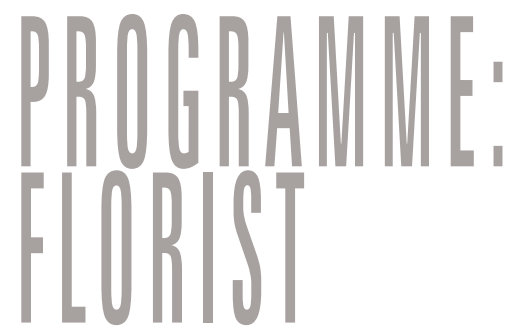

The research proposes that permanent market stalls for small shops such as a florist, or a bakery outlet where goods are baked off site, could be an efficient use of the space. Various form layouts are outlined in Figure.93.

Each form would provide a sectioned area that stall owners would have the freedom to adapt to display their product. However at this stage of the design amenities would not extend beyond basic electrical work and communal facilities would offer water to the stalls. 


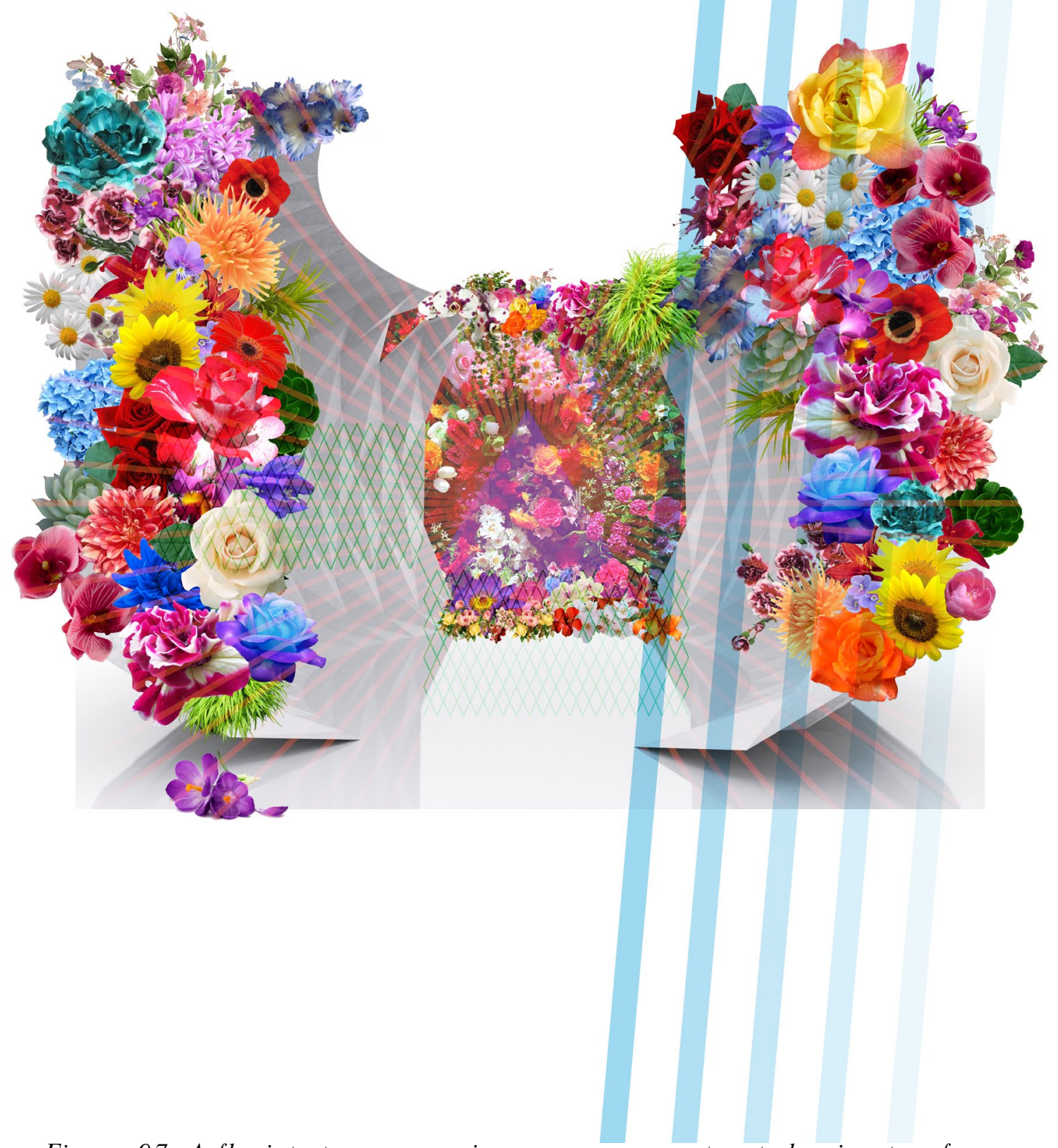

Figure.97. A florist store occupying one area constructed using two forms of the design. 


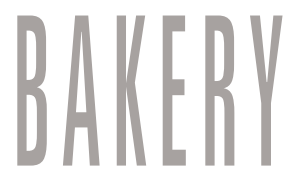

Stalls such as a bakery would currently be limited by the design and only able to display and sell their products, they may choose to have heating facilities however a certified kitchen would not be an option. 


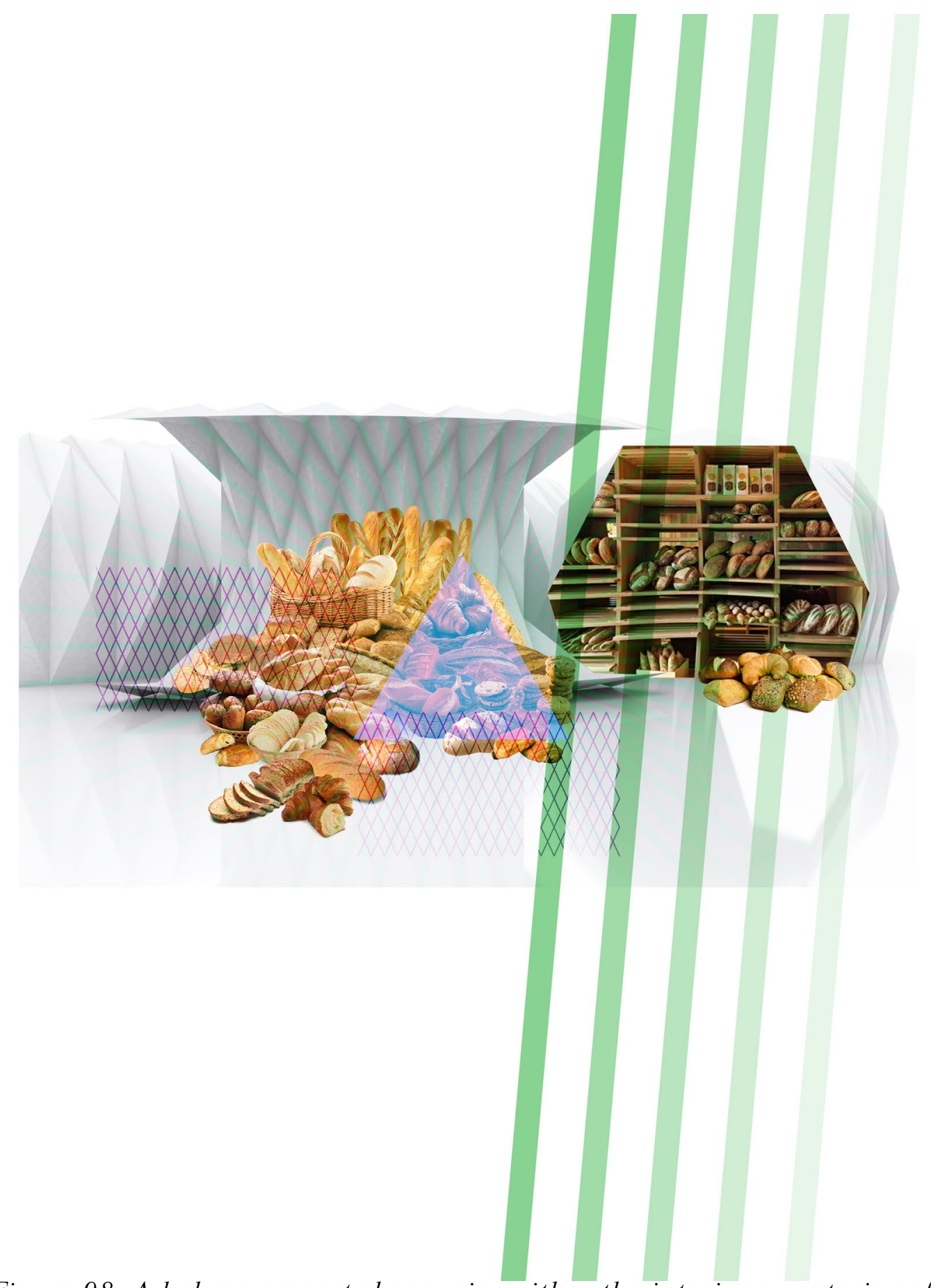

Figure.98. A bakery presented occuping either the interior or exterior of the design.

Design Development 


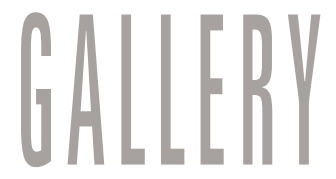

Research suggests another use of the design could be to organise the forms to create a gallery or museum environment. The gallery image shows the work of local Wellington artist Ruth ThomasEdmond. Her work has previously been displayed at the Douse Museum. 


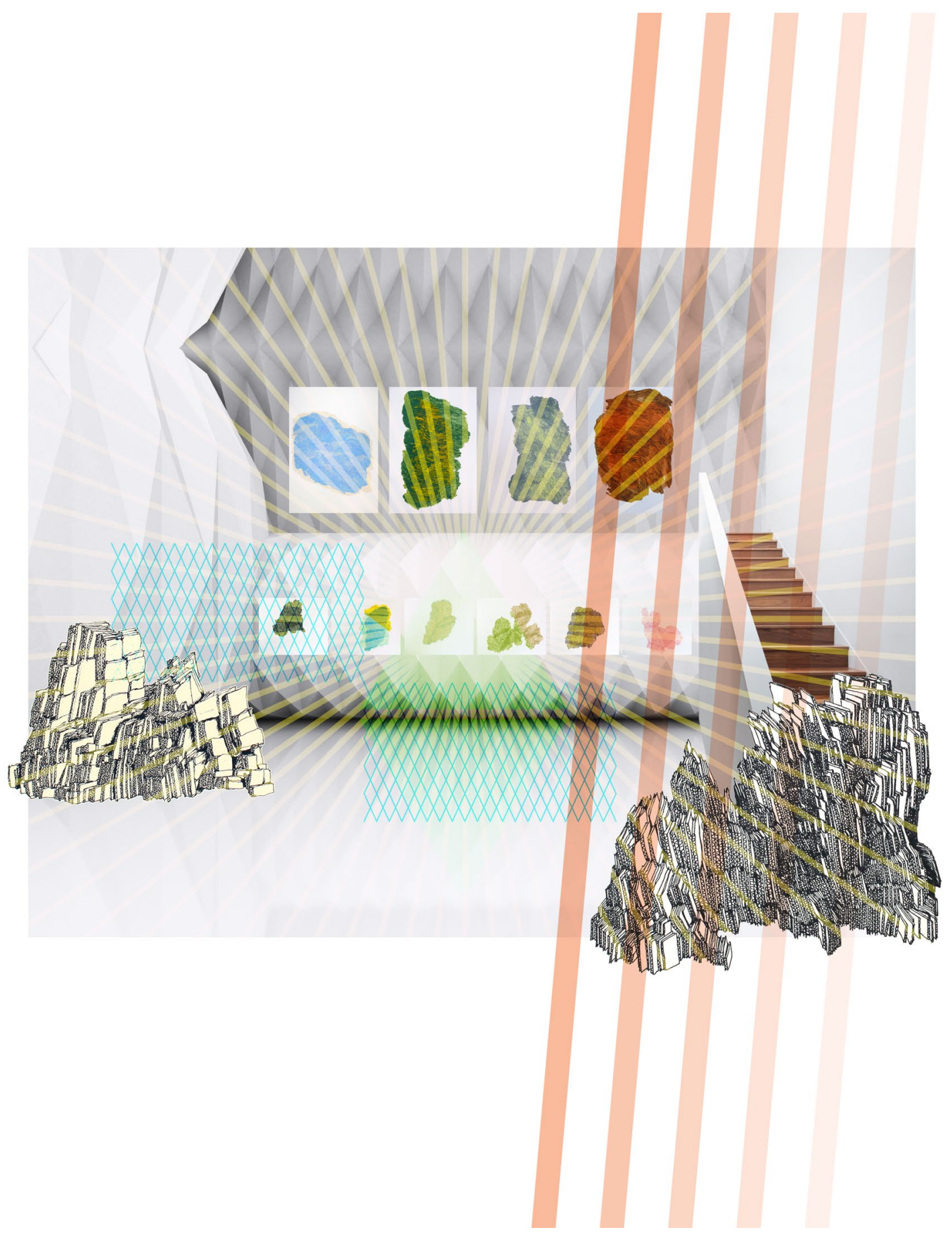

Figure.99. A gallery built using multiple forms of the design. 


\section{๑}

7 he author is pleased to conclude that by deferring from using site context as a driver of design it opened up opportunities for the research to pursue other channels of design motivators. This challenge arose with the acknowledgment that many of New Zealand's historic buildings are being demolished as they become obsolete and decay in their abandonment. In an attempt to offer a stay of demolition, this research proposed that by working with the interior of the buildings it would introduce an intervention to accommodate a new programme within the older architecture. A contemporary approach to the design has had the ability to engage contemporary ideas within the historic architecture context.

The three sites presented by the research drew attention to the assorted nature of New Zealand's architecture. An initial review of what has been done by architects in the past concluded that a universal design that would fit into any architecture could not be designed based on site. Opting to disregard the site context as a design driver produced more questions for the research to answer: how would the new design happen and what would the new design derive from? Answering these questions with one solution, to separate the interiors into layers, the research was left to decide what to do with these new layers. 
Considering the existing layers of wallpaper, paint and fabrics, the design evolved from the folding of paper using origami techniques. The limitation of this is that when one design was chosen to work with; no new pattern came from the development to represent the design of this research.

The research followed through in detailing the chosen form, fabricating one of the triangle pieces at a 1:1 scale to help with the understanding the limitations of materials; and the intentions of a flexible design that could fold and unfold. The research into material development was particularly interesting however all other design halted at this stage due to its complexity. There was opportunity to push this research further to realise a material compatible with the requirements of the form in both rigidity and orchestrated flexibility on the fold patter. In reflection the material research required more resources than this research could offer and moving on with the design was the only viable outcome.

Ultimately the design of the form is the product of research narrowed to inhabitable buildings with historical significance to the communities they serve. The transient nature of the design provides a stay of demolition for a period of time until the architecture is deemed significant enough that demolishing the building is not an option. There are almost always elements of the original heritage interior that are vital in retaining the atmosphere of the architecture, hence the offer to preserve decay while also offering a new interior use. 


\section{reFEREELES}

BK Architecten. Broerenkerk - Zwolle. Architects Press Release. Zwolle: BK Architecten, 2013. Document.

Blanciak, Francois. Siteless: 1001 Building Forms. London: The MIT Press, 2008. Book.

Buri, Hani and Yves Weinand. Origami - Folded Plate Structures, Architecture. Conference Paper. Miyazaki, 2008. Document.

Carpo, Mario. “Ten Years of Folding." Lynn, Greg. Folding in Architecture. Hoboken: Wiley-Academy, 2004. 14-19. Book.

Cramer, Johannes 1950, and Stefan Breitling. Architecture in Existing Fabric: Planning, Design and Building. Basel; London: Birkhauser, 2007. Book.

David Chipperfield Architects. "Neues Museum, Museum Island Berlin, 19972009.” 2009. David Chipperfield Architects. Architects Press Release. 8 September 2015. <http://www.davidchipperfield.co.uk/downloads/projects/11/neuesmuseum_ dca.pdf>.

Detail: Inspiration. "A Critical View: The 21st Century Museum of Contemporary Art in Kanazawa." Detail: Inspiration (2005). Online Article. <http://www.detailonline.com/inspiration/a-critical-view-the-21st-century-museum-of-contemporaryart-in-kanazawa-107938.html>. 
Franco, Arturo. "The warehouse 17c in Madrid, Spain by Arturo Franco Office." 14 June 2011. AECCAFE. Article. 20 April 2015.

Gehry, Frank and Jeremy Gilbert-Rolfe. Frank Gehry: The City and Music. London: Routledge, 2002. Book.

Hansen-Smith, Bradford. "Order Without Boundary." 4 March 2014. wholemovement. Online Article. 15 June 2015. <http://wholemovement.com/blog/ item/130-order-without-boundary>.

—. "Regularity and Randomness." 8 June 2015. wholemovement. Online Article. 15 June 2015. <http://wholemovement.com/blog/item/736-regularity-andrandomness $>$.

Heritage New Zealand. Introduction to Heritage New Zealand. 2015. Website. 24 April 2015. <http://www.heritage.org.nz/about-us/introduction>.

—. Lost Heritage 2000-2004. 2015. Webpage. 11 March 2015. <http://www. heritage.org.nz/the-list/lost-heritage/heritage-lost-2000-to-2004>.

Hill, Jennifer. "Six Degrees of Intervention." The Double Dimension: Heritage and Innovation (2004): 63-85. Research Article. 
Hutt City Council. The District Plan chapters . Council Document. Wellington: Hutt City Council, 2015. Electronic Document.

ICOMOS New Zealand (Inc.). ICOMOS New Zealand Charter: For the Conservation of Places of Cultural Heritage Value, Revised 2010. Heritage Conservation Report. Auckland: ICOMOS New Zealand (Inc.), 2010. Electronic Document.

Lower Hutt Borough Council. 009 Application Water Supply_Connection_ Alteration.TIF. Council Building Document. Wellington: Lower Hutt Borough Council, 1931. Electronic Document.

Lynn, Greg. "Introduction." Lynn, Greg. Folding in Architecture. Hoboken: WileyAcademy, 2004. 9-13. Book.

Miyake Design Studio. Main Lines. 2014. Website Article. 15 July 2015. <http:// $\mathrm{mds}$.isseymiyake.com/mds/en/collection/>.

Moussavi, Farshid. The Function of Form. Barcelona ; New York: Actar, 2009. Book.

Naus, Natasha and Alison Dangerfield. Lower Hutt Central Fire Station (Former), Lower Hutt. Registration Report for a Historic Place. Wellington: New Zealand Historic Places Trust, 2010. Print.

Nebojić, Alek A. OUT OF CONTEXT: Arhitekton. 20 June 2012. Article. 8 October 2015.

Roma, Caterina. "Kintsugi." Ceramic Review March/April (2013): 62-65. Article.

Rypkema, Donovan D. The Economics of Heritage. Wellington, 2012. DVD. 
Rypkema, Donovan. The Economics of Historic Preservation : A Community Leader's Guide. Washington D.C: PlaceEconomics , 2014. Book.

Scott, Fred, 1939. On Altering Architecture. New York; London: Routledge, 2008. Book.

Silverberg, Jesse L. et al. "Using origami design principles to fold reprogrammable mechanical metamateriels.” Sciencemag Vol. 345 no. 6167 (2014): 647-650. Online Report.

Spanjers, Kees. "Foreword.” Leydecker, Sylvia. Designing Interior Architecture: Concept Typology Material Construction. Basel: Birkhäuser, 2013. 9. Book.

The Dominion Post. Briscoes move a blow for Lower Hutt. 31 May 2014. Article. 21 June 2015. <http://www.stuff.co.nz/dominion-post/business/commercialproperty/10107080/Briscoes-move-a-blow-for-Lower-Hutt>.

Vyzoviti, Sophia. Folding Architecture. Corte Madera: Gingko Press Inc., 2004. Book.

-. Supersurfaces: folding as a method of generating forms for architecture, products and fashion. Amsterdam: BIS Publishers, 2006. Book.

Zoran, Amit and Leah Buechley. "Hybrid Reassemblage: An Exploration of Craft, Digital Fabrication and Artifact Uniqueness." Leonardo 46.1 (2013): 4-10. Research Article. 


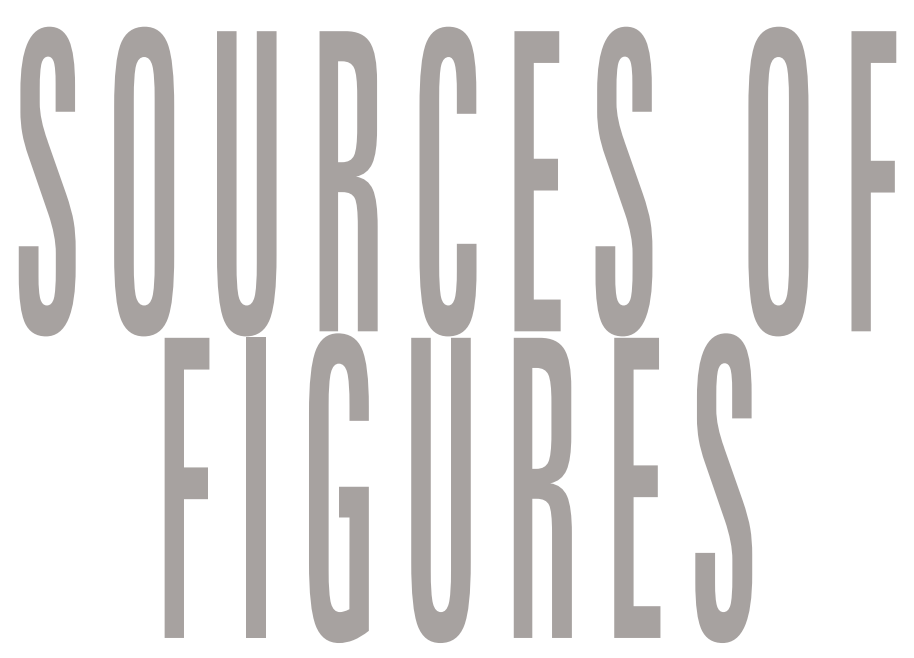

Figure.1. Diagram of the research process, reads from top to bottom. Author's own image (2015).

Figure.2. Map of the Lower Hutt Region. Author's own image (2015).

Figure.3. Central Lower Hutt District Plan. Author's own image (2015).

Figure.4. Location of the Methodist Church, also shown in Figure.3. Central Lower Hutt District Plan. Author's own image (2015).

Figure.5. Plan view of the Church. Author's own image (2015).

Figure.6. Section A-A' of the Church. Author's own image (2015).

Figure.7. Section B-B' of the Church. Author's own image (2015).

Figure.8. Location of the Automatic Telegraph Exchange, also shown in Figure.3. Central Lower Hutt District Plan. Author's own image (2015).

Figure.9. Plan view of the Telegraph Exchange. Author's own image (2015). 
Figure.10. Front elevation and facade section of the Telegraph Exchange. Author's own image (2015).

Figure.11. Location of the Fire Station, also shown in Figure.3. Central Lower Hutt District Plan. Author's own image (2015).

Figure.12. Plan view of the Fire Station. Author's own image (2015).

Figure.13. Front elevation of the Fire Station. Author's own image (2015).

Figure.14. Bookstore inside the Cathedral, designed by BK Architecten. Source BK Architecten. Document.

Figure.15. Cafe inside the Cathedral. Source BK Architecten. Document.

Figure.16. The main staircase in the Neues museum. Source http://www. davidchipperfield.co.uk/downloads/projects/11/neuesmuseum_dca.pdf.

Figure.17. Shrapnel damage from WWII. Source http://www.davidchipperfield. co.uk/downloads/projects/11/neuesmuseum_dca.pdf.

Figure.18-20. Interior features of the $17 \mathrm{c}$ slaughterhouse renovation. Source http://www10.aeccafe.com/blogs/arch-showcase/2011/06/14/the-warehouse-17c-inmadrid-spain-by-arturo-franco-office/.

Figure.21. A bowl repaired with Kintsugi. Source http://www.thisiscolossal. com/2014/05/kintsugi-the-art-of-broken-pieces/.

Figure.22. Vases produced as an outcome of the reassemblage research. Source http://www.archdaily.com/332525/the-indicator-craft-in-the-digital-age.

Figure.23. Author's representation of what materials may be exposed by the peeling back of historic layers within the interiors of architecture. Author's own image (2015).

Figure.24. ENOTA contrasts the aged stone with white a design in the Dominican Monastery. Source http://www.archdaily.com/431421/ptuj-performance-center-enota.

Figure.25. The entrance of the Palais de Tokyo. Source http://www.archdaily. com/248026/palais-de-tokyo-expansion-lacaton-vassal. 
Figure.26. Scarpa's design recreates where the statue would have been prior to the deterioration of the architecture. Source https://dome.mit.edu/handle/1721.3/68185.

Figure.27. Author's image to depicted architecture balanced on its own financial worth and heritage value. (2015).

Figure.28. Inside the Swavoski Crystal Dome. Source http://www.travelandleisure. $\mathrm{com} / \mathrm{slideshows/swarovski-kristallwelten-austria-reopens/6.}$

Figure.29. Paper folds using pleating in Series One. Author's own image (2015).

Figure.30-35. Continued paper folds using pleating in Series One. Author's own images (2015).

Figure.36. One paper fold design from Series One which combined pinching of the material in three places. Author's own image (2015).

Figure.37. Forms created using the pleating in Series One. Author's own image (2015).

Figure.38. Paper folds in Series Two. Author's own image (2015).

Figure.39. Author's own sketches of the Series Two fold pattern. (2015).

Figure.40-42. Paper folds in Series Two. Author's own images (2015).

Figure.43-44. The first origami pattern trialled in Series Three. Author's own images (2015).

Figure.45. Author's own sketch of the second origami pattern, the design incorporated mountain and valley folds as represented by the dashed lines (valley fold) and solidlines (mountain fold). (2015).

Figure.46. The second origami pattern trialled in Series Three. Author's own image (2015).

Figure.47-48. Two paper folds using the second origami pattern, trialled in Series Three, combined with pinching of the material. Author's own images (2015).

Figure.49-55. Renders from parametric computer modelling. Author's own images (2015). 
Figure.56-58. Author's collages using photos by Mark Beehre. (2015).

Figure.59. Showing the worth of the design within the church, where it can be most usefull, in this case repairing the damaged flooring. Author's own image (2015).

Figure.60. Considering the effects of the design within a narrow space such as the vestibule. Author's own image (2015).

Figure.61. One way the design can control what the occupants see within the architecture. Author's own image (2015).

Figure.62. One pod from the office design by Vincent. Source http://www.dezeen. com/2015/01/29/ekimetrics-office-interior-estelle-vincent-wooden-meeting-roomspods-slide/.

Figure.63. The Archiproba glass kiosk. Source http://www.dezeen.com/2014/10/07/ archiproba-renovation-art-deco-telecommunication-building-moscow/.

Figure.64. The Chipbaord shed designed by Schemata Architects. Source http:// www.dezeen.com/2015/03/07/schemata-architects-takahashi-hiroko-oshiage-studioworkshop-tokyo-plants/.

Figure.65. Diagram of the development process. Author's own image (2015).

Figure.66. Sectioned image exploring dimensions of the triangle and the spatial effects of the dimensions. Author's own image (2015).

Figure.67. Graham Wiles diagram reproduced by author. (2015).

Figure.68. Initial material aesthetic exploration using the Lower Hutt Region Map. Author's own image (2015).

Figure.69. Continued material aesthetic exploration considered translucencies. Author's own image (2015).

Figure.70. Material research considered two shape options for the construction of the form; one option was to use rectangles folded on the diagonal. This would require some solid connectors and some flexible, concepts of these are shown in Figure.72. Author's own image (2015). 
Figure.71. Option two was to use solid triangle shapes, this would require only flexible connectors, concepts of these are shown in Figure.72. Author's own image (2015).

Figure.72. Sketches for initial connection brackets with varying flexibility. Author's own image (2015).

Figure.73. Sketch development of connectors. Author's own image (2015).

Figure.74. Sketch of one form the design could produce. Author's own image (2015).

Figure.75. Sketch idea considering the use of power supplied from the pre-existing ceiling light wiring. Author's own image (2015).

Figure.76. Section image depicting the design protecting the existing stairwell. Author's own image (2015).

Figure.77. Section image depicting the design protecting the existing stairwell. Author's own image (2015).

Figure.78. Sketch section with the final designs proposed dimensions. Author's own image (2015).

Figure.79. Sketch concepts for the profile of the frame, where the sheet material meets the bracket and where wiring runs through. Author's own image (2015).

Figure.80. Sketch of a frame with the 'C' profile. Author's own image (2015).

Figure.81. More detailed sketch of the profile of the ' $\mathrm{C}$ ' frame. Author's own image (2015).

Figure.82. Sketches of development for the profile of the bracket, the author established that one fold was easier for manufacturing. Author's own image (2015).

Figure.83. Sketch considering the location and number of brackets. Author's own image (2015).

Figure.84. Concepts for the bracket cut out. Author's own image (2015). 
Figure.85. Drawings taken to the first meeting with Ullrich Aluminium, it was recommended by the manufacturers to remove the 'point' of the triangle as it resulted in unnecessary wasted material. Author's own image (2015).

Figure.86. Holes were punched in the frame for rubber bungs, this is to allow for tolerance when building the full form. Author's own image (2015).

Figure.87. Final drawings supplied to Ullrich Aluminium for the fabrication of the prototypes frame. Author's own image (2015).

Figure.88. Section of the final bracket design with the material connection. Author's own image (2015).

Figure.89-91. Photographs of the 1:1 component prototype including LED strip lighting inserted into the ' $\mathrm{C}$ ' frame and $3 \mathrm{~d}$ printed bungs for tolerance. Author's own images (2015).

Figure.92. Sketch interations of potential floor plan designs involving various forms and layouts. Author's own image (2015).

Figure.93. The design occupying the fire station floor plan. Author's own image (2015).

Figure.94. This image portrays the potential the design has to bring new life to the interior of the architecture. Author's own image (2015).

Figure.95. The design influencing the occupants experience of one circulation area in the firestation. Author's own image (2015).

Figure.96. The design with semi translucent material panels, within the fire station. Author's own image (2015).

Figure.97. A florist store occupying one area constructed using two forms of the design. Author's own image (2015).

Figure.98. A bakery presented occuping either the interior or exterior of the design. Author's own image (2015).

Figure.99. A gallery built using multiple forms of the design. Author's own image (2015). 


\section{APPENDILES}

ICOMOS NZ, HERITAGE NZ, THE LOWER HUTT DISTRICT PLAN

7 his information considers regulations and laws that relate to developing aged buildings in $\mathrm{New}$ Zealand, along with literature offering guidance when dealing with the historic architecture in New Zealand; the main sources are the ICOMOS document, Heritage New Zealand and the Lower Hutt District Plan.

- TheICOMOS NewZealand Charter(International Council on Monuments and Sites) (ICOMOS New Zealand (Inc.)) is not a legal document that needs to be followed. Written following the Venice Charter 1964, then later revised in 2010, New Zealand's own Charter "is a statement of professional principles," and is intended to guide those proposing to develop a structure or area of historic or cultural significance to New Zealand. The ICOMOS Charter is available to the public, however not referred to by the District Plan.

- Heritage New Zealand is a historic agency that 
offers support when considering alterations to cultural heritage (Heritage New Zealand). They are a supportive resource; the council may choose to consult with them, as can building owners. Heritage New Zealand has a list which identifies buildings which the agency considers as having significant qualities. Included in these qualities are social significance, aesthetic value and technological advancement. Buildings on this list can be treated with more care by local councils.

- The District Plan, written by local council, is the only legal restraints imposed on the owners of historical buildings. A building may come under multiple chapters of the District Plan, this is affected by its location, its programme and if it is historical or not (Hutt City Council). The Lower Hutt City Council's District Plan requires any development in breach of a rule to apply for resource consent. Resource consent can be biased, if it is minor changes to the rear of a building it will likely be approved, whereas demolition to part of the building could present problems in the consent being granted. If work is carried out unlawfully then the council has enforcement powers available under the Resource Management Act. 

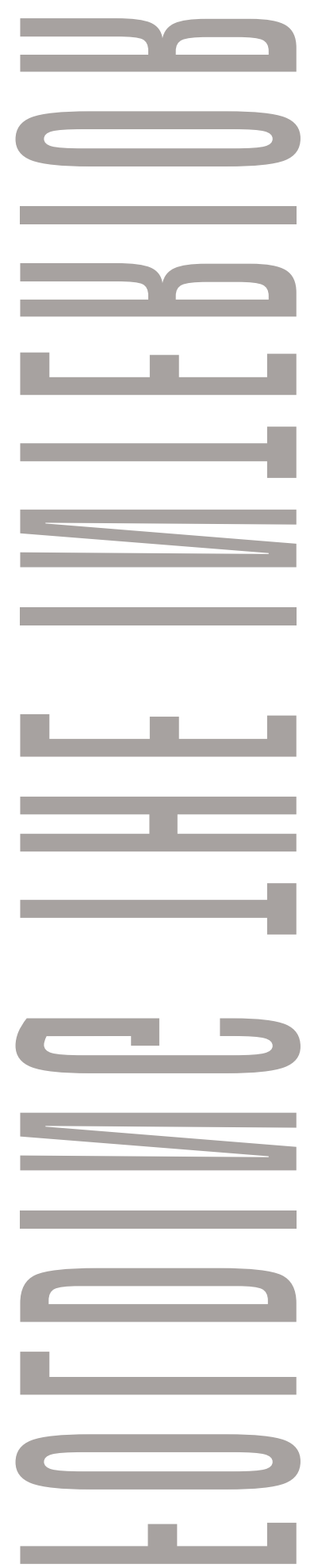